Portland State University

PDXScholar

Winter 3-11-2016

\title{
Tryon Trekkers: An Evaluation of a STEM Based Afterschool Program for At-Risk Youth
}

Chessa Eckels Anderson

Portland State University

Follow this and additional works at: https://pdxscholar.library.pdx.edu/open_access_etds

Part of the Educational Methods Commons, Elementary Education and Teaching Commons, and the Science and Mathematics Education Commons

Let us know how access to this document benefits you.

\section{Recommended Citation}

Anderson, Chessa Eckels, "Tryon Trekkers: An Evaluation of a STEM Based Afterschool Program for AtRisk Youth" (2016). Dissertations and Theses. Paper 2720.

https://doi.org/10.15760/etd. 2716

This Thesis is brought to you for free and open access. It has been accepted for inclusion in Dissertations and Theses by an authorized administrator of PDXScholar. Please contact us if we can make this document more accessible: pdxscholar@pdx.edu. 
Tryon Trekkers: An Evaluation of a STEM Based Afterschool Program for At-Risk Youth

by

\title{
Chessa Eckels Anderson
}

A thesis submitted in partial fulfillment of the

Requirements for the degree of

\author{
Master of Science in Teaching \\ in \\ General Science
}

Thesis Committee:

William Becker, Chair

Stephanie Wagner

Cary Sneider

Portland State University

2016 
(C) 2016 Chessa Eckels Anderson 


\begin{abstract}
This study contributed to the body of research that supports a holistic model of afterschool learning through the design of an afterschool intervention that benefits elementary school students of low socioeconomic status. This qualitative study evaluated a science focused afterschool curriculum that was designed using principles from Risk and Resiliency Theory, academic motivation theories, science core ideas from the Next Generation Science Standards, and used environmental education philosophy. The research question of this study is: how does an outdoor and STEM based afterschool program impact at-risk students'self-efficacy, belonging and engagement and ability to apply conceptual knowledge of environmental science topics? The study collected information about the participants' affective experiences during the intervention using structured and ethnographic observations and semi-structured interviews. Observations and interviews were coded and analyzed to find patterns in participants' responses. Three participant profiles were developed using the structured observations and ethnographic observations to provide an in depth understanding of the participant experience. The study also assessed the participants' abilities to apply conceptual understanding of the program's science topics by integrating an application of conceptual knowledge task into the curriculum. This task in the form of a participant project was assessed using an adapted version of the Portland Metro STEM Partnership's Application of Conceptual Knowledge Rubric. Results in the study showed that participants demonstrated self-efficacy, a sense of belonging and engagement during the program. Over half of the participants in the study demonstrated a proficient understanding of program concepts. Overall, this holistic afterschool program demonstrated that specific instructional practices and a multi-modal science curriculum helped to support the social and emotional needs of at-risk children.
\end{abstract}


TABLE OF CONTENTS

ABSTRACT

LIST OF TABLES

IV

LIST OF FIGURES

V

INTRODUCTION AND LITERATURE REVIEW 1-41

INTRODUCTION

LITERATURE REVIEW

DEFINING AT-RISK YOUTH

13-41

AFTERSCHOOL PROGRAM INTERVENTIONS FOR AT-RISK YOUTH

$13-20$

AFTERSCHOOL PROGRAMS FEATURING STEM TOPICS

20-23

SCIENCE BASED AFTERSCHOOL INTERVENTIONS FOR AT-RISK YOUTH

23-31

INSTRUCTIONAL PRACTICES

$32-36$

SUMMARY

$36-38$

$38-41$

METHODS

42-63

OVERVIEW

$42-43$

PARTICIPANTS

43-44

INTERVENTION

44-56

TABLE 1 (CURRICULUM SCHEDULE)

47-48

TABLE 2 (THEORETICAL FRAMEWORK)

$51-52$

INSTRUMENTS

$57-56$

TABLE 3_(INTERVIEW QUESTIONS)

PROCEDURE

$62-63$

RESULTS

64-88

INTERVIEWS

59-70

TABLE 4 (SELF-EFFICACY)

65

TABLE 5 (BELONGING)

69

FigURE 1 (ENGAGEMENT)

70

STRUCTURED OBSERVATIONS

$70-65$

TABle 6 (STRUCtUREd ObSERVATION Form)

Participant Profiles

71-84

APPlication Of CONCEPTUAL KNOWLEDGe

85-88

TABLE 7 (RUBRIC)

85

FiguRE 2 (PARTICIPANT RESPONSES)

87

FIGURE 3 (RUBRIC RESULTS OF EACH GROUP)

87

FIGURE 4(COMBINED RUBRIC RESULTS) 
SELF-EFFICACY

90-96

BELONGING

88-99

ENGAGEMENT

99-102

CONNECTION TO NATURE

102-104

TABLE 8 (CONNECTION TO NATURE)

103

APPLICATION OF CONCEPTUAL KNOWLEDGE

104-110

INTERVENTION LOGISTIC LIMITATIONS

110-112

CURRICULUM LIMITATIONS

$112-113$

THEORETICAL FRAMEWORK LIMITATIONS

$113-114$

QUALITATIVE EVALUATION LIMITATIONS

114-116

CONCLUSION

$117-120$

\section{REFERENCES}

121-123

Appendix A. Create a Creature Task

123

APPENDIX B. CREATE A CREATURE RUBRIC

124

APPENDIX C. STRUCTURAL OBSERVATIONS

$125-126$

APPENDIX D. INTERVIEW QUESTIONS

127

APPENDIX E. TRYON TREKKERS SPRING TERM LESSON PLANS

$128-135$

APPENDIX F. ETHNOGRAPHIC OBSERVATIONS

$136-143$

APPENDIX G. IRB APPLICATION

144-162 


\section{List of Tables}

\section{TABLES}

TABLE 1 (CURRICULUM SCHEDULE)

$47-48$

TABLE 2 (THEORETICAL FRAMEWORK)

$51-52$

TABLE 3 (INTERVIEW QUESTIONS)

TABLE 4 (SELF-EFFICACY)

TABLE 5 (BELONGING)

69

TABLE 6 (STRUCTURED OBSERVATION FORM)

71

TABLE 7 (RUBRIC)

85

TABLE 8 (CONNECTION TO NATURE) 


\section{LIST OF FIGURES}

\section{FIGURES}

FIGURE 1 (ENGAGEMENT) $\quad 70$

FIGURE 2 (PARTICIPANT RESPONSES)

FIGURE 3 (RUBRIC RESULTS OF EACH GROUP)

FIGURE 4 (COMBINED RUBRIC RESULTS) 88 


\section{Chapter 1: Introduction}

In our country today, there are many children who are struggling to succeed. They may face physical, emotional, or developmental challenges that impact their lives at home or at school. At-risk youth, as defined by Berzin (2010) are youth who experience poor outcomes during the transition to adulthood due to exposure to negative life experiences, or risk factors, throughout development. Many of the youth that face these challenges come from communities with low socioeconomic status (SES) or from public housing neighborhoods. Public housing neighborhoods have been shown to feature harsh conditions, drug use, and low performing schools (Forrest-Banks et. al., 2013, p.2). The National Center for Children in Poverty report that over 16 million children or $22 \%$ of children of the United States live in poverty (NCCP, 2015). Growing up in these environments may lead to poor performance in school, substance abuse, teen pregnancy, or delinquency. In school, these challenges can lead to children being held back, or may even result in failure to graduate. Current studies show that the dropout rate of students from low SES households is about five times greater than students from affluent homes (Jensen, 2013, p.1).

The negative outcomes expressed by at-risk youth are a symptom of a deeper problem. Low SES environments do not meet the needs of children as they grow and develop, and consequently these environments cause high amounts of stress in a child's life. For example, children from poor families may not receive enough food to eat, or they may not get enough sleep each night. Often parents in these families do their best 
to take care of their children, but unforgiving socioeconomic pressures may cause them to fail to meet the needs of their children. For example, parents may have to work long hours preventing them from spending quality time with their children. Parents themselves may be unable to meet their own personal needs because they are overwhelmed with life's problems. They may turn to maladaptive coping behaviors like substance abuse or crime (Biederman, et. al., 2000, p. 793) which may also hinder their ability to support their families.

Even with these extensive challenges, children from low SES backgrounds are expected to learn and succeed in school. Studies in adolescent development have supported a link between poor academic achievement and internal distress (Ansary, Luthar, \& McMahon, 2011). When a child from a low SES background is faced with large challenges at home, they are unable to dedicate focus and energy toward learning in school. For example, a child may be too preoccupied with worry or sadness to pay attention, or their bodies may be lacking the fuel and rest they need for proper cognitive functioning. Poor performance in the core subjects of reading and math has been noted for at-risk students, and these students are also falling short in the sciences. The National Assessment of Educational Progress reports that there is an achievement gap among at-risk students across grades 4, 8, and 12 in the sciences (NGSS Lead States, 2013, Appendix D).

Many public school districts are unable to provide proper support for at-risk students who come to school with vulnerabilities. Studies have shown that at-risk 
students are more likely to attend schools that are struggling financially, have high teacher turnover rate, have large class sizes, and have less rigorous curricula (Jensen, 2013, p. 7). Because of the system wide challenges in education funding and policy, there is a growing trend in the reduction in teacher involvement with their students, including providing hands-on and dynamic curriculum in the classroom. One study discovered that, “despite students' overwhelming preference for group activities, $5^{\text {th }}$ graders, on average, spent 91 percent of their time either working alone or listening to a teacher, with less than 5 percent of their time spent engaging in group learning activities (Jensen, 2013, p. 2).”

The shortcomings of public schools may cause at-risk students to feel negatively toward the traditional learning environment. At-risk students then exhibit symptomatic behavior of stress such as poor performance, or negative behaviors. This perceived failure to fit within the structure of a school may cause students to feel even more alienated, and they may begin to feel a sense of disconnection with the subjects they are learning. The manifestation of these poor outcomes may be explained by the theory that successful learning takes place when there is a balance between the cognitive and affective components within a student (Littledyke, 2008). When students do not have social and emotional support in school, they will not be able to learn or perform well in school. One of the foundational ideas presented by Skinner and Belmont (1993) on the development of motivation in a school setting states that, "the source of motivation is internal to the child, so that when the social surrounding provides for children's basic psychological needs, motivation will flourish (p. 572).” 
In recent years, many education and anti-poverty organizations have looked to out-of-school programs to support children and families, and to supplement the shortcomings symptomatic of the strained and underfunded public school system( Anthony, Alter, \& Jensen, 2009; Grolnic et. al, 2007; Lundh, et. al. 2013). These new programs aim to reduce the negative influences in childrens' lives and, at the same time bolster positive experience. In order to explore the relationships between adaptations (positive experiences) and disruptions (negative influences), researchers in the field have developed Risk and Resiliency Theory. Resiliency—defined as the capacity to overcome the disruptions in one's environment through adaptations that allow for the return to effective functioning - is fostered during experiences that combine both negative influences, and positive experiences. Anthony, Altar, and Jensen (2012) have developed an intervention model that uses Risk and Resiliency theory to define how risk factors can be reduced or buffered by the application of protective factors. Psychological theory has defined resiliency as "positive patterns of adaptation in the context of adversity (Masten \& Obradovic, 2006, p. 14).”

Afterschool programs have gained popularity as an out-of-school time resiliency intervention strategy. Many afterschool programs provide elementary and middle school students with a safe environment, an evening meal, an opportunity to socialize with peers and positive role models, and assistance completing homework. Anthony, Alter, and Jenson (2009) developed a theoretical framework based on Risk and Resiliency Theory to assist in building afterschool programs that address the needs of at-risk 
students. This model allows students to practice resiliency by utilizing the protective supports offered by a well-designed afterschool program. Other studies have shown that positive affective outcomes can be measured after interventions of this style. Grolnick et. al. (2007) performed a study that showed how providing a supportive afterschool program can increase motivation, engagement, and competence in at-risk middle school students.

Afterschool programs feature a wide range of topics and have been designed for many age groups and ability levels. Many studies (Beven \& Michalchik, 2013; Grolnick, et. al., 2007; Rahm, Martel-Reny, \& Moore, 2005) argue that afterschool programs can be effective interventions for at risk youth, even if academic performance does not show improvement. Afterschool programs may be the perfect opportunity to provide affective support that at-risk students may be lacking. A new model of afterschool programming, called expanded learning, seeks to increase students' interests and engagement by providing students with a supportive environment with new and exciting learning opportunities (Bevan \& Michalchick, 2013). The expanded learning model supports the idea that afterschool environments should be places to provide children with the social and emotional support they may not receive at home or in school. Many studies on motivation and resilience have established a relationship between negative affective states such as anxiety, alienation, and low self-esteem in students to low performance in school (Ansary, Luthar, \&McMahon, 2011). 
Although many afterschool programs have positive results, measuring the utility of these programs is still in its infancy. Few afterschool programs feature a common science curriculum or identify learning objectives for content areas. Program quality may vary across locations. As there has been a shift in science education away from learning facts and toward learning science practices and concepts, researchers have spent time evaluating the factors that contribute to quality afterschool programs. The quality of STEM classes can depend on the level of administrative support for the local program, the abilities and experience of a program coordinator, and the quality of instructors (Lundh, et. al., 2013).

The expanded learning model for afterschool programs can also support the aims of STEM education reform principles. The afterschool environment has the potential to provide an opportunity for students to participate in inquiry based science programs that feature the student as an active participant in learning. Inquiry based and experiential learning encourages students to explore their own abilities through active observation and experimentation. Littledyke's (2008) research on motivation in the classroom has shown that "non-contextual subject content is unlikely to foster meaningful learning that is essential for positive engagement with science (p. 6).” Many at-risk students who are struggling in school lack exposure or interest in STEM fields (NGSS Lead States, 2013, Appendix D). Often disadvantaged students lack a sense of connection to science topics. After Rham, Moore, and Martel-Reny (2005) completed a case study describing the positive experiences of poor youth in science based afterschool programs, they concluded that, "there is the need to build a science 
practice with youth that is based on respect, and a science they can relate to and that fits with their own world-views and culture, is particularly crucial for urban afterschool and youth programs (p 289).” By providing science opportunities for these students in their local community, they gain confidence in their own ability to be successful at school and in the sciences. In my own experience teaching science in a summer camp, I have observed that once students have had positive experiences in the field of science outside of school they may choose to pursue other science related programs in school, they may be inspired to pursue higher education, or even choose a career in science, math, or engineering.

Partnering with Friends of Tryon Creek, I had the opportunity to implement many of these ideas in an afterschool program for at-risk and ethnically diverse students at Mitchell Elementary School in southwest Portland. This school features a high percentage of students that receive free or reduced lunch, and many students live in public housing neighborhoods. I taught a pilot program in the winter of 2015, and then carried out the research intervention in the spring. Each program featured two groups of students. One group had 11 children ages 6-8, and the other group had 11 children ages 8-11. Each group had class once a week for an hour and a half after school. The pilot program ran for 10 weeks, and the intervention lasted 8 weeks. The course included classes at the elementary school and field trips to Tryon Creek State Natural Area. 
My research aimed to design and evaluate an inquiry focused and place based afterschool science curriculum. The holistic intervention design provided students with a foundation of social and emotional support, and gave students the opportunity to explore environmental science topics in their own community. By first supporting the social and emotional needs of my students, my goal in the program was to increase students' motivation toward learning science. In my study I chose to examine three affective constructs: self-efficacy, belonging, and engagement. Self-efficacy is defined by Bandura (1997) as "the belief in one's capability to organize and execute the courses of action required to produce given attainments." Self-efficacy is an important part of motivation because it may determine the activities a person may choose to pursue. If someone has low self-efficacy in school, they may not choose to participate in class, complete homework, or study for tests. "Self-efficacy beliefs are strongly related to student learning and achievement, and teachers have the potential to greatly influence these beliefs (Anderman \& Anderman, 2014, p. 7).” Next, I chose to include a sense of belonging, or "the need to feel connected to and accepted within a larger social network" as a part of the definition of motivation for this study (Anderman \& Anderman, 2014, p. 5).” A sense of belonging is particularly important for STEM students because children often feel science is a lofty profession reserved for only highly intelligent people. In order to connect students with science, STEM programs must convey that all people can be scientists in everyday life, and as a career. The final affective construct I used in my study was engagement. Engagement is "high quality participation in academic work, including effort (hard work, exertion, follow-through) and enthusiasm (interest, curiosity) (PMSC Academic Identity Survey, 2015).” 
Engagement is the behavior that is seen when students are motivated in the classroom. These three constructs began as constructions that contribute to the social and emotional state of participants in this study, and later they were viewed as protective factors in the intervention theoretical framework that could buffer against risk factors in students' lives.

My intervention design included a model for future afterschool programs that would support struggling students early in their academic careers, and expose underserved audiences to STEM subjects. My research supported the larger shift in intervention strategy from academic focused afterschool programming, toward a holistic and expanded program model. It contributed to the body of research on risk and resiliency that stated that successful interventions provide opportunities for students to build social and emotional skills and increased their abilities to effectively cope with environmental stressors. I believe that the support that students gain from resiliency based interventions may guide them toward developing into successful contributing members of society and informed citizens. My research also contributed to the nationwide effort toward providing STEM opportunities to a diverse audience of students. My program inspired students to seek and participate in future STEM programming.

One of the central goals of my research was to develop a curriculum that can be used to help at-risk youth build social and emotional skills while experiencing and engaging with science. To support this goal, along with developing a STEM based 
curriculum that aligns with the Next Generation Science Standards, I created a set of instructional practices that were implemented along with academic content instruction. I used components of established research to develop a theoretical framework in order to determine which instructional practices were most appropriate for the students at Mitchell Elementary School.

In my framework, risk factors were defined by Risk and Resiliency theory developed by Anthony, Alter, and Jensen (2009). I first identified the risk factors of the students at Mitchell Elementary school by making informal observations from the pilot program to identify deficiencies and assets of the participants in their school community. Once risk factors were identified, I designed the curriculum with built-in supports, or protective factors. Protective factors are the practices or resources that compensate for the disadvantages faced by at-risk youth (Anthony, Alter, \& Jensen, 2009). Once the protective factors of my study were determined, I incorporated applicable instructional practices that developed the classroom culture of the intervention. The instructional practices were an essential part of the intervention because they established the practical action that directly supported the affective constructs of self-efficacy, belonging, and engagement.

The thematic focus of the intervention was on the ecology of local native animals. I chose this topic because it was applicable for both age groups (grades 1-2 and grades 3-5). Animals are a subject that children find approachable and interesting. David Sobel in his essay Beyond Ecophobia (1996), explains that "Cultivating 
relationships with animals, both real and imagined, is one of the best ways to foster empathy during early childhood (p. 13)." This idea fits with the goal for youth to develop relatedness to the world around them, as well as a sense of engagement with local creatures. The conceptual focus for the intervention was examining structure and function. The learning objective is taken from the Framework for k-12 Science Education k-2 grade band explanation for Life Science concept 1A. "All organisms have external parts. Different animals use their body parts in different ways to see, hear, grasp objects, protect themselves, move from place to place, and seek, find and take in food, water, and air (NRC, 2012, p. 144).” Developmentally, these children are exploring who they are by determining differences and similarities between themselves and others. They are also learning to identify and express their own feelings. To expand on this idea, Sobel (1996) quoted Paul Shepard, “Animals have a magnetic affinity for the child, for each in its way seems to embody some impulse, reaction, or movement that is 'like me.' In the playful, controlled enactment of them comes a gradual mastery of the personal inner zoology of fears, joys, and relationships. In stories told, their forms spring to life in the mind, re-presented in consciousness, training the capacity to imagine (p. 13)." The topic of animal adaptations - structures and functions, allowed the students to deviate from the traditional learning practices of the classroom. Instead, they approached learning through real life experience in their own community.

The research question for my study was: How did an outdoor and STEM based afterschool program impact at-risk students' self-efficacy, belonging, and engagement, 
and their ability to apply conceptual knowledge of environmental science topics? The independent variable within my study was the afterschool curriculum I developed using Risk and Resiliency Theory, academic motivation theory, and science concepts. The dependent variables were observations and interviews collected from the participants during the program, and the rubric scores of participants' performances on an Application of Conceptual Knowledge task. I predict that my curriculum will produce an increase in positive affective states. At the end of the program, the students will also be able to apply conceptual knowledge about animals' structural adaptations and their functions. 


\section{Chapter 2: Literature Review}

This review of the research literature begins with studies that define the at-risk status of youth, next describes theoretical frameworks behind interventions that address risk, summaries of research on out-of-school STEM intervention programs aimed at increasing at-risk youth's resiliency and academic performance, and describes instructional practices applicable for the at-risk population.

\section{Defining at-risk youth}

Stephanie Cosner Berzin (2010) took a holistic approach to defining the experience of at-risk youth by collecting demographic, social, and economic outcome data. She used this information to develop a model that included a dynamic set of risk profiles relevant to today's society. For the study the author used data collected by the Bureau of Labor Statistics called the National Longitudinal Survey of Youth that featured information about factors that influence a child's success during the transition from school to work. This survey was administered by the Bureau to a sample of US residents of varying race and class from 1997 through 2005. The survey included a questionnaire, youth interviews, and family member interviews. The survey measured life events that indicate successful and unsuccessful steps in the transition to adulthood by asking questions about risk and resiliency factors that included information about the

youth's physical environment, psychological abilities and beliefs, and problem behavior. In addition, the survey collected information about each participant's involvement in social system programs such as foster care, special education, or the juvenile justice system. To analyze the data sets the author used latent class analysis to develop 
groupings of student success that incorporated factors of risk presented in the surveys. She identified four classes that coincided with a profile of risk and resiliency factors collected from survey data set. Each class represented low, moderately low, moderately high, to high successes in youth. This study defined at-risk youth in relation to their specific life circumstances. Many times, designations of at-risk status can depend on isolated life events, which may not take into consideration development of a person over time. This study incorporated many events in a child's life over time. The author argued that this shows a more complete picture of what it means to be at risk. In addition, this study highlighted how many factors can influence at risk status, and to what extent a youth can be at-risk. By utilizing a more complete and dynamic definition of the at-risk status, social services and education organizations can design interventions that are both applicable and effective.

Ansary, Luther, and McMahon (2011) compared how emotional distress, delinquency and substance abuse impact the academic performance of middle school students from low and high income homes. This study aimed to map the interactions between these three risk factors on a temporal scale by identifying which factors influence children first, and if these factors correlate with frequency of students exhibiting risk factors later. The study collected information from 318 students from an affluent suburban community, and from 280 students from a low-income community. Socioeconomic status was determined by the average median annual income in each community and percentage of students who received free or reduced lunch at each community's corresponding school district. This study used previously validated self- 
report surveys in combination to collect information about emotional distress (negative mood and anxiety), the frequency of delinquent behavior and the frequency of substance abuse (cigarette and alcohol) in middle school students. Data were collected from students once a year for three years during sixth, seventh, and eighth grade. Each factor was analyzed to identify a temporal order and correlation between events. Methods included using longitudinal statistical analyses that tracked variables over time, and used generalized estimating equations to organize and correlate variables. The study also found that when low income students reported emotional distress in sixth grade, their performance in school decreased over a three year period. In addition the use of alcohol and cigarettes lowered performance over time for students from the low income community. For high income students the data indicated no significant trends in substance abuse, emotional distress, or delinquent behavior influencing academic performance. The researchers concluded that low income children are vulnerable to social and emotional disturbances making them more susceptible to low academic performance. In addition, once a low income student experiences poor outcomes in one of these categories they become increasingly at risk to other negative factors creating a negative feedback loop that perpetuates and intensifies risk factors. Since no significant relationships between emotional distress and academic performance could be found in the high income students, researchers propose that they are protected from the negative effects of emotional and behavioral influences. These results are important because the interaction between these three factors can shed light on how risk factors influence the successes and failures of low income children. This study highlights how children from low income communities have an increased risk to negative influences, and how many 
negative influences may combine to make academic achievement suffer. It also provides support for the idea that low income students have a decreased ability to cope with negative events in life. It provides a compelling need for the development of interventions that can provide emotional and behavioral support for these children, and these results can drive future policy decisions that influence quality of our schools and academic support systems.

Masten and Obradovic (2006) summarized 40 research studies that traced the development of Risk and Resiliency Theory. The review defined resiliency theory and traced the development of resiliency research over time. The authors defined resilience as the "positive patterns of adaptations in the context of adversity that can be applied to a system (p. 14)." The authors began by reporting that research on resiliency has been studied through multiple lenses which include: behavioral evaluation, evaluation of environmental risks through the categorization of life processes and regulatory systems, through the development of prevention theory, and more recently through identifying genetic factors that contribute to resiliency through the study of bio-behavioral processes. The field of research began by identifying what factors in the lives of children supported successful or unsuccessful adaptation to life conditions. Early research used variable focused models and performed multivariate statistics to determine the interactions between variables, and the influences of these variables on the subjects over time. After many different studies, researchers determined a list of common factors that influence successful adaptation to negative life events. Once researchers identified the factors in a child's life that influence their resiliency, 
researchers moved on to develop interventions through quasi-experimental studies that aimed at recreating resiliency conditions that reverse or buffer stressors. These clinical trials and case studies tracked development factors and resiliency traits in individuals before, during, and after an intervention treatment. In particular, researchers were interested in identifying individuals who have experienced high amounts of trauma and who have found ways to overcome adversity. These case studies helped point researchers toward biological influences that contribute to resiliency. The next step in resiliency research was to examine how genes and physiology are linked to environmental influences, and using bio-imaging technology to track how resiliency manifests in the brain. Knowing about the evolution of resiliency research is important to understand how risk and resiliency has been validated both as a theory and as research methodology. Each type of study in this field has contributed to the body of knowledge that explains how individuals can adapt or fail within a system. The future development of research in this field can give educators and practitioners more information about how to design effective interventions that can mitigate or reverse negative impacts of risk factors during early developmental phases in life.

Shandra Forrest-Bank, et al. (2013) contributed to the body of qualitative research that supports resilience as a developmental strategy that can reduce failures and negative academic outcomes of young people in poor communities. Previous research showed that when youth in high risk environments practiced protective and resilience skills, they had higher rates of success when transitioning to adulthood. This study adds greater depth of context to the field of resiliency research because it includes specific 
examples of how youth experience the ways risk and resilience affect their lives. This valuable information can then provide the basis for the development of future intervention program practices. The authors interviewed thirty students from public housing neighborhoods that attended an afterschool program. They collected interviews from 10 elementary age students, 10 middle school students, and 10 high school students. The interview questions were designed to gain information about the students' risks, protections, and resilience. Questions followed the social ecological model of youth development and used age appropriate prompts to gather information about mental, spiritual, physical, and emotional health. The interviews were coded and analyzed in a comparative analytic method to identify common themes and to develop categories related to risk and resilience. Then the researchers did a second analysis using an applied constant comparison method to further narrow and define the categories. The result of the study was the development of five categories that describe risk and resilience: challenges that youth face, how they cope with difficulties, healthy influences, what supportive connections youth have, and what aspirations they have. Each category included culturally relevant information, as well as information about the values held by youth living in public housing. The authors chose to evaluate qualitative data because quantitative data can often miss culturally relevant information that contributes to risk and resiliency. Often quantitative data is unable to accurately record and communicate important affective factors such as coping response, having positive role models, and having aspirations because there isn't a common measurement system for these influences. In addition, quantitative data may categorize youth based on one specific negative behavior or outcome, and may not accurately represent life changes 
before or after the negative behavior. In response to these limitations, this study provided relevant and organized interviews that the research community and stakeholders can examine to understand both the positive and negative influences of children living in public housing neighborhoods. Findings from this study can be incorporated into the development of resiliency theory and into the development of successful interventions.

In summary, a number of researchers have studied at-risk youth by analyzing the positive and negative influences on young people's lives that result in positive and negative outcomes at home and at school. When placing youth into risk categories, it is important to consider cultural perspectives, socioeconomic issues, as well as the change in behavior over time (Berzin, 2010). Research has shown that if vulnerable children begin to exhibit negative behaviors they may be subject to poor performance in school or be susceptible to other risky behavior such as substance abuse and delinquency. Children from a low socioeconomic background show a significantly increased vulnerability to risk factors when compared to their peers from upper middle class neighborhoods indicating that they may be lacking resiliency skills (Berzin, 2010; Ansary, Luther, \& McMahon, 2011). In response to this finding, researchers have developed the Risk and Resiliency theory that seeks to identify social and emotional support that will translate into protective factors that buffer the negative influence of risk factors (Masten and Obradovic, 2006). In addition, many social and education organizations have developed specific interventions that directly provide protective 
experiences in order to reduce or reverse negative influences in the lives of at-risk youth (Shandra Forrest-Bank, et al., 2013).

\section{Afterschool program interventions for at-risk youth}

Hall, Williams, and Daniel (2010) collected feedback from parents, staff, and students involved in an afterschool program in order to identify the components that contributed to a successful program. This feedback is valuable to build quality future programming and influence the scope of funding of future afterschool initiatives. This study focused on an afterschool program called TEAM UP that was administered in six elementary and middle schools with economically disadvantaged students in Jacksonville, Florida. To assess attitudes toward the afterschool programs, the researchers administered surveys to afterschool program students, parents, and staff with questions that use a likert scale. Results from these surveys were analyzed with descriptive statistics and regression analyses to test for correlational effects across variables. In addition, discriminant analyses were performed to examine differences in parent and child perceptions. The researchers also held group interviews of both parents and students during focus group meetings. Participant responses were recorded and transcribed. Finally, the researchers gathered information from the TEAM UP director of programming during an individual interview that was recorded, transcribed, and coded. The interview data were analyzed using constant comparative analysis to identify patterns and themes within the responses. Synthesizing the results of the surveys with interviews of parents, students, and staff, the authors identified a common group of concepts that students, parents, and staff thought were important components 
of the TEAM UP afterschool program. All of these categories provided students positive opportunities for growth and improvement. Each sample group developed a set of components that afterschool programs should focus on. There were overlaps in common concepts in many areas. Parents, staff, and students agreed that a successful afterschool program should provide an environment that is a safe haven, and that provides opportunities to build social and emotional skills and character. This study is valuable because it demonstrated the effectiveness of an afterschool program that focused on issues beyond academic performance. In addition, it showed that parents and students from low income neighborhoods are motivated to participate in afterschool programs in order to gain opportunities to build social skills and gain confidence. This study contributes to the body of research that states that afterschool programs can incorporate a holistic approach to academic interventions that are effective for youth from low income housing.

Anthony, Alter, \& Jenson (2009) proposed a theory based framework that supported the development of risk and resiliency focused afterschool programming. The researchers then evaluated their programming through a case study. The framework was based on risk and resilience theory that seeks to support at-risk youth and families. The case study was carried out by a nonprofit partnership between the authors, the graduate school of social work at Denver University, the Denver Public Housing Authority, and private stakeholders concerned with the quality of education in Denver. The authors first developed an afterschool program using risk and resiliency theory called the Bridges Afterschool Program. The program's stakeholders identified 
risk factors in their local community, and incorporated corresponding protective factors into their program. Data from this case study was collected during one academic school year from students in grades 3-8 from three different public housing complexes in Denver. Pre-tests and post-test were administrated at the beginning of the year and end of the year. Each student was tested on five measurement domains that matched with the risk and resiliency framework: competence, confidence, character, connection, and long-term outcomes. Data were gathered using validated self-reporting survey instruments that were matched to each domain, as well as data collected from the school such as demographic information, academic grades, and standardized test scores. Data from pre- and post- tests were analyzed using a paired t-test. The results of these analyses showed that using the risk resiliency framework increased student self-efficacy as well as improved and sustained academic performance in reading. The authors concluded that effective out of school programs for at-risk students should address cultural, social, physical, and academic issues. In addition out of school programs must provide a safe local environment that forms connections with families and the community. This research is important because the authors believe that a common framework should be established for social welfare programs such as afterschool programs in order to maintain quality and effectiveness of interventions. Currently there isn't a standardized system for afterschool programming, and consequently quality and focus can vary across locations. One strength of using the risk and resilience theoretical framework to develop programming is that once risk and protective factors are identified each can be evaluated as a component of assessing the effectiveness of the 
intervention. In this way, quality afterschool programming can have a unified focus that begins to gain support and funding as an effective intervention for at-risk youth.

Afterschool programs are considered to be an effective intervention strategy to support disadvantaged youth. Programs designed to address problems faced by at risk and low income communities and that incorporate risk and resiliency theory have been shown to be valued by participants, school personnel, and community members (Hall, Williams, \& Daniel, 2010). In addition, studies have been designed to assess the effectiveness of interventions that support social and emotional factors by using the Risk and Resiliency Theory as a framework. One such study has shown that students can increase academic performance not only by directly supporting academic goals, but by providing students with support for their basics needs that may not be met at home or in school (Anthony, Alter, \& Jenson, 2009).

\section{Afterschool programs featuring STEM topics}

In order to evaluate the current status of afterschool programing today, Bevan and Michalchik (2013) identified and outlined two theoretical frameworks that have led to two opposing learning models for out of school learning. The "extended learning" model seeks to increase academic performance by teaching content consistent with school day curricula. The "expanded learning" model seeks to increase students' interest and future engagement in science by providing students with new and varied science experiences. Stakeholders currently evaluate the effectiveness of extended day programs by using in school performance data such as grades and standardized tests. 
The authors posited that the extended day model is not effectively measuring how well afterschool programs work because student performance data does not accurately measure the skills of motivation and academic identity provided by these programs. These incompatibilities often prevent "expanded learning" based programs from receiving sustained support by policymakers and program stakeholders. The authors argued that programs that follow the "extended learning" model cannot produce an additive learning effect, or an experience that will directly produce an increase of student performance in school. Instead, they proposed that afterschool programs can provide new contexts for students to foster interest in learning and experiences that will build students' capacity to engage in science over time. In order to test this idea, the authors proposed that future studies should examine child learning and development across different settings over time. This type of research could provide a foundation for the expanded learning model to be further implemented in out of school time programs.

Krishnamurthi, Bevan, and Coulon (2013), as part of the Afterschool Alliance, conducted a study to identify achievable outcomes of STEM afterschool programs. Specifically, the authors wanted to identify which parts of afterschool programs can support the goals of STEM in order to direct policy and STEM funds to appropriate afterschool STEM initiatives. To conduct this study, the authors identified afterschool program stakeholders that included 55 afterschool program providers such as school leaders, facilitators and curriculum designers, and 25 afterschool STEM supporters such as policy leaders, and department of education representatives. Once the stakeholders were identified, they were asked to complete an online questionnaire about afterschool 
program outcomes, and send their responses to the authors. The authors used a research method called the Delphi method to gather the questionnaire responses, give feedback to narrow the focus of each response, and send the feedback back to the stakeholders for refinement. After a number of rounds of feedback and refinement, the answers to the questions began to converge into common responses, and the stakeholders were able to reach a consensus for each question. From this data, the researchers identified three common achievable outcomes that afterschool programs could provide for STEM education: a) developing an interest in STEM; b) building capacity to productively engage in STEM learning activities; and c) increasing students' attitudes about the value of STEM goals and STEM learning activities. Using these outcomes the authors built a framework that included a description of each outcome with indicators and subindicators that described how afterschool programs can successfully implement STEM programming goals. Since there have been many new developments in the STEM field, and the NGSS Standards have been adopted, it is an important time for out of school programs to define how they can contribute to STEM initiatives. Specifically, this study identified the strengths and weaknesses of afterschool programming when considering STEM goals. This information is valuable because it can influence funding and policy for afterschool programs in the future, and steer the development of afterschool STEM programming. In addition, the study identified components of afterschool programming that need future reform, such as developing instruments to measure STEM learning across settings, building in professional development opportunities for afterschool instructors, and identifying logistical and contextual limitations of an afterschool program setting. 
Papzian, Noam, Shah, and Rufo-McCormic (2013), researchers at the Program in Education, Afterschool, and Resiliency (PEAR), have developed an assessment tool called the Dimensions of Success (DoS) that can be used to measure the quality of afterschool STEM programming. The primary purpose of the tool is to enable leaders of afterschool STEM programs to assess and improve their own programs. There are many in-school measures of quality STEM instruction, but no current and effective measures for "Out of School Time" (OST) programs. Quality afterschool programming can provide experiences that build students' positive attitude toward STEM subjects, and conversely if programs aren't properly administered, afterschool experiences may damage student attitudes toward STEM. The DoS outlined twelve dimensions of success under four categories of program features, to assess quality in afterschool programming. It also included instructions for using the tool, and a four point rubric. To test the usability of this tool, the authors designed a pilot protocol and used it to evaluate the summer Math Engineering Technology and Science (METS) program in Kansas City. Next, the authors standardized the tool by evaluating multiple OST programs that included a wide range of STEM topics in a variety of contexts. Then, they used the tool to perform a case study of eight after school sites by partnering with the Informal Learning of Science Afterschool (ILSA) project. To evaluate the effectiveness of the DoS the authors compared their own measure to data from an already established afterschool measurement tool called the Promising Practices Rating Scale (PPRS), as well as the Classroom Observation Protocol (COP) for science programming. The authors also cross referenced and aligned the philosophy behind each of DoS's measurement domains of success with the impact categories of two 
nationally recognized frameworks for evaluating OST and STEM projects. One framework was developed by Friedman (2008) for the National Science Foundation called the Framework for Evaluating Impacts of Informal Science Education Projects. The other framework was developed by the National Research Council and outlines six strands of goals and practices for informal science (NRC, 2009). Finally, the authors designed an in depth training protocol for using the DoS to familiarize practitioners with the proper method of evaluation. The authors are convinced that this method of evaluation can increase the quality of STEM afterschool program by providing an effective measurement tool that will guide OST programs with information about quality of activities and capability of staff members.

Bruyere, Wesson, and Teel (2012) carried out a study in an urban school in New York City that examined the interest of students, instructors, and parents on nature lessons presented as part of an afterschool program. The authors aimed at identifying the barriers in attitude toward nature topics of urban afterschool program participants in order to propose effective ways of integrating environmental education into afterschool programming. First, the authors coordinated with the afterschool program leaders and instructors to develop a nature based curriculum and design a set of goals for the afterschool program. The program theme was conservation and included daily activities such as homework assistance, recreation, and academic enrichment in a range of subjects. One hundred and forty students participated from grades 1-8. The program lasted for 18 months and was implemented for three hours a day, Monday-Friday. To collect data, the researchers held focus groups with instructors and parents before and 
after the program. Authors asked focus group participants about their interest in nature, science, and how they feel about their children participating in nature based programming. The researchers also facilitated three instructor trainings on environmental education that included a survey that measured the instructors' interest in teaching nature based lessons. The authors recorded responses from the focus group and the survey using open coding methods, and analyzed the code using statistics to identify conceptual themes in the responses. Using this data, the authors found that both parents and instructors were interested in nature education and allowing their children to have environmental education opportunities during afterschool time. Many family members talked about their own childhood outdoor experiences when they were asked about why nature education was valuable. The study identified time constraints, lack of funding, and misconceptions about outdoor learning as barriers for instructors integrating nature based concepts into their curriculum. After participating in training sessions, the instructors reported feeling more confident about teaching environmental concepts. In addition, they felt more prepared to teach nature based activities from the afterschool curriculum to their students. The data collected and presented in this study demonstrated that environmental education can be successfully incorporated into informal education program in urban areas. By identifying barriers and challenges to implementing environmental education programming, the authors identified practices that may help make future urban environmental education programs be more successful. 
A case study by Lundh, House, Means, and Harris (2013) evaluated the quality of afterschool science programs by examining constraints and supports that influenced science classes at nine afterschool programs in California. The study used the six strands of science learning developed for learning in informal environments by the NRC in 2009 to measure how effective the programs were at teaching quality science. The six strands are: developing interest in science, understanding science knowledge, engaging in scientific reasoning, reflecting on science, engaging in scientific practices, and identifying with the scientific enterprise (NRC, 2009). The authors first surveyed 406 state-funded afterschool programs about a range of factors that may impact science learning. The factors included: having support from partnering organizations, time restrictions, availability of supplies, frequency of classes, professional development and training, etc. Out of the larger group the authors chose twenty schools to interview by phone. From those twenty interviews, the authors chose nine schools that were representative of afterschool programs in California. Next, the authors visited the nine sites, implemented semi-structured interviews with site coordinators and science facilities, and carried out structured observation and debrief forms after observing science classes. The data from the interviews were used to determine which key factors impacted the quality of science programming in each of the schools. These factors included: amount of time per class, frequency of science throughout the week, staff training, access to curriculum, materials, etc. The authors used their program observations to determine which sites practiced the NRC's six strands of science learning. The study found that schools that received staff training, materials, and staff from partnering organizations implemented the most science learning strands. Then, 
they compared the success of science programing to the factors that constrained or supported the facilitation of science. Those schools without much support did not practice many strands of science learning. Constraints common throughout all of the school were time per class (usually around 40 minutes), frequency of the class during the week, and lack of materials. The authors found a qualitative link between the amount of program constraints and the extent to which the program taught the six strands of science learning. This study suggests that successful afterschool programs should have training on inquiry-based teaching, have frequent classes throughout the week, and teach projects that allow for open ended questions, experimentation, and reflection.

Currently, there is a movement toward incorporating STEM education into afterschool programs. As the focus in STEM education shifts toward teaching science practices, quality afterschool programs have also attempted to change teaching practices (Lundh, et. al., 2013). This informal setting can provide a forum to increase interest and motivation for students in the sciences (Krishnamurthi, Bevan, \& Coulon, 2013). There are two different models that afterschool programs follow. The extended day model that seeks to continue focusing on the topics that are being taught in schools, and the expanded model that provides new and varied activities that are different than what students experience in school. Afterschool and STEM advocates support the expanded model as a more appropriate approach to science topics (Bevan \& Michalchik, 2013). Since the reform and development of new STEM education practices, afterschool programs have been evaluated for their potential to fit within the new framework. 
Current research has identified that lack of resources, program partners, time, and qualified instructors influence the quality of afterschool programming (Lundh, et. al., 2013). Afterschool program facilitators and other stakeholders have identified that this informal setting can be a great place to increase students' interest in STEM, build capacity to productively engage in STEM activities, and increase the value that students attach to STEM learning (Krishnamurthi, Bevan, \& Coulon, 2013). In addition, researchers in out of school STEM programs have developed methods to evaluate the quality of afterschool programs in order to better align these informal programs with STEM goals (Papzian, Noam, Shah, \& Rufo-McCormic, 2013). When specific science topics, like environmental science and conservation, were taught in an afterschool program in an urban school district in New York City, parents and staff showed support for these topics supporting the movement toward hands on science programs during afterschool time (Bruyere, Wesson, \& Teel, 2012). 


\section{Science Based Afterschool Interventions for At Risk Youth}

As part of a larger three year research project, Rham, Moore, and Martel-Reny (2005) collected data about the role of science-based afterschool programs in the lives of at-risk youth, as well as what motivated the students to attend science programs. The ethnographic study documented participants through observations and interviews. The authors selected two afterschool programs that served low income and ethnically diverse urban communities, offered hands on science programming, and were long term programs. The programs being studied were Les Scientifines an afterschool program for urban girls in Canada ages 9-12, and an Upward Bound summer math program called COSMOS for low income students ages 13-15 funded by the U.S. Department of Education. After collecting information from each student that participated in each program through interviews and journal entries the researchers were able to describe how the afterschool program impacted each student's life. The study describes the experience of three students. Rosine and Kumila who participated in the Les Scientifines program, and Edric who participated in the COSMOS program. These case studies highlighted how out-of-school experiences inspired students to pursue more science opportunities in the future. These pivotal experiences are often missing in the lives of children from poor urban neighborhoods, and therefore education organizations and school districts should encourage this type of programming. All three students performed poorly in science before participating in the afterschool programs, and improved their confidence and academic performance after completing the program. 
Using these examples the authors identified how science afterschool programs provided a safe and inviting setting for these students to explore science. The programs built confidence in each student by providing relevant and flexible experiences that validated the students' cultural background and prior experiences. The programs also widened the scope of possibilities for these students' futures.

The authors Grolnick, Farkas, Sohmer, Michaels, and Valsiner, (2007) developed a science based after school program, using the intervention strategy based on SelfDetermination Theory, to evaluate motivation and its relationship to academic performance. Participants were 90 seventh graders from one middle school in an urban low income neighborhood. The students were randomly assigned to an experimental group of students who would receive the after-school intervention, or an in-school program control group. The control group was given an in-school presentation of facts without hands on activities. The students from each treatment group were paired with one another based on demographics. The pairing of the students from the treatment group and the control group was confirmed by statistical analyses that showed that these student groups were demographically equivalent. Those students in the experimental group participated in a hands on science based afterschool program called the Investigator's Club three days a week for 15 weeks. Students in the control group were given science lectures during in-school meetings. Both groups were given a motivation assessment before and after the program. In addition, participants' teachers in the subjects of math, science, English, and social studies were interviewed about each participant's performance after completion of the intervention. The authors then used 
multivariate statistics to determine correlational relationships between variables over time and between treatment groups. The findings from this study showed that after students participated in the afterschool program, they reported feeling a greater sense of internal motivation than before the program, and showed an increase in academic performance in science subjects. The control group did not show an increase in motivation. These students showed a decrease in motivation toward academic subjects over time during the middle school years. Although there was an overall trend of a decrease in engagement in learning for all students in the study during the middle school years, those who participated in the afterschool program (the treatment group) saw a smaller reduction in interest than those in the control group. The results gathered from both the control and the treatment groups show that just providing the students with additional science material as seen in the control group, was not responsible for the buffering of motivation seen in the treatment group. The treatment intervention of providing addition science education plus providing a supportive environment and hands-on curriculum was shown to support less loss of motivation in middle school. These results support the growing body of research that suggests that motivation in students is closely linked with their academic performance. This study was able to show an effective intervention strategy that incorporated the sciences as well as using a well-established theoretical framework based on motivational factors can improve middle school academic performance.

Simon, Aulls, Dedic, Hubbard and Hall (2015) examined the relationship between three different psychosocial constructs of motivation with academic achievement and persistence of junior college students in Quebec, Canada. The authors 
wanted to determine how a student's motivation impacted their pursuit of STEM classes and careers after high school. The three psychosocial constructs were: Bandura's theory of self-efficacy, achievement goal theory, and academic autonomy as defined by the self-determination theory developed by Deci and Ryan (2009). These motivational constructs were compared to the amount of intrinsic motivation, positive or negative affect, academic performance, and persistence in school. The authors surveyed 1,309 first year junior college students (46\% male) that had taken science courses in high school. The survey used items from previously validated instruments to ask students to rate their motivation during high school using constructs from all four of the motivational components using a Likehert scale (1-5). Then, the authors used structural equation modelling (SEM) to show how the motivational constructs affected achievement, intrinsic motivation, affect and persistence in high school. The authors used the data from the model to predict the students' success in STEM classes in junior college. The results of this study showed that if a student had high self-efficacy, they would also show higher intrinsic motivation, and higher achievement. If students identified with mastery goals, they also had higher intrinsic motivation, and reported higher achievement. Students with high levels of autonomy did not also show high levels of intrinsic motivation. This study indicated that the psychosocial constructs of motivation are important for developing career aspirations for STEM careers. Setting mastery goals, having intrinsic motivation, and feeling competent are skills that aid students in high achievement in science and persistence through science coursework. 
Both qualitative and quantitative research on afterschool programs that feature science topics and support motivational resilience have been shown to have positive impacts on at-risk youth participants. These programs can provide youth with new experiences that increase their interest in science, as well as increase their motivation to pursue science in the future (Rham, Moore, \& Martel-Reny, 2005). Students that build positive self-efficacy, autonomy, and set mastery focused achievement goals in afterschool programs report higher academic achievement in school (Simon, et.al., 2015). In addition, by comparing students who participated in an afterschool program and those who did not, research has shown that the afterschool hours can improve academic performance and engagement by providing a new venue for hands on science experiences (Grolnick, et.al., 2007). These out-of-school programs can be an effective intervention that can increase motivation and resilience as well as align with the goals of the STEM education movement.

\section{Instructional Practices}

Classroom Motivation by Anderman and Anderman (2014) is a text that describes theories in motivation, and then discusses how to use these theories in practice in a classroom setting. It begins by defining different motivation theories. These theories include: Self-Determination theory, Attribution Theory, Expectancy-Value Theory, Social Cognitive Theory, and Goal Orientation Theory. The book discusses relevant research that demonstrate how these theories impact student learning. In the following chapters, the authors develop ideas on the applications of these theories in different parts of the classroom experience. The classroom experience is separated into 
teaching skills, and developing a motivational environment. The section of the book on teaching skills offers valuable advice about instructional practices that promote positive student motivation. For example, teaching skill chapters include: Using Rewards Effectively, Working with Parents, Assessment, and Working with Parents. The chapters that focus on developing a motivational environment develop ideas about how the structuring of experience in the classroom can promote student motivation, as well as external factors that are detrimental to student motivation. Chapters that cover the motivational environment include: Promoting Autonomy, Expectations for Students, and Motivational problems. The book provides a well-rounded view of how motivational theories can be practically applied in the classroom to support student motivation and facilitate a positive learning environment.

\section{Engaging Students with Poverty in Mind: Practical Strategies for Raising}

Achievement is a book written by Eric Jensen (2013). This book describes ways to help students from poverty learn. Students that come from low socio-economic backgrounds have many vulnerabilities, and as a consequence have many barriers toward successful learning. This book considers these barriers, describes current research on these topics, and suggests practical strategies to help students learn. The book begins by establishing that academic achievement is closely linked to student engagement. If a student is not able to engage with learning, they will not perform well in school. Then, Jensen uses the research and his experience to define seven factors that correlate with student engagement: health and nutrition, vocabulary, effort and energy, mind-set, cognitive capacity, relationships, and stress level. The proceeding chapters address these factors 
by defining each of them, and then listing practical steps in the form of "teacher actions" a teacher can take to promote the factors in the classroom. Each action is then defined, and instructional practices in the form of solutions are then described. This book is a great bridge between the academic research on barriers to learning and practical suggestions for overcoming those barriers in the classroom.

These books form a bridge between academic research in education with practical strategies for educators in the field. Forming applications for theories developed by research is an important step in continuing to reform and improve the field of education today. Anderman and Anderman (2013) connect theories in motivation to the classroom by discussing how motivational constructs affect student performance. The book also suggests ways that teacher can bolster student motivation in order to promote positive learning experiences in the classroom. Jensen (2012), discusses the research on children from low socio-economic status and then based on the research makes suggestions on now to boost engagement in the classroom. These texts serve as resources for teacher to improve their instructional practices.

\section{Summary}

This review describes how at risk youth today can be categorized in a dynamic way that includes information about cultural influences and socioeconomic status. Methods for defining at risk youth include examining specific risk factors and their relationship with negative outcomes, which have been found to profoundly affect the lives of youth from low income neighborhoods, but not youth from middle class neighborhoods (Berzin, 2010). As social scientists seek to understand the relationships 
among risk factors, protective factors, and outcomes, Risk and Resiliency Theory has been developed to explain these relationships (Masten, \& Obradovic, 2006). Using this theory, many social service organizations have developed intervention frameworks that contribute to building the knowledge base behind this theory, and demonstrate the theory's effectiveness through practical applications. These applications can include informal out-of-school programs such as afterschool programs, mentoring programs, and summer learning opportunities. Research in this review shows that afterschool programs have become a prominent and effective intervention strategy to support the social and emotional needs of struggling youth (Anthony, Alter, \& Jenson, 2009). In particular, leaders of science afterschool programs for at risk youth have successfully incorporated risk-resiliency theory, and researchers have documented positive youth experiences through quasi-experimental and case studies. Researchers have been exploring the impacts of afterschool interventions that use risk and resiliency theory (Forrest-Bank, et. al, 2014; Grolnick, et. al., 2014; Hall, Williams, \& Daniel, 2010.) The STEM education field is underging reform and theoretical shifts in response to the growing demand for professionals in the STEM field and a need for the general population to be more science literate. Afterschool programs have been identified as being a great venue for implementing new instructional practices, especially where such programs expand the range of science learning activities, rather than just extend the kind of learning that students experience in school (Bevan, \& Michalchik, 2013). As afterschool programs and STEM education agencies align their goals and develop program evaluation methods, more quality afterschool programming can be implemented. Instructional practices that support holistic science programming can be 
implemented in these science programs. These practices align with current research on motivation and engagement for at risk students (Anderman \& Anderman, 2013; Jensen, 2012). When science afterschool programming incorporates motivational support, studies show that participants show an increased interest and confidence about science topics (Grolnick, et.al, 2007; Rham, Moore, \& Martel-Reny, 2005).

My research provided additional qualitative support for STEM intervention programs that support the Risk and Resiliency Theory as the foundations for effective afterschool programming. My curriculum design and instructional practices considered the risk factors unique to the students involved in my program, and provided both social and emotional support, in addition to providing quality inquiry based STEM programming. By collecting data on both affective factors and the application of conceptual knowledge, I was able to examine relationships between the participants' thoughts and feelings about science, and their abilities to demonstrate what they learned about science. This research contributed to the field of research that shows that holistic approaches to out-of-school is an effective way to promote motivation and academic performance for at-risk students. My research, like many of the studies above, demonstrated how using an expanded afterschool model that utilizes risk and resiliency theory had a positive influence on students' motivation. My study was unique because it used an instrument developed by the Portland STEM Partnership's common measurement system to show participants" conceptual understanding of science topics (Saxton et. al. 2013). It used ethnographic data to evaluate the effects of social and emotional support on participants' sense of motivation defined as self-efficacy, 
belonging, and engagement. It focused on one life science topics taken from the Next Generation Science Standards (NGSS Lead States, 2012a). 


\section{Chapter 3: Methods}

\section{Overview}

The research question of this study was: How does an outdoor and STEM based afterschool program impact at-risk students' self-efficacy, belonging, and engagement, and their ability to apply conceptual knowledge of environmental science topics? In this study, I chose to use self-efficacy, a sense of belonging, and engagement as affective components that influence learning. The intervention treatment was a curriculum developed from a theoretical framework that I developed and taught to the students. The framework was based on established theories in risk and resiliency, the theory of intelligence, environmental education, and science concepts from the Framework for K-12 Science Education (NRC, 2012). The independent variable of this study was curriculum that I developed that corresponds with the above mentioned theories, core concepts in life science from the Framework for k-12 Science Education, and environmental education philosophy. The dependent variables within my study were observations of the participants' self-efficacy, sense of belonging, and engagement, and the measurement of students' ability to apply conceptual knowledge.

I measured self-efficacy, belonging, and engagement by making observations of the student experience during each class period throughout course. The observations were collected using an observational checklist developed using the intervention's theoretical framework. Since I was the teacher in the class, I also recorded Informal observations of students' experiences after each class. The observations were used to evaluate the effectiveness of instructional practices during the program. After the study 
these observations were used to gain insight about student behaviors, and student responses to the intervention curriculum.

The curriculum featured the life science concept of Structure and Function (LS1.A) from the core idea of "From Molecules to Organisms: Structures and Processes" found in the Framework for K-12 Science Education (NRC 2012, p. 143 145). I gave the participants a conceptual knowledge task during the last class of the program. I used an adaptation of the Application of Conceptual Knowledge Rubric designed by the Portland Metro STEM Partnership to measure students' abilities to apply conceptual knowledge. (See Appendix II)

\section{Participants}

The participants were elementary students from Mitchell Elementary School in Southwest Portland. As part of Portland Public School's enrollment summary Mitchell Elementary reports 386 students were enrolled in the school during the 2013-2014 school year. The demographic breakdown showed: 7\% Hispanic, 20.7\% African American, 2.8\% Asian, 3\% Native American, 1\% Pacific Islander, 57\% White, and 6.5 $\%$ multiple races. The intervention was part of the 2015 spring term of the Schools Uniting Neighborhoods (SUN) Afterschool program managed by Multnomah County and facilitated by the Neighborhood House organization. Neighborhood house is a local non-profit organization that provides assistance to low income and recently immigrated families in the Portland area. The 2012-2013 SUN program at Mitchell 
reported serving 270 students; $60 \%$ students of color, $76 \%$ students identified 'at risk of academic failure', and 75\% qualified for free and reduced lunch.

The sample size in this program was 22 students two groups. One treatment group contained 11 participants ages 6-8 from first and second grade classrooms. This treatment group was designated as the younger group. A second treatment group was composed of 11participants ages 9-11 from third through fifth grade classrooms. This treatment group was designated as the older group. These students self-selected to participate in the study by choosing to take the Tryon Trekker class during registration for the SUN afterschool program. Each student received an activity guide that described each SUN class, and the students choose their top choices during registration. The sun coordinator filled each class on a first come first serve basis until they had both reached capacity. Twenty eight students enrolled in the class at the beginning of the afterschool program term. Three students dropped out, and three students were absent during the intervention interviews.

\section{Intervention}

The intervention was an eight week afterschool program called Tryon Trekkers, developed to support some of the vulnerabilities faced by at-risk elementary school students and to provide outdoor STEM learning opportunities. I assumed the teacher role and facilitated the activities involved in this program. During the program, I had one co-teacher that was a trained outdoor educator with over ten years of informal education experience. The program also supported an undergraduate student volunteer 
from Portland State University. The intervention was scheduled one day a week for an hour and twenty minutes, for Eight weeks. During the intervention the participants experienced a mixture of outdoor and indoor experiences. The activities combined a range of multi-modal learning tasks that involved kinesthetic tasks, group work, problem solving, etc.

The intervention focused on the science topic of structure and function by using examples of local animals and their adaptations. The life science concept that the course focused on was,Structure and Function. I used the k-2 gradeband understanding of this concept from the Framework for k-12 Education. "All organisms have external parts. Different animals use their body parts in different ways to see, hear, grasp objects, protect themselves, move from place to place, and seek, find and take in food, water, and air (Framework, p. 144)." I developed the curriculum by identifying one learning objective that related to the structure and function concept by highlighting how local wildlife use body parts to survive. Each class reinforced the central concept of structure and function, and built upon previous lessons. I chose to use the k- 2 benchmark description for the learning objective in this intervention because observations from the pilot program indicated that both age groups were better suited for the most basic topics within this concept. Each lesson featured a specific learning objective in the form of an essential question (see table 1). In addition to the activities that supported conceptual understanding, and instructional practices that supported affective components, a class meeting sometimes featured research tasks that were completed for this research 
project, such as an Application of Conceptual Knowledge (ACK) task, or semistructured interviews.

To help in the development of the intervention I ran a ten week pilot program during the winter term of SUN school at Mitchell Elementary School. During the pilot program I experimented with different natural science topics and different activity designs. I taught life science concepts that related to local ecology. No research was conducted during the pilot program. From the pilot program I learned that the limited time frame was optimal for presenting just one science concept. In addition, I observed that the students were fatigued from participating in a full day of school before the program. For this reason, I chose a flexible programming schedule and hands-on activities that could hold the students' attention.

The Tryon Trekker curriculum used hands-on and experiential activities to showcase native Pacific Northwest animals. The class meetings focused on different animals and the structural adaptations that helped each animal survive in their environment. The class was held at Mitchell Elementary school and at Tryon Creek Natural Area (TCNA). The activities incorporated environmental education philosophy by including games, hands-on projects, and activities from established environmental programs such as: "The Coyote Guide" by Jon Young, "Project Wild" and "Sharing Nature with Children" by Joseph Cornell. The curriculum also incorporated novel activities that I developed myself. Many of the curriculum activities reinforced the instructional practices designated for the curriculum, and therefore supported the goals of the protective factors chosen for the participants. 
Table 1. Curriculum Schedule. MES stands for Mitchell Elementary School. TCNA stands for Tryon Creek Natural Area.The curriculum schedule for the Tryon Trekkers Spring Program. This schedule includes the location of the program, the learning objective for each class, and the research intervention data being collected during each class.

\begin{tabular}{|c|c|c|c|c|c|}
\hline Week & Class Date & $\begin{array}{c}\text { Locati } \\
\text { on }\end{array}$ & $\begin{array}{l}\text { Learning } \\
\text { Objective }\end{array}$ & Activities & $\begin{array}{c}\text { Research Data } \\
\text { Collected }\end{array}$ \\
\hline 1 & $\begin{array}{c}\text { Tuesday, } \\
\text { April } 7 \\
\text { (older) } \\
\text { Thursday, } \\
\text { April } 9 \\
\text { (younger) }\end{array}$ & MES & $\begin{array}{c}\text { Organisms } \\
\text { look } \\
\text { different, } \\
\text { and they do } \\
\text { different } \\
\text { things }\end{array}$ & $\begin{array}{c}\text { Introductions, name games, } \\
\text { animal riddles, outdoor } \\
\text { scavenger hunt, decorate } \\
\text { journals }\end{array}$ & $\begin{array}{l}\text { Gather Assent } \\
\text { and send home } \\
\text { Consent forms }\end{array}$ \\
\hline 2 & $\begin{array}{l}\text { Tuesday, } \\
\text { April } 14 \\
\text { (older) } \\
\text { Thursday, } \\
\text { April 16 } \\
\text { (younger) }\end{array}$ & MES & $\begin{array}{l}\text { What do } \\
\text { organisms } \\
\text { need to } \\
\text { survive? }\end{array}$ & $\begin{array}{l}\text { Animal Survival posters, } \\
\text { outdoor survival game, } \\
\text { Create-A-Creature activity }\end{array}$ & $\begin{array}{c}\text { Collect } \\
\text { ethnographic and } \\
\text { behavioral } \\
\text { observations }\end{array}$ \\
\hline 3 & $\begin{array}{c}\text { Tuesday, } \\
\text { April } 21 \\
\text { (older) } \\
\text { Thursday, } \\
\text { April } 24 \\
\text { (younger) }\end{array}$ & TCNA & $\begin{array}{l}\text { How to } \\
\text { organisms } \\
\text { survive in } \\
\text { the habitat } \\
\text { at TCNA? }\end{array}$ & $\begin{array}{l}\text { Use journals to Find } \\
\text { evidence of food, water, } \\
\text { and space used by animals. } \\
\text { Reflection. }\end{array}$ & $\begin{array}{c}\text { Collect } \\
\text { ethnographic and } \\
\text { behavioral } \\
\text { observations }\end{array}$ \\
\hline 4 & $\begin{array}{c}\text { Tuesday, } \\
\text { April } 28 \\
\text { (older) } \\
\text { Thursday, } \\
\text { April } 30 \\
\text { (younger) }\end{array}$ & MES & $\begin{array}{l}\text { How do } \\
\text { organisms } \\
\text { eat? }\end{array}$ & $\begin{array}{l}\text { bird beak tools, outdoor } \\
\text { animal food hunt, build an } \\
\text { origami beak }\end{array}$ & $\begin{array}{c}\text { Collect } \\
\text { ethnographic and } \\
\text { behavioral } \\
\text { observations }\end{array}$ \\
\hline 5 & $\begin{array}{l}\text { Tuesday, } \\
\text { May } 5 \\
\text { (older) } \\
\text { Thursday, } \\
\text { May 6 } \\
\text { (younger) }\end{array}$ & TCNA & $\begin{array}{l}\text { How do } \\
\text { organisms } \\
\text { collect } \\
\text { food? }\end{array}$ & $\begin{array}{l}\text { Listen to woodpecker calls, } \\
\text { how woodpeckers use their } \\
\text { tongue, find clues of } \\
\text { woodpeckers at TCNA }\end{array}$ & $\begin{array}{c}\text { Collect } \\
\text { ethnographic and } \\
\text { behavioral } \\
\text { observations }\end{array}$ \\
\hline 6 & $\begin{array}{l}\text { Tuesday, } \\
\text { May } 12 \\
\text { (older) } \\
\text { Thursday, } \\
\text { May14 } \\
\text { (younger) }\end{array}$ & MES & $\begin{array}{l}\text { How do } \\
\text { organisms } \\
\text { move? }\end{array}$ & $\begin{array}{l}\text { Group drawing of a slug, } \\
\text { observe real slugs on plexi- } \\
\text { glass, discuss body parts, } \\
\text { draw a slug diagram }\end{array}$ & Interviews \\
\hline 7 & $\begin{array}{l}\text { Tuesday, } \\
\text { May } 19 \\
\text { (older) } \\
\text { Thursday, } \\
\text { May } 21 \\
\text { (younger) }\end{array}$ & MES & $\begin{array}{l}\text { How do } \\
\text { organisms } \\
\text { stay alive? }\end{array}$ & $\begin{array}{l}\text { Predator/Prey tag, circle } \\
\text { discussion using skulls, } \\
\text { engineer a flying squirrel }\end{array}$ & Interviews \\
\hline
\end{tabular}




\begin{tabular}{|c|c|c|c|c|c|} 
& $\begin{array}{c}\text { Tuesday, } \\
\text { May 26 } \\
\text { (older) } \\
\text { Thursday, } \\
\text { May 28 } \\
\text { (younger) }\end{array}$ & TCNA & $\begin{array}{c}\text { Create a } \\
\text { Creature } \\
\text { Task }\end{array}$ & $\begin{array}{c}\text { Create a creature in small } \\
\text { groups }\end{array}$ & $\begin{array}{c}\text { Application of } \\
\text { Conceptual } \\
\text { Knowledge Task }\end{array}$ \\
\hline
\end{tabular}

During the first week of the class we spent most of the class getting to know each other. The other instructors and I introduced ourselves, we discussed the science topics, and we established class rules and expectations. The participants played get to know you games, solved animal riddles, and did an outdoor nature scavenger hunt. During this first class, the participants also decorated their nature journals. During the second week of our class we focused on what animals need to survive. To zero in on the idea that animals need food, water, and shelter/space the participants first participated in a group activity exploring what people, pets, and wild animals need to survive. Then, I took the class outside to play an active game. During the game, participants pretended to be different animals. Each animal had to run around and collect poker chips that represented food, water, and space. Finally, the group came inside and built a clay creature that featured body parts that helped them survive on the Mitchell school campus. On the third week of class, we went on our first field trip to Tryon Creek State Natural Area (TCSNA). At the park, I separated the participants into small groups with an instructor. Each group hiked through the forest with their nature journals looking for clues of animals. In particular, participants were asked to find clues of food, water, or shelter/space that animals could use for survival in TCSNA. At the end of the hike we had a group discussion to reflect on what we saw. During the fourth class we focused on how animals eat. As part of our circle time discussion we 
talked about our favorite foods and what tools we used to eat them. Next, the participants explored how birds use their beaks to eat food during a hands-on activity. Then we went outside to find other sources of bird food on campus, and finally returned inside to engineer our own bird beak out of paper. The fifth week of the intervention was our second field trip to TCSNA. During this field trip we focused on woodpeckers. During an introduction before our hike, we discussed how woodpeckers use their beak and tongue to help them peck at trees and extract bugs from under the bark. During the hike, the participants were on the lookout for clues that woodpeckers were active in the park.

We focused on how organisms move during our sixth class meeting. During this class an instructor from Friends of Tryon Creek led activities during class. I conducted 5-10 minute interviews during this class. The students explored slugs during this class. At the beginning of class, the participants were asked to make a group drawing of a slug — showing and naming specific body parts. Then, each participant spent time observing slugs moving on a piece of plexiglass, then they participated in a group discussion about how these slugs moved. Finally the participants made a drawing of the slug in their journal after learning about the different body parts. The seventh class focused on how animals use their bodies to escape from danger. Again, the instructor from Friends of Tryon Creek led activities during this class, and I conducted research interviews. The participants began this class by participating in an active tag game where prey had to avoid predators. Then the students participated in circle time where they discussed predators and prey by looking at skulls. Finally, the participants engineered a paper flying squirrel. As they built their squirrel they tested their design 
for gliding distance and modified their design to develop the longest glide possible. The final class meeting was a third field trip to TCSNA. During this field trip, the participants broke into small groups and did the Create-A-Creature task. At the end of the project we had a final reflection circle where participants talked about their favorite part of the class.

Intervention Design. The intervention design was developed using a theoretical framework that was based on the body of literature on motivation and resiliency for atrisk students, afterschool programming, and environmental education (see Table 2). I modified a framework developed by Anthony, Alter, \& Jenson (2009) to designate risk factors faced by the students that attend Mitchell Elementary School. Then I matched corresponding protective factors and affective components that guided the structure of the program, and influenced the type of instructional practices during the intervention. Science topics in the intervention focused on one core concept, Structure and Function that has been outlined in the Framework for K-12 Science Education (NRC, 2012).

Intervention Implementation. The spring term of Mitchell Elementary SUN school began on Tuesday, March $10^{\text {th }}$ and ran for eight weeks. Tryon Trekker classes were scheduled on Tuesday and Thursdays from 3:15-4:40 pm. I acted as the lead teacher in the program, and one education staff member and one volunteer from Friends of Tryon Creek Education Department assisted in the intervention. The sample group on Tuesdays were composed of participants ages 9-11 and were in the third, fourth, and fifth grade. The sample group on Thursday were participants ages 6-8 from the first and 
second grade. Assent was collected from the participants by during the first class. No research was collected during the first class. Consent forms were sent home with the participants during the first week of class. The consent forms were collected throughout the term by a Tryon Creek Education staff member so that participants remain anonymous to the researcher during the facilitation of the class.

\section{Participants attended four field trips to Tryon Creek State Natural Area (TCNA)} during the third, fifth, and eighth week of the program. The field trips included a hike through the park, as well as introduction and reflection activities associated with weekly topics. The students spent approximately forty minutes at the park, and twenty minutes being transported to and from the park. The students were transported to and from TCNA by the Friends of Tryon Creek staff in a mini-bus.

Table 2. Theoretical Framework. The theoretical framework for the classroom management and classroom culture of Tryon Trekkers. The framework incorporates risk and resiliency theory, the affective components evaluated in the program as protective factors, and the instructional practices used to develop protective factors during instruction.

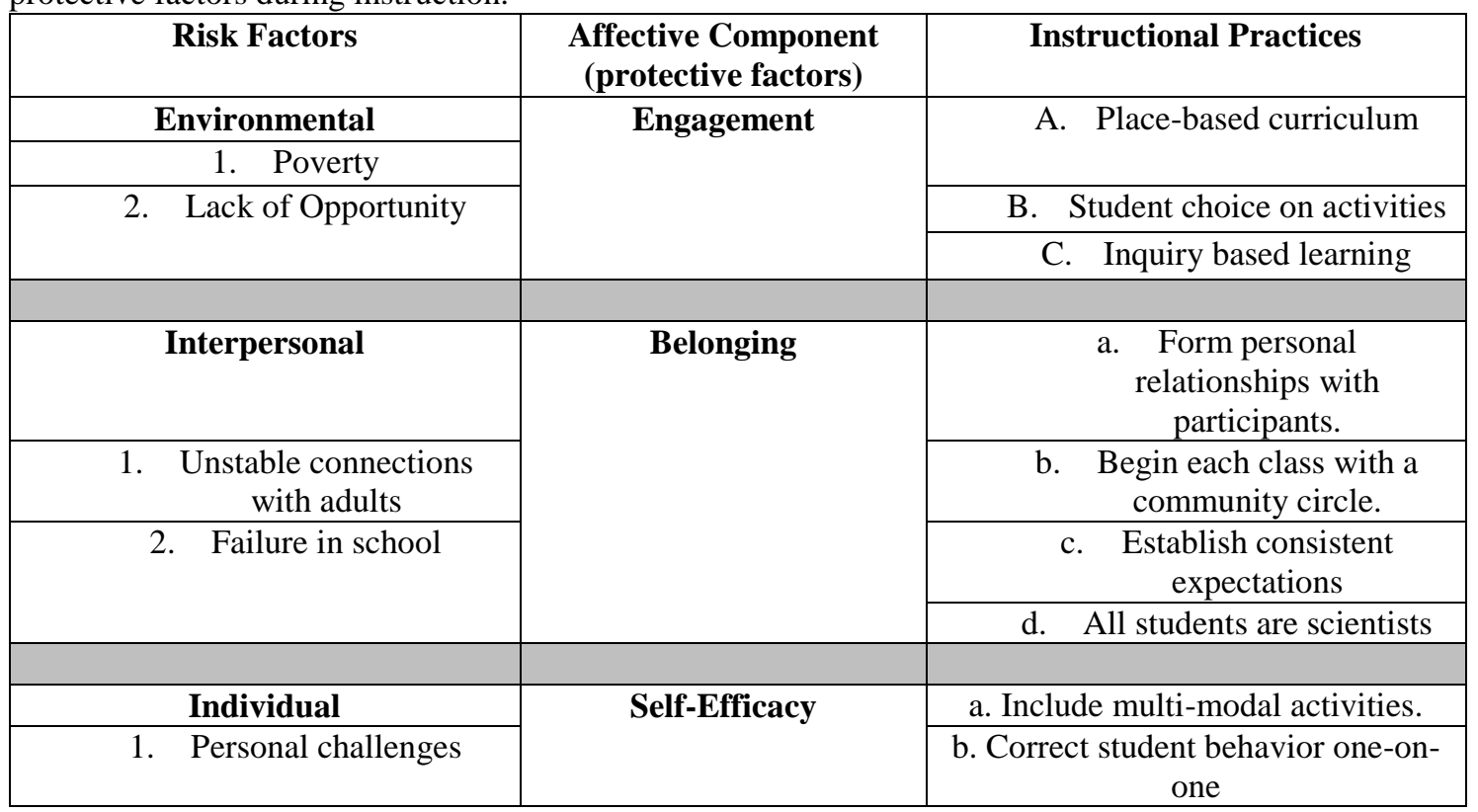




\begin{tabular}{|c|c|c|}
\hline $\begin{array}{c}\text { Manage attention levels } \\
\text { and energy levels }\end{array}$ & $\begin{array}{c}\text { c. Model appropriate responses to } \\
\text { challenges }\end{array}$ \\
\hline
\end{tabular}

Theoretical Framework. In order to build a curriculum that can increase student motivation and increase protective factors, I identified factors that prevent students from being successful learners, or risk factors (see table 2). I adapted a risk and resiliency framework developed for out-of-school time programs by Anthony, Alter, \& Jenson (2009) to develop a risk and resiliency framework specific to the participants at Mitchell Elementary School. Within Anthony, Alter, \& Jenson's (2009) framework, risk is defined as events, conditions, or experiences that increase the probability, but do not ensure, that a problem will be formed, maintained, or exacerbated. Their framework established three categories of risk: environmental, interpersonal and social, and individual. Using these categories, I identified the specific risks that were applicable to the participants in my study by making observations during a pilot afterschool program at Mitchell Elementary school. For example, the environmental risks for the demographics at Mitchell Elementary are poverty and lack of opportunity.

Next, I identified corresponding protective factors that, when incorporated into my curriculum may provide opportunities that reverse or buffer the effects of risk factors for the participants. Anthony, Alter, \& Jensen (2009) defined protective factors as individual traits or environmental resources that minimize the effects of risk. The protective factors in my study are components of motivation. I chose to use motivational components as protective factors against risks because I wanted to observe how motivation can mitigate the effects of risk. The protective factors I chose for my 
curriculum were be the building blocks for the instructional practices and activities I implemented during the intervention. The risks (environmental, social and interpersonal, and individual) and protective factors aligned with the components of motivation that I chose to include within this study.

After determining the risk and protective factors central to the students at Mitchell elementary, I identified a set of instructional practices that aligned with the goals of the protective factors. The instructional practices used were: classroom organization techniques, teaching practices, activity styles, and classroom management strategies. The instructional practices informed the flow of the program and also created a context to teach the course content. By incorporating these instructional practices throughout the curriculum, the program provided continuous protective support for risk factors that the participants faced.

The instructional practices were then matched with applicable activities that fit within the curriculum. I developed some of the instructional practices featured in the curriculum, and some of the instructional practices have been taken from applicable resources focusing on addressing barriers to learning. Resilience occurs when students build the ability to successfully adapt to challenging situations caused by risk factors, by using the supports provided by protective factors (Anthony, Alter, \& Jenson, 2009). The protective factors within my program design will give the participants the opportunity to practice resilience in a safe and supportive environment. The study measured motivation by observing students' self-efficacy, sense of belonging, and engagement. 
Research and Development. I began the study by researching the goals and expectations of partnering organizations: Portland Metro STEM Partnership, Friends of Tryon Creek, Neighborhood House, SUN afterschool programs, and Mitchell Elementary School. Next, I developed a pilot afterschool curriculum based on the expectations of the partnering organizations. This curriculum included engaging activities based on life science topics that were appropriate for participants ages 6-12. It incorporated hands on activities that were done in both indoor and outdoor settings. The pilot afterschool curriculum also included three field trips to Tryon Creek State Natural Area. I worked with Friends of Tryon Creek education staff and the Mitchell SUN School coordinator to organize the logistics of the field trips. The pilot afterschool program was implemented over ten weeks from January $12^{\text {th }}$-March $13^{\text {th }}$, 2015. During the pilot program, I formed relationships with SUN program students, staff members, school staff, and community members. I recorded observations after each session of the pilot program. Then, I evaluated the observations in order to improve the program curriculum for my research study. The modifications between the pilot program and the research study included changing the order of activities for younger students, focusing on one topic, and incorporating teaching strategies that promoted student motivation. Some participants that were involved with the research intervention also attended the pilot program.

I worked with environmental education staff from Friends of Tryon Creek to implement the programming. I assumed the role of lead teacher and curriculum 
developer, and education staff from Tryon coordinated logistics of the program and assumed a support role during programming. During interviews, the Tryon Creek Education staff assumed the role of lead teacher. Tryon Creek Education staff also contributed to the modification of the pilot program by providing feedback about parts of the program that worked well, and what parts needed improvement. Friends of Tryon Creek staff also helped develop a more specific set of learning goals for the research curriculum.

Instructional Practices. I incorporated several instructional practices into the intervention in order to support the protective factors chosen to buffer the participants against risk factors (see table 1). These instructional practices helped frame curriculum projects and activities, and they worked to build community in the classroom. Some of these instructional practices were research based, while others were strategies I had used in my own science teaching practice. I utilized many practices described by Eric Jensen (2011), who researched effective teaching for students of low socioeconomic status. Jensen (2012), describes five actions that can create a positive classroom climate. I adapted practices from the five actions to incorporate into my theoretical framework. These practices were: incorporating student choice into the program, maintaining a flexible schedule, correcting student behavior one-on-one, and modeling appropriate coping strategies (p.34-51). During the development of the Next Generation Science Standards, a research team was charged with addressing equity and diversity issues associated with the new standards. The ultimate goal of the team was to ensure that the standards were accessible to all students (NGSS, 2012a). As part of this 
project, the authors developed a research based list of effective teaching strategies for different demographic groups. I utilized strategies that targeted two demographic groups, the economically disadvantaged students, and racial and ethnic groups. The instructional practices I used from this research were: placed-based learning, utilizing multimodal experiences, and developing personal relationships. Finally, I used some teaching strategies that I had found useful from my experience as a science teacher. These strategies were: all students are scientists, and using inquiry based learning activities. 


\section{Instruments}

Structured Observations. I traced the impact of protective factors by making observations about three affective constructs: engagement, belonging, and self-efficacy. The affective components chosen for the structured observations correspond to protective factors outlined in the risk and resiliency framework developed by Anthony, Alter, and Jensen (2009). The protective factors have been selected to reduce specific risk factors identified for students at Mitchell Elementary School. The structured observation form had student behaviors that corresponded to positive and negative affective constructs. During class time, I used the structured observation as a quick way to track how many students demonstrated positive or negative behaviors. After each class I summarized the participants' experiences using information from the structured observations.

This structured affective observation instrument was given face validity by showing it to three experienced professors and researchers who were asked to provide their expert judgement about whether or not the checklist was adequate to characterize students' motivation. These experts gave feedback, and the structured observation form was modified.

Ethnographic Observations. I collected unstructured observations in the form of journal entries. These journal entries were completed at the end of each class or after discussions with other program instructors. These observations noted participant 
behaviors, summarized conversations with participants, and noted facts about participants' personal lives.

Interviews. Interviews were used to gain a deeper understanding of participant social and emotional experiences during the intervention. Each interview question was based on an affective component outlined within the theoretical framework of the intervention (see Table 1). This interview was designed to measure how participants saw themselves in relation to the natural environment and how they felt during the intervention (see table 3). The interview data was transcribed and coded to identify patterns and themes that indicate how participants gained motivation during the program. The interview questions were developed based on observations gathered during the pilot program and rephrasing items from the Student Affective Survey: Academic Identity \& Motivational Resilience, developed by the Portland Metro STEM Partnership (Saxton, et al. 2013).

Table 3. Interview Questions asked during weeks 6 and 7 of the Tryon Trekkers Intervention at Mitchell Elementary School.

\begin{tabular}{|l|l|}
\hline 1. & What would you tell other kids they would learn if they participated in Tryon Trekkers? \\
\hline 2. & $\begin{array}{l}\text { Did you do anything new in Tryon Trekkers that you have never done before? How did you feel } \\
\text { about it? If you were to do it now, how would you feel? }\end{array}$ \\
\hline 3. & What was the hardest part of Tryon Trekkers? How did you overcome this challenge? \\
\hline 4. & $\begin{array}{l}\text { Did you get along with the other kids in the class? How did you feel about working in groups } \\
\text { with other students? }\end{array}$ \\
\hline 5. & $\begin{array}{l}\text { Did you feel like a part of Tryon Trekkers? If so, what did the instructors do to make you feel } \\
\text { welcome? If not, why? }\end{array}$ \\
\hline 6. & Do you think that what you learned will relate to your life? Can you give an example? \\
\hline 7. & What activity was your favorite? Why? \\
\hline 8. & What was your least favorite activity? Why? \\
\hline 9. & Do you spend time outside, or in nature at home or with your family? \\
\hline 10. & Had you been hiking before our class? \\
\hline
\end{tabular}




\section{Application of Conceptual Knowledge Task. I used the Portland Metro STEM}

Partnership's Application of Conceptual Knowledge rubric and framework to develop an application of conceptual knowledge task called Create a Creature. This task was designed to measure the ability of Tryon Trekker participants to apply knowledge about structure and function after participating in the intervention. The students were distributed into four groups. Each group had a group leader from Friends of Tryon Creek that would administer the task and collect participant responses. The task asked each participant to describe how the structures on their creature helped it to: a. find food, b. escape predators, and c. find or make shelter. Then the group leaders recorded participant answers as participants verbally explained their creatures. The learning goal for the task was: I can build a creature that has different external parts. Then I can describe how the creature uses its body parts to find food, escape from other animals, and find or make shelter.

The task was composed of two parts. One portion of the task asked participants to demonstrate their conceptual understanding by matching pictures of an animal's structure to a function (find food, escape for other animals, find or make shelter). The participants worked together in a small group to match nine structures to the appropriate functions. Each group was scored by the number of correct matches out of the total nine presented. Three structures fit within each function example. The students were scored together as a group on this part of the task. The instructor recorded the number of correct matches for the group once the participants had completed the task. This portion of the task did not align with the PMSP Application of Conceptual Knowledge rubric. I 
scored this task using by counting the number of correct answers for each participant group.

The second portion of the task asked participants to apply their conceptual knowledge of Structure and Function to make a new creature out of clay and natural materials, and verbally explain the structure and function to the group. This part of the task was an individual project. Students were scored individually on this part of the task independent of the Application of Conceptual Knowledge Rubric. I scored this task by recording if each student described the functions of their creatures according to the three function strategies described in the task instructions. These categories were: get food or water, find shelter or move through space, and escape predators.

Application of Conceptual Knowledge Rubric. The task was also scored by a corresponding Application of Conceptual Knowledge rubric that measured how well students understood and applied the concept of Structure and Function, LS1.A (NRC, Framework for k-12 Education, 2012). The rubric used a 0-4 scale to score each task. This rubric and framework was developed based on research showing that much science curricula only tests a student's ability to recall facts, and not to know and understand a concept (Saxton, et. al. 2013). I modified the rubric developed by Saxton, and her colleagues (2013) to be applicable to the Create a Creature task. The rubric was given face validity by expert educators, and colleagues that were familiar with the Portland STEM Partnership instruments. (See Appendix) In developing the framework Saxton et. al. (2013) used research in conceptual understanding in education to develop a 
framework for appropriate assessment questions that are able to measure a student's conceptual knowledge and their ability to apply those concepts. The framework also includes previous research that has demonstrated reliability and validity for these dimensions. 


\section{Procedure}

Data Collection. I made observations of participant affective responses during and after each class using the Structured Affective Observation forms. After each class, program staff and I discussed observations from the day, and I recorded unstructured observation notes in a journal.

All of the participants present during the sixth and seventh class were interviewed. Three students were absent during the interviews. A total of 22 participants were interviewed. The semi-structured interviews were designed to gather data about the motivation (self-efficacy, belonging, and engagement) of the participants. Each interview took approximately ten minutes. The interviews were administered during class time in the same classroom as activities. I asked each participant to take a break in class activities to answer the survey questions at a nearby table with me.

The participants were assessed using the Create a Creature Task during the final field trip to TCNA (week 8). Three Friends of Tryon Staff members assisted in the data collection during the task. Before the participants arrived at the park, I designated four groups, each led by an adult instructor. The instructors were each given a written description of the ACK tasks with prompts for the students, the task materials, and forms to record the student data. Each group went to a different location in the park. When the participants arrived, they were given a short introduction to the instructors, broken into groups, and brought to their group location. At the group location, they first completed the Demonstration of Conceptual Knowledge task, and then completed 
the Application of Conceptual Knowledge task. Each response was recorded by the instructor and the creatures were photographed.

Data analysis. I collected data from the structured observation forms and recorded the frequency of behaviors related to affective states. After collecting the observations, I used them to find patterns in student behavior associated with their motivation during the intervention. I used the observations and behavior patterns to develop three vignettes that showed an in depth description of the motivation of three different students.

I analyzed the interview transcripts by identifying common themes in responses for each question. Once I identified a set of themes common throughout each sample group, I counted the number of individuals within that group that identified with each theme. Themes for each question were not discrete. In some cases a participant identified with many answer themes for one question. The themes for each sample group were not combined and two sets of results were generated.

In order to analyze the measures of application of conceptual knowledge, I scored the Create a Creature projects using the Application of Conceptual Knowledge Rubric. Then, I calculated the average rubric score for each age group and for both groups as a whole. 


\section{Chapter 4: Results}

\section{Interviews}

Self Efficacy. Participants in the program showed positive self-efficacy during the program. During the interviews, students described positive perceptions of self-efficacy during the program. Most participants reported being successful in the program, overcoming challenges, and enjoying new experiences. Some participants who showed high self-efficacy during the program were observed to have low self-efficacy related to school performance.

When students were asked about their success in the program, ten out of eleven students in each sample group indicated they felt they were successful (see table 4). In the older group, one student answered that she wasn't successful in the earlier weeks of the class, but that she was successful by the end. In the younger group, one student cited being afraid of the other children as the reason for her being unsuccessful.

When participants described why they felt successful, the responses fell into one of two goal orientations: mastery goals, or performance goals. Mastery goals are goals that are dedicated toward intrinsic learning. Performance goals are goals that seek to complete a task in order to appear competent. For example, one older student described her success in terms of a performance goal by saying, "I think I've accomplished what you've given me in terms of work." Another student fit within the mastery goal category by describing her success as "I know a lot more about animals than when I 
came here." In the older group, six students identified achieving mastery goals, and three cited performance goals, and two students did not answer the question. In the younger group seven students discussed mastery goals, while six mentioned performance goals (see Table 4).

\begin{tabular}{|c|c|c|c|c|c|c|}
\hline Question & $\begin{array}{c}\text { Older group } \\
\text { answer } \\
\text { category }\end{array}$ & $\begin{array}{c}\begin{array}{c}\text { Number } \\
\text { of } \\
\text { students } \\
\text { (out of 11) }\end{array}\end{array}$ & $\%$ & $\begin{array}{l}\text { Younger } \\
\text { group } \\
\text { answer } \\
\text { category }\end{array}$ & $\begin{array}{l}\text { Number } \\
\text { of } \\
\text { Students } \\
\text { (out of 11) }\end{array}$ & $\%$ \\
\hline \multirow{2}{*}{$\begin{array}{c}\text { Do you feel you were } \\
\text { successful in Tryon } \\
\text { Trekkers? }\end{array}$} & Yes & 10 & $90 \%$ & Yes & 10 & $90 \%$ \\
\hline & No & 1 & $9 \%$ & No & 1 & $9 \%$ \\
\hline \multirow[t]{2}{*}{ Goal Orientation } & Mastery goal & 6 & $55 \%$ & Mastery goal & 7 & $64 \%$ \\
\hline & $\begin{array}{l}\text { Performance } \\
\text { goal }\end{array}$ & 3 & $28 \%$ & $\begin{array}{l}\text { Performance } \\
\text { goal }\end{array}$ & 6 & $55 \%$ \\
\hline \multirow[b]{2}{*}{$\begin{array}{c}\text { Did you do anything } \\
\text { new in Tryon } \\
\text { Trekkers that you } \\
\text { have never done } \\
\text { before? }\end{array}$} & Yes & 6 & $54 \%$ & Yes & 8 & $73 \%$ \\
\hline & no & 1 & $9 \%$ & No & 1 & $9 \%$ \\
\hline \multirow{3}{*}{$\begin{array}{l}\text { What type of activity } \\
\text { would you try in the } \\
\text { future? }\end{array}$} & $\begin{array}{c}\text { Nature related } \\
\text { activity }\end{array}$ & 5 & $45 \%$ & $\begin{array}{c}\text { Nature related } \\
\text { activity }\end{array}$ & 5 & $45 \%$ \\
\hline & $\begin{array}{c}\text { Other } \\
\text { extracurricular }\end{array}$ & 4 & $36 \%$ & $\begin{array}{l}\text { Science } \\
\text { related }\end{array}$ & 2 & $18 \%$ \\
\hline & $\begin{array}{l}\text { General } \\
\text { openness }\end{array}$ & 4 & $36 \%$ & Sports & 2 & $18 \%$ \\
\hline \multirow{5}{*}{$\begin{array}{c}\text { What was the hardest } \\
\text { part of Tryon } \\
\text { Trekkers? }\end{array}$} & $\begin{array}{l}\text { Academic } \\
\text { projects }\end{array}$ & 4 & $36 \%$ & $\begin{array}{l}\text { Physical } \\
\text { activities }\end{array}$ & 3 & $27 \%$ \\
\hline & $\begin{array}{c}\text { Social } \\
\text { interactions }\end{array}$ & 4 & $36 \%$ & Academic & 5 & $45 \%$ \\
\hline & Being outside & 2 & $18 \%$ & $\begin{array}{c}\text { Classroom } \\
\text { norms }\end{array}$ & 3 & $27 \%$ \\
\hline & & & & Social norms & 1 & $9 \%$ \\
\hline & & & & Being outside & 1 & $9 \%$ \\
\hline
\end{tabular}

Table 4. Self-Efficacy. Student interview data from questions in the self-efficacy construct. Sample groups are separated into columns that represent the younger group (grades 1-2), and the older group (grades 3-5). The total number of children in each sample group was 11 individuals. The children may have answers in more than one category per question. For each categorical answer, number of students and percentage of whole are given. 
Students were then asked if they had tried something new during the class. In the older group six of eleven indicated that they had a new experience during class. One student said that she hadn't done anything new during the class, and three students did not answer this question. In the younger group, eight of eleven students said that they had tried something new. One student indicated that she hadn't done anything new, and two students did not answer the question. Around half of each group said they would try new outdoor or nature related activities in the future. When one student was asked what she would do in the future, she said "I would want to take care of animals. I would when I say that I was a vet and I could help animals when they are sick and hurt.” Around one third of each group said that they would try other non-STEM based extracurricular activities after participating in Tryon Trekkers. Another student described a future experience as a scientist. "Yes, maybe I will be a scientist when I grow up. If I was a scientist I could study nature, and I could study weather, and pebbles, and rocks."

During the interviews students discussed some of the challenges they faced during the program (see table 4). The older group identified challenges as academic projects, social interactions, and being outside. The younger students' challenges varied more. Their challenges included: participating in physical activities, completing academic tasks, following classroom norms, following social norms, and being outside. The older children described the academic projects and social interactions as the most prevalent challenges. Five children in the younger group identified academic projects as being the most challenging part of the class. 
Belonging. The students were asked if they felt like they belonged at Tryon Trekkers (see Table 5). All of the older group indicated that they felt they belonged. These students reasons for feeling a sense of belonging included: having positive peer relationships (6 students), positive student-teacher relationship (7 students), and the content aligned with their interests (4 students). The younger group had nine students that felt like they belonged. This group also identified three reasons for feeling like they belonged: content aligned with their interests ( 3 students), kids looked similar to them (2 students), and others were kind (4 students). In the younger group two students reported that they did not feel like they belonged because our group was different from their family. In order to dig deeper into how the intervention fostered a sense of belonging, the participants were asked to describe what helped them feel belonging during the interviews. The older students identified three factors that helped them feel a sense of belonging in the program: having positive peer relationships $(55 \%)$, have a positive student-teacher relationship (64\%), and have interests that align with the content (36\%). The younger groups identified a different set of factors that influenced their sense of belonging. These factors were: the content aligned with their interests (27\%), they felt similar to other children (18\%), and others acted kindly (36\%).

Next, I asked the participants if their experience in Tryon Trekkers related to their life outside of school. Both groups identified three ways that their home life related to Tryon Trekkers. Many participants described that when they were outside they take time making nature observations ( 9 older students, 3 younger students). 
Other participants talked about identifying plants and animals while outside $(5$ older students, 4 younger students). And a few participants said that they did not talk about science or nature at home (1 older student, 2 younger students). 
Table 5. Belonging Student interview data from the Motivation category of relatedness and belonging Sample groups are separated into columns that represent the younger group (grades 1-2), and the older group (grades 3-5). The total number of children in each sample group was 11 individuals. The children may have answers in more than one category per question. For each categorical answer, number of students and percentage of whole are given.

\begin{tabular}{|c|c|c|c|c|c|c|}
\hline Question & $\begin{array}{l}\text { Older group } \\
\text { answer } \\
\text { category }\end{array}$ & $\begin{array}{l}\text { Number of } \\
\text { students (out } \\
\text { of 11) }\end{array}$ & $\%$ & $\begin{array}{l}\text { Younger group } \\
\text { answer category }\end{array}$ & $\begin{array}{l}\text { Number of } \\
\text { students (out } \\
\text { of 11) }\end{array}$ & $\%$ \\
\hline \multirow{5}{*}{$\begin{array}{l}\text { 1. Did you feel } \\
\text { like you } \\
\text { belonged at } \\
\text { Tryon } \\
\text { Trekkers? }\end{array}$} & Yes & 11 & $100 \%$ & Yes & 9 & $82 \%$ \\
\hline & $\begin{array}{l}\text { Positive peer } \\
\text { relationships }\end{array}$ & 6 & $55 \%$ & $\begin{array}{l}\text { Content aligns } \\
\text { with interests }\end{array}$ & 3 & $27 \%$ \\
\hline & $\begin{array}{l}\text { Positive } \\
\text { student- } \\
\text { teacher } \\
\text { relationship }\end{array}$ & 7 & $64 \%$ & $\begin{array}{l}\text { Similar to } \\
\text { others }\end{array}$ & 2 & $18 \%$ \\
\hline & \multirow{2}{*}{$\begin{array}{c}\text { Content aligns } \\
\text { with interest }\end{array}$} & \multirow[t]{2}{*}{4} & \multirow[t]{2}{*}{$36 \%$} & Others act kind & 4 & $36 \%$ \\
\hline & & & & No & 2 & $18 \%$ \\
\hline \multirow{3}{*}{$\begin{array}{l}\text { 2. How did } \\
\text { what you } \\
\text { learned in } \\
\text { Tryon } \\
\text { Trekkers relate } \\
\text { to your life } \\
\text { outside of } \\
\text { school? }\end{array}$} & $\begin{array}{c}\text { Make } \\
\text { observations } \\
\text { outside }\end{array}$ & 9 & $82 \%$ & $\begin{array}{c}\text { Make } \\
\text { observations } \\
\text { outside }\end{array}$ & 3 & $27 \%$ \\
\hline & $\begin{array}{l}\text { Recognizing } \\
\text { plants and } \\
\text { animals }\end{array}$ & 5 & $45 \%$ & $\begin{array}{l}\text { Recognized } \\
\text { plants and } \\
\text { animals }\end{array}$ & 4 & $36 \%$ \\
\hline & $\begin{array}{c}\text { Did not talk } \\
\text { about science } \\
\text { or nature at } \\
\text { home }\end{array}$ & 1 & $9 \%$ & $\begin{array}{c}\text { Did not talk } \\
\text { about science or } \\
\text { nature at home }\end{array}$ & 2 & $18 \%$ \\
\hline
\end{tabular}

Engagement. Students from both age groups enjoyed different parts of the program

(see figure 1). Most of the students identified creative projects (5 participants), active games (6 participants), and field trips (5 participants) as their favorite activities during the program. When asked about a least favorite activity, most participants said that they didn't have a least favorite activity (12 participants). Many student from both groups said that they liked everything in the class (3 participants). 


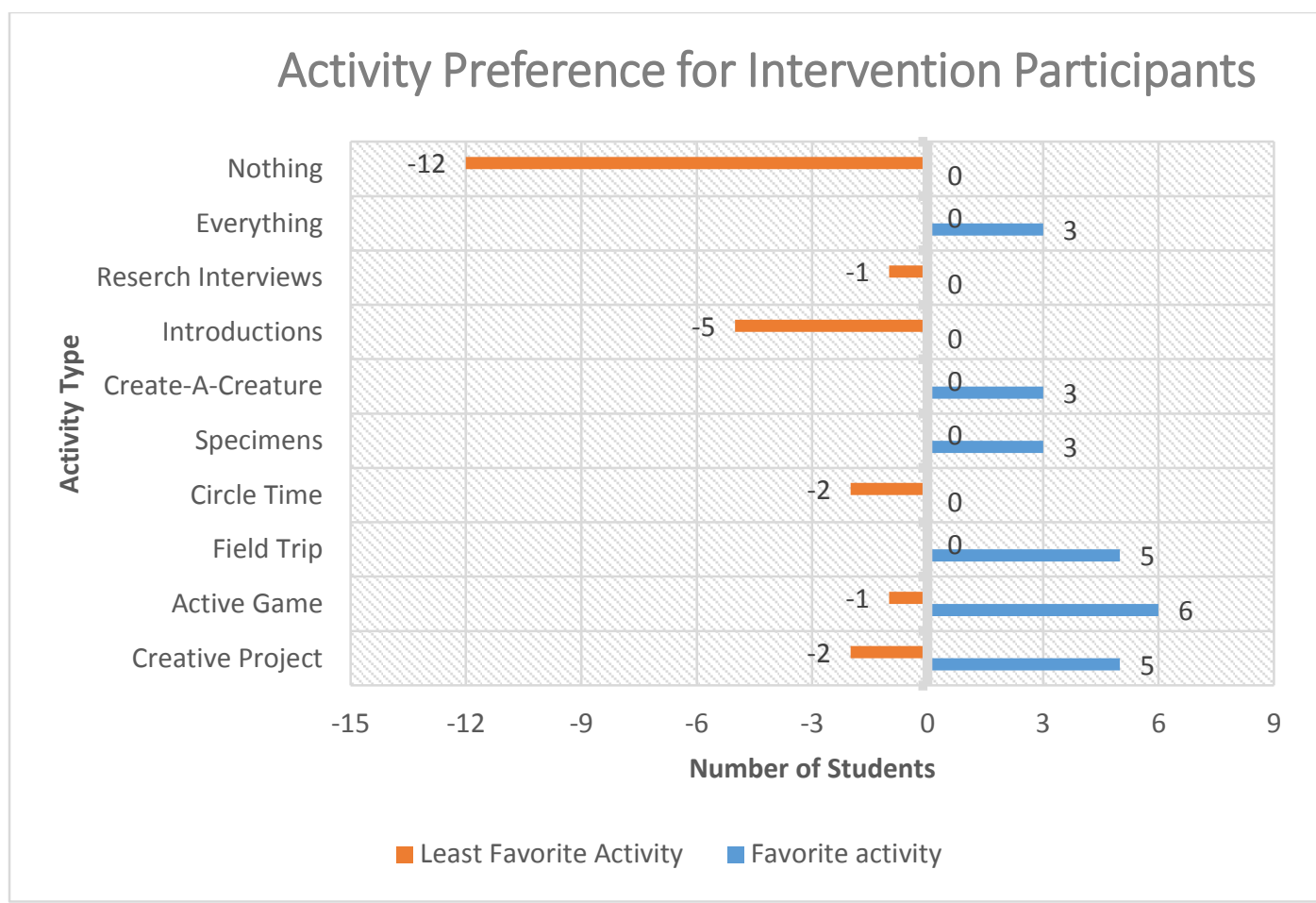

Figure 1. Activity Preference for Intervention Participants. Student interview data from questions about engagement. The blue bars represents participants' favorite activity, and the orange bars represent participants' least favorite activities. Sample groups response are combined. The total number of children in each sample group was 11 individuals. One participant the younger group did not answer questions on engagement. The children may have noted one or more activity in their interview response.

\section{Structured Observations}

The structured observations show that participants demonstrated both negative and positive behaviors that corresponded with motivation constructs, as well as behaviors that indicate a connection to nature (see table 6). Participants were most often observed sharing life events and stories in class (11 observed behaviors). This behavior is associated with a sense of belonging. The second most observed behaviors were volunteering to describe phenomenon, and showing effort during activates (9 observed behaviors). These behaviors correspond to positive engagement. The most 
frequent negative behavior observed was that a student asked to do something else (5

observed behaviors). This behavior also corresponds to engagement.

Table 6. Structured Observations. Table seven shows the frequency of behaviors associated with motivational components over the course of five classes during the intervention. A behavior is denoted as being positive demonstration of a component with a (+) symbol. A behavior is negative if denoted with a $(-)$. These results show the behaviors of both sample groups combined.

\begin{tabular}{|c|c|c|}
\hline Affective Construct for Motivation & Positive/Negative & $\begin{array}{c}\text { Frequency of Behavior } \\
\text { Observed } \\
\text { (from both sample } \\
\text { groups) }\end{array}$ \\
\hline \multicolumn{3}{|l|}{ Self-efficacy } \\
\hline Student volunteers to show their project in class & $(+)$ & 4 \\
\hline Student is eager to volunteer to answer questions & $(+)$ & 6 \\
\hline Student comments they are not smart & $(-)$ & 1 \\
\hline Student expresses worry about grades & $(-)$ & 2 \\
\hline Student does not participate in activity & $(-)$ & 4 \\
\hline \multicolumn{3}{|l|}{ Relatedness/Belonging } \\
\hline Student shares life events and stories in class & $(+)$ & 5 \\
\hline Student participates in group activities & $(+)$ & 6 \\
\hline Student takes time to talk with instructor one on one & $(+)$ & 5 \\
\hline Student doesn't talk to others during class & $(-)$ & 3 \\
\hline \multicolumn{3}{|l|}{ Engagement } \\
\hline student shows effort during activities & $(+)$ & 9 \\
\hline Student shares life events and stories in class & $(+)$ & 6 \\
\hline student volunteers to answer questions & $(+)$ & 9 \\
\hline Student is off task & $(-)$ & 2 \\
\hline Student ask to do something else & $(-)$ & 5 \\
\hline Student has to be prompted to participate in activity & $(-)$ & 4 \\
\hline \multicolumn{3}{|l|}{ Connectedness to Nature } \\
\hline Shows concern for a living creature $(+)$ & $(+)$ & 4 \\
\hline Expresses concern for being outside (-) & $(-)$ & 3 \\
\hline
\end{tabular}

\section{Participant Profiles.}

Below I describe the experiences of three different participants in the program.

Each of these participants showed vulnerability in one of the three affective constructs that contribute to motivation (belonging, self-efficacy, and engagement). I wrote these 
participant profiles using data from the structured observations and my ethnographic observations.

Anya's profile demonstrates how having a learning style that doesn't align to classroom norms in school can lead to low self-efficacy at school. She struggled with feeling limited by a learning disability, and didn't feel supported by her classroom teacher. The intervention provided Anya with the opportunity for multi-modal and hands on learning and a positive relationship with instructors that helped increase her self-efficacy.

Many of the students at Mitchell Elementary school had not visited Tryon Creek State Natural Area before participating in the intervention. Viviane's experience illustrates how giving participants a new opportunity to visit Tyron allowed participants to find a sense of belonging. During the program, the visits to Tryon went from being uncomfortable and scary, to exciting and interesting. As a result, Viviane increased her sense of belonging with the natural environment.

Participants in the intervention had risk factors at play in their lives that impacted their ability to engage with the program content. Hani's story shows how those risk factors can manifest during learning, and how they can prevent participants from engaging with learning opportunities. The intervention supported Hani holistically by using instructional practices that built her motivation. These supports 
allowed Hani found moments to overcome her vulnerabilities and connect with her intrinsic curiosity.

\section{Anya: A Conversation about Self-Efficacy}

Anya is an energetic Eastern European eleven year old fifth grader. She was born in Bulgaria. She was adopted and brought to the United States when she was five years old. She attended both the winter pilot program and spring research intervention sessions of Tryon Trekkers. During the program, she was friendly with her peers, and she was well liked by other students. She often told jokes, and added slap stick style humor to group discussions and activities. She enjoyed talking. She was eager to contribute her thoughts and opinions to group discussions.

When she arrived to the Tryon Trekkers program after school, she frequently talked about her school day, and she would often express frustration about her schoolwork and about her teacher. She identified having trouble with reading, writing, and math. She also commented that she was not smart.

One day, during a one-on-one conversation during snack time, Anya described that she had been in trouble during school. During a partner activity, she had been laughing and talking loudly. She believed that even though she was laughing she was still focusing on the activity. During the activity, the teacher singled her out in front of the class for being disruptive. The teacher announced that Anya would be punished for her disruption by losing points from a classroom reward system. After school Anya felt ashamed about behavior, and felt the punishment was not warranted. She then expressed distrust toward her teacher because she perceived the teacher was targeting her. 
During the first field trips, Anya told me that she had dyslexia. She talked about many of her struggles in school within the context of her learning disability. She reported she had trouble reading and writing, and she felt bad for not doing well in school. During another field trip, Anya discussed being in a differentiated math group. She was in the lower level group in her class, called the "gold group." She admitted that being in the group was sometimes helpful when she needed additional assistance to understand math concepts. But, at other times being part of the group made her feel dumb and self-conscious in front of her peers.

Inferences. Because Anya often expressed feelings of inadequacy in school, she demonstrated a sense of low self-efficacy in school. Her doubts about her academic performance, and her sensitivity to her learning disability made her feel like she could not be successful in school. "Sometimes [I have a hard time] in writing or in science. Because I'm dyslexic, it's harder [for me] in class." She may have felt isolated from her peers because of her learning disability. Her frustration with her teacher may have prevented her from feeling comfortable asking the teacher for help, or talking about her struggles.

Using my observations about how Anya learned during Tryon Trekkers, and listening to Anya's stories about her classroom, I believe her preferred learning style was verbalizing concepts and ideas. Using Howard Gardner's theory of multiple intelligences, Anya learns best using a verbal-linguistic style. "This intelligence encompasses the ability to use language to convey information well and to analyze 
language use (Willis, J., 2007, p. 54).” Her aversion towards reading and writing because of her learning disabilities, may also influence her tendency to want to discuss ideas or act things out as she learns. During her interview she said that she gets through challenges in school by "having friends beside me to help me out, and talk with me about how things work. If I thought something different than them, I would try something different, and see how it worked."

Anya's explanation of getting in trouble in class sheds light on how her traditional classroom may not differentiate learning to support her preferred mode of learning. Many of her in class activities in school were independent projects that involved reading and writing. Anya is very intelligent, and she is motivated to do well in school, but her low self-efficacy surrounding her reading and writing skills may prompt her to act out or use learning strategies that appear disruptive in the classroom. If Anya has found success using verbal-linguistic learning strategies she is going to want to talk and interact with others during class. If the expectation in the classroom is to do silent independent written work, her behavior of talking with others may appear disruptive and disrespectful. Using this example, her learning strengths were devalued in the classroom, and her self-efficacy suffered.

She contrasted her experience in Tryon Trekkers to her experience in school by saying "In here we are doing activities. You guys can make it understandable for me." She describes her success as "getting along with people, just joining in with the class, and making new friends. I finished the activities with everybody [by] not quitting." 
During the program, she built relationships with her peers - other $5^{\text {th }}$ grade students, and younger students in $3^{\text {rd }}$ and $4^{\text {th }}$ grade. She built a positive relationship with both of the instructors, and she was able to talk about issues in her life, as well as talk about what she was learning. To build positive relationships with students, the instructors took the role of teacher, mentor, and friend. They intentionally had meaningful personal conversations with students, and kept a positive and encouraging attitude. During the interview, Anya described her perception of the instructors. "They want to try to make you have fun and enjoy class. They aren't trying to make you feel like you don't belong in the class."

The multi-modal, hands on nature of the curriculum featured activities that could be approached using multiple learning styles — verbal, written, collaborative, etc. When Anya participated in the varied modes of learning - some of which were strengths, some of which were weaknesses, it helped her build her self-efficacy toward being successful in school. Anderman and Anderman (2014) believe when "students have the opportunity to demonstrate their talents and learning in a variety of ways they may be less likely to directly compare their performance to that of other students." Anya had the opportunity to experience successes in a supportive environment where she didn't have to compare herself to her peers. She also had the freedom to collaborate with peers and instructors throughout the process. When describing her overall experience in the Tryon Trekker program she said, "I felt happy, and it was one of the best classes I've ever been in because the kids and teachers are nice. You guys are really comforting. I got use to it really fast." 


\section{Vivian: An Evolution toward Belonging}

Vivian is a ten year old African American fourth grader. She participated in both the winter and spring term of Tryon Trekkers. By the end of the intervention, Vivian discovered that she enjoyed being outside and embraced the exploratory nature of the program. During the beginning of her journey, she was very apprehensive about spending time at Tryon Creek State Park. On the first field trip, she was quiet, reserved, and hesitant during activities on the trail. By the last field trip during the spring term, her sixth time visiting the park, she appeared excited about spending time in the forest. During this visit, she and her peers skipped along the trail. They periodically stopped to examine plants and bugs. They climbed along branches and roots.

Viviane had never been hiking before the Tryon Trekker program. She was an active participant in school extracurriculars and in sports, but she had not had the opportunity to spend time in natural areas. Viviane described her time at home as spent time outside playing in her neighborhood and playing on the playground. During her interview, I asked Viviane if she talked with her family members about nature or science. Viviane said that her family talked "about life" but didn't talk about nature. She specified that her mom doesn't like going outside into the woods, and she was concerned that nature was too far away from where she lived. Later in the interview, when I asked her about the new things she had seen during the program, she said "I 
never went out in the woods before. And I've never seen a woodpecker before, I've never seen a mole before, and I've never seen a fort outside."

Viviane visited Tryon Creek State Natural Area (TCSNA) a total of seven times. Each time she was exposed to new plants and animals. As her experiences grew, she became more and more comfortable with the environment. "At first I didn't know what [the plants and animals] were, then you [the instructors] said what they were, and I was interested." One of the most meaningful experiences during the program for Viviane was seeing a pileated Woodpecker along the trail at TCSNA. The participants were learning about woodpeckers and adaptations that helped the birds find food. Before the hike, the group listened to recorded woodpecker calls, and learned about how the birds use their sharp beaks and long tongues to get bugs from trees. The group split into smaller trail groups, and took a 20 minute hike. Viviane and three other students were in my trail group. Along the hike, the group was stopped in their track by a loud knocking sound. About ten feet off of the trail, a Pileated Woodpecker was in clear view pecking away on a large tree. They quietly crept closer, within 8 feet of the bird, as it continued to hammer away at its hole on the tree. The students were mesmerized by the woodpecker. They stood, speechless with attention and curiosity for about five minutes. When asked later about what she was thinking when she saw the woodpecker, Viviane said "Is this real life? Am I in a dream?"

Inferences. New experiences, and especially new places can be scary. Viviane had many misconceptions about nature before her experience in the program. "Being out in 
the woods scared me because when I think about camping strange things can come into your tent, and it's creepy." These fears explain why she was apprehensive during her first visit to the forest.

Viviane's new experience helped her connect nature and animals to her own life. Before her experience, nature was a boring topic that she didn't relate to. Once she spent time at TCSNA she began to connect the park with her own community. During the interview she explained her evolution toward belonging during the program. "The first time I went there I thought it was boring. I saw some strange things and some weird things. When I came there the second [term], I liked it a lot." By the end of the program, her misconceptions about what it means to be in the woods were changed. "Since going out into the woods, [I learned] it's not all about camping. You can stay there less than a day. I can go out in the woods now, and it makes me happier. Before I wouldn't have done that because I thought all you do is walk." When asked if she would do more things outside after the program, she said "I would [go] a little bit more because [Tryon Creek] is really close to my church so I could walk. If you spend more time outside [I will] see more animals.”

The place based curriculum and the inquiry based activities in the intervention allowed the participants to experience learning in a new way. Animals went from a distant topic to something she could actually see. Instead of labeling woodpeckers as "boring," she later found them fascinating. During her interview she reflected upon her experience. "When you guys were talking about woodpeckers, I didn't know that they 
reach their tongue around their brains. It makes sense now because if it didn't do that it would hurt itself. If you didn't have a tongue to wrap around your head, it [your brain] would go all over the place." These ideas were solidified in her mind because Viviane had the opportunity to actually see a woodpecker in action. Not on T.V., not in a book, but in real life. Once she saw and heard the bird pecking on the tree, she found a real life connection between a science concept and her own life. 


\section{Hani: Engagement Barriers}

Hani is a seven year old African American girl of Somali descent. She attends the first grade at Mitchell Elementary School. She participated in the spring term of Tryon Trekkers, as part of the younger sample group of first and second students. During the program, I observed that Hani's behavior ranged from being highly energized and focused, to low energy, irritable and low interest. She also exhibited oppositional behavior during the program's group discussions, games, and field trips. When Hani was engaged she spoke confidently about her beliefs, she shared thoughtful ideas, and she didn't hesitate to share her thoughts. Hani preferred art projects such as drawing or sculpting. She got along with her peers well. She demonstrated leadership abilities because she often helped organize and unite her peers during unstructured activities.

When asked about the hardest part of the program Hani said, "listening because I want to do whatever I want. Because all I do is sit around and listen to the teacher." During each class meeting, Hani exhibited oppositional behavior. Her oppositional behaviors included loud verbal protest of activities, not participating in activities, and attention seeking behavior. In my ethnographic observations I recorded Hani's behavior throughout our class routine. The class began by the instructors presenting the day's schedule during circle time. After hearing about the activities, Hani interrupted the instructor by saying "no" to each of the activities described. Her behavior encouraged other students to also protest to the day's plan. However, after the circle 
time discussion all of the students except for Hani participated in the planned activities. During daily projects, Hani often drifted between being focused on the project, and being concerned with other things. On at least two different days, Hani asked about the time, and commented that she wanted to go home.

During field trips, Hani was actively oppositional before and after each hike. Before one of the hikes, she made five comments that she did not want to be at Tryon. Along the trail, Hani refused to participate in structures activities, and drew attention from other children during the activity. After the activity the instructor talked one-onone with Hani about distracting the other children. The instructor asked her why she didn't want to participate. Hani replied, "Because I don't want to be here.” This attention from the instructor appeared to encourage Hani to continue her protesting behavior throughout the rest of the field trip.

Hani was engaged with the environment during one part of this field trip. Along the trail, the instructor allowed the students to stop and explore nearby plants and animals. Hani discovered a snail. She called the rest of the students over to her, and the group examined the snail together. In this moment, Hani was engaged. She was not complaining or protesting. She was fully focused on the snail and her classmates. Once the children were done observing, Hani released the snail back into the forest, and then she continued her protest behavior. 
Hani was unable to complete the research interview. Out of twenty two students, she was the only student who was unable to complete the process. I gave Hani two opportunities to talk with me and complete the interview. She exhibited oppositional behavior during both of the interview opportunities. During the second interview, I allowed her to draw while we talked. During this interview attempt, she answered three abbreviated interview questions. When I asked her about what she liked during the program, she said, "first I felt happy, and then when I get there I'm not so happy because I have to do what the teacher says."

Inferences. There could be many reasons for Hani's resistance to participate during the intervention. Throughout my observations, there was no clear reason for her lack of engagement. As I collected data, I attempted to search deeper for underlying causes of Hani's behavior. One of the major barriers with Hani, was that throughout I was unable to collect candid information from Hani. Most of her interactions with the instructors were oppositional.

I believe that her oppositional behavior was a form of avoidance behavior. "Students engage in avoidance behavior when they move away from, or avoid, some perceived threat in the learning context (Anderman \& Anderman, 2014, p. 195).” Acting like she didn't want to participate in activities, was Hani's way of avoiding situations in order to protect herself from engaging in activities that may have asked her to take risks, or face challenges. "Students engage in avoidance behaviors to maintain positive perceptions of themselves as a student (Anderman \& Anderman, 2014, p. 195).” 
A second explanation for Hani's behavior may have a more physiological explanation. Before the Tryon Trekker program starts, students are given an evening meal provided by the Neighborhood House organization. Each week, Hani did not eat any of the meals. As a result, she may have been tired and hungry during the intervention. "Poor nutrition poses a strong risk to students' learning and engagement. When kids don't eat well, or when they don't eat at all, their behavior stuffers, and they have a tougher time learning. The two most important fuels for the brain are oxygen and glucose. Unstable glucose levels, whether too high or too low, are linked to weaker cognitive and behavioral outcomes (Jensen, 2013, p. 10).” Hani’s physical hunger was a risk factor that was a stronger influence than the intervention's strategies for engagement. 


\section{Application of Conceptual Knowledge}

Table 7. Application of Conceptual Knowledge Rubric. The Create a Creature Application of Conceptual Knowledge rubric was developed for this study and adapted from the Portland STEM Partnership Application of Conceptual Knowledge Rubric.

\begin{tabular}{|c|c|}
\hline \multicolumn{2}{|r|}{ Create a Creature Application of Conceptual Knowledge Rubric } \\
\hline $\begin{array}{l}\text { Rubric } \\
\text { Score }\end{array}$ & Score Description \\
\hline 4 & $\begin{array}{l}\text { Student built a creature and he or she described how a structure works by giving a detailed } \\
\text { description of the body part. The student explained why the structure is best at performing } \\
\text { its function. }\end{array}$ \\
\hline 3 & $\begin{array}{l}\text { Student built a creature and identified a structure that carries out a function clearly } \\
\text { identifying a relationship between the two. }\end{array}$ \\
\hline 2 & $\begin{array}{l}\text { Student build a creature and described the structures } \text { or functions, but he or she did not } \\
\text { identify a relationship between the two. }\end{array}$ \\
\hline 1 & Student built a creature, but he or she did not explain the functions of any structures \\
\hline 0 & Student did not build a creature. \\
\hline
\end{tabular}

To score the Application of Conceptual Knowledge task using the rubric, I gave the participants a score for their demonstration of conceptual knowledge, and then scored on their application of conceptual knowledge rubric. All of the participant groups received a score of $8 / 9$ or $9 / 9$ on the demonstration of conceptual knowledge task. Each group was scored by the number of correct matches out of the total nine presented. These scores were recorded as group score. Three structures fit within each function example. The participant scores for application of conceptual knowledge ranged from two to four on the Create a Creature Rubric (see figure 3 and 4). For a description of the scores, see table 7. Over half of both groups, the older and younger groups, scored a three, or showed proficiency (64\% and 52\% respectively). (See figure 3). A smaller percentage of both groups' students (9\% and 17\%) scored a four, the highest rubric category. When comparing the percentage of scores from the younger 
group with the older group, the distribution of scores are similar. Sixty nine percent of all students scored a three or higher on the rubric (see figure 4).

I also scored the Create a Creature Project by recording how many students described a structure on their creature within the function categories described in the task. These categories were: get food or water, find shelter or move through space, or escape predators. The participants described structures on their creatures that functioned to help their creature get food or water in $82 \%$ of the responses. Only $59 \%$ of the participants were able to correctly describe how their creature found shelter or moved through space. Sixty four percent of the participants mentioned how their creature's body parts helped it to escape body parts. (See Figure 3). The student descriptions that were recorded during the task ranged in detail. Four different instructors recorded student responses and there was not a standard method of recording student responses. For example, one instructor recorded the participants' responses word for word, while another instructor wrote down key words from the participants' responses. One example of a detailed student response recorded word for word is: "The alarm bird. What it does is, it's able to get food it has just like a woodpecker has a forked tongue like an actual fork. And its tongue is as hard as cardboard. It escapes predators to soar off. It pulls its feet into sockets and it can shut down blood in its legs to put more blood in its wings so it can dash away fast and the predator gets confused and walks away. It has a flap over its face and make a flashing hologram over its face making an alarming sound that scares off animals near it because the sound is so 
alarming." An example of a response using key words is: "swoops down, eats bugs, goes to lake to get water."

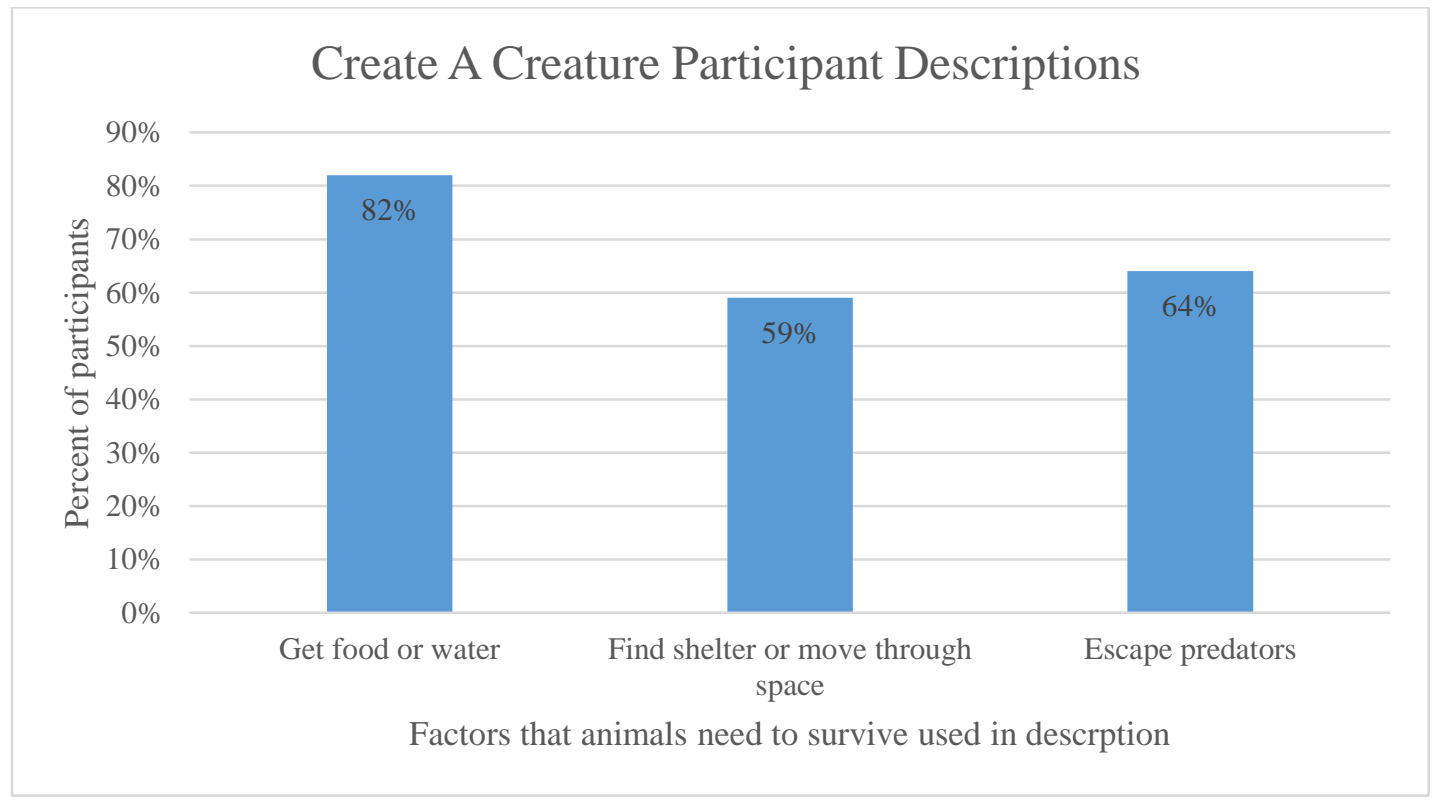

Figure 2. Participants' descriptions of structure and function for the Create a Creature Application of Conceptual Knowledge Task. The was a total of 22 participants from two sample groups. There were 11 participants in each sample group.

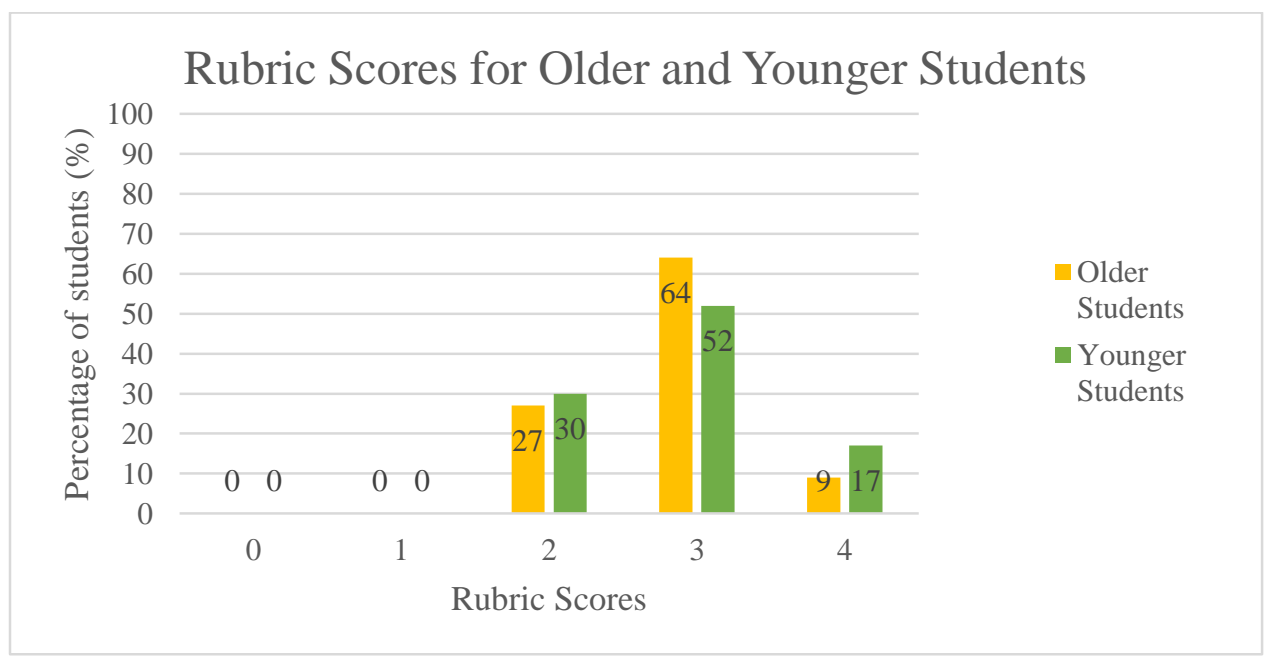


Figure 3. Rubric scores by sample group. The student scores using the Create a Creature rubric. Scores are shown as percentages for rubric score categories for both the younger sample group and the older sample group.

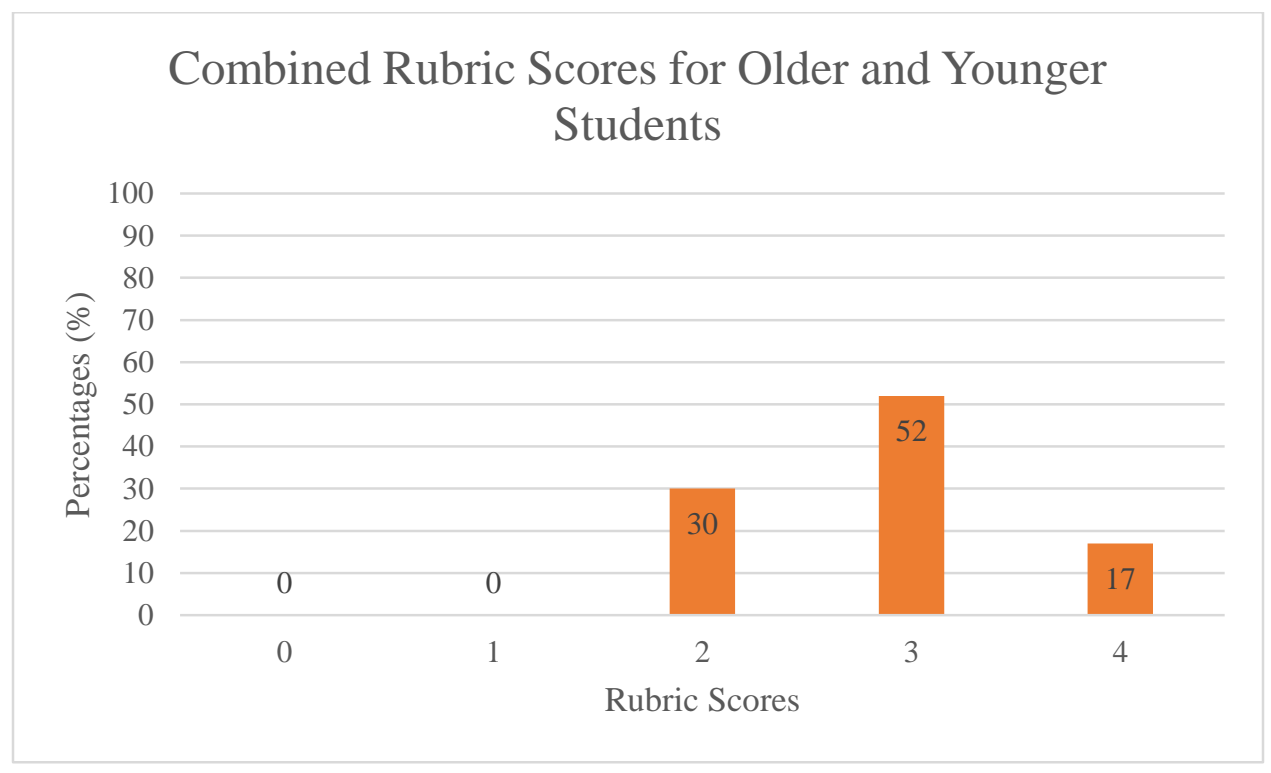

Figure 4. Combined Rubric scores. The Create a Creature rubric scores of both sample groups combined. There are 22 total participants. The scores are shown as percentages for each rubric score. 


\section{Chapter 5: Discussion}

The data collected in this study contributes to answering a research question that asked: How does an outdoor STEM based after-school program impact at-risk students' self-efficacy, sense of belonging, and engagement, and ability to apply conceptual knowledge?

The instructional practices outlined in the theoretical framework of the intervention provide practical ways for teachers to support students' social and emotional learning. The results collected in this study support that these instructional practices are effective ways to develop a holistically supportive program. The interviews provided participant feedback about the three affective constructs: selfefficacy, belonging, and engagement. When interviewed the participants described having high senses of self-efficacy, high senses of belonging, and identified activities they were engaged in. The participant profiles developed an in depth understanding of three participants and their affective states during the program. The participant profiles used data from the interviews, structured observations, and ethnographic observations. Finally, the Create a Creature task and the Application of Conceptual Knowledge rubric showed that over half of the students showed a proficient or higher understanding of the conceptual knowledge taught during the program. . By helping participants build motivation toward STEM subjects, and giving them opportunities to learn science in their own community, this program has contributed to the body of research that seeks to make quality holistic STEM learning available to underserved audiences (Bruyere, 
Wesson, \& Teel, 2012; Hall, Williams, \& Daniel, 2010; Lundh, et. al., 2013; Rahm, Martel-Reny, \& Reny, 2005).

Self-Efficacy. Self-Efficacy is defined as an individual's belief that he or she has the ability to perform a specific task (Anderman \& Anderman, 2014, p. 7). It is important that students feel a sense of self-efficacy when they face learning challenges. A sense of self-efficacy may provide the student with the motivation needed for taking on assignments or projects. During the afterschool program in my study, I provided students with opportunities to build self-efficacy by using specific instructional practices, and by providing activities that helped build participant confidence. The participants in the study showed self-efficacy in many ways. By gathering information from the observations, the interviews, and the participant profiles, I found that participants showed varying degrees of self-efficacy, but the data shows an overall trend of positive self-efficacy. Ninety percent of both sample groups believed they were successful in the program. A participant's perception of success during the program indicated whether or not they had the confidence in their own abilities, and therefore had high self-efficacy. Anya's profile showed that her low self-efficacy in reading and writing in the classroom caused her to feel isolated and frustrated in school. During the Tryon Trekker's intervention, she reported having high self-efficacy. She explained her success in the program this way, "[in Tryon Trekkers I was] getting along with people, just joining in with the class, and making new friends. I finished the activities with everybody [by] not quitting." 
Another theme that was uncovered during the interviews that informed my understanding of the participants' self-efficacy was goal orientation. Using achievement goal theory, goals can be divided into two categories, mastery goals or performance goals. Mastery goals, are defined as an individual's desire to master content or learn ideas. Performance goals are focused on the ability to demonstrate to complete a specific task or appear competent when compared to others performing the same task (Anderman \& Anderman, 2014, p. 7). In this study 55\% of older children, and $64 \%$ of younger children identified a mastery goal orientation (see table 4). Research shows that a mastery goal orientation is better for long term motivation because it teaches students to practice using an internal sense of value for a learning subject. "Mastery goals are associated with increased effort and persistence, increased engagement in tasks, improved academic achievement, and less use of ineffective cognitive and selfregulatory strategies (Anderman \& Anderman, 2014, p. 22).” This intervention provided a great opportunity for the participants to develop mastery goals. Because it was an afterschool program, there were no formal assignments, grades, or assessments. This learning environment may contrast the traditional classroom where students are pressured to perform on high-stakes assessments and compete with their peers for good grades. During this intervention, the participants were encouraged to find more intrinsic reasons for learning — curiosity, exploration, and stewardship for the environment. These results align with results found by Grolnick et. al. (2007) in their study of a science based afterschool program on the motivation of at risk students. Their project reported that the students that participated in the afterschool program that featured inquiry-oriented activities "helped the students feel less coerced in their school learning 
behaviors (p. 342)," and in the process find a more internal sense of motivation. These findings from a research study with an experimental design that tracked student motivation before, during, and after an intervention, and in comparison to a control, lends support to the observations I made about goal orientation in my study.

Data from my structured observations showed that participants demonstrated behaviors of positive self-efficacy during the intervention. Over the course of five classes students volunteered to show their projects to the entire class four times. Students were eager to volunteer to answer questions six times. These behaviors showed self-efficacy because they demonstrated the participants had high amounts of confidence in their own ideas and their projects. The participants also showed some behaviors that may denote low self-efficacy (see table 6). There were four times during the program that participants did not participate in an activity. Not participating may have meant that that a participant was unsure about their ability to perform in the activity so they did not attempt the task.

Three of the negative self-efficacy observations were about Anya. Anya expressed reservations during the program if she believed that she was being graded or evaluated in some way. She expressed worry about grades two times during the program, and she once commented that she was not smart. I believe that these insecurities were related to Anya's low self-efficacy about school in general. In her participant profile, she described having difficulty performing in a traditional classroom. "Self-efficacy differs from other related constructs in that it refers to students' beliefs that they can attain designated types of performances and achieve 
specific results (Anderman \& Anderman, 2013, p. 165).” This means that an individual can show low self-efficacy related to one type of performance, and have feel high-self efficacy toward another. Anya expressed her insecurities about her learning disabilities and showed low self-efficacy toward graded learning tasks. Anya's self-efficacy toward learning during the intervention contrasted with her stories about learning in school. During her interview, Anya described feeling successful in Tryon Trekkers. She indicated that she understood concepts and she always fully participated in the activities.

Anya is a great example of how participants' low self-efficacy in one context may manifest in another context. It is challenging to help participants feel motivated if they are already starting with very low confidence in a subject. The instructional practices, outlined in the intervention's theoretical framework, were used to support self-efficacy during the program (see table 4). They helped support the participants' transitions from low self-efficacy to high self-efficacy because they ensured that the program offered opportunities for social and emotional growth. One key instructional practice that I believe helped students build self-efficacy was including multi-modal activities. As seen with Anya's profile, some participants are more successful with learning tasks in one modality over another modality. The various types of activities provided the participants with both opportunities for success and opportunities that were challenging to them. Over the course of one class, I made sure that I planned at least one activity that each of my participants would be successful at. The success the participants felt in one or two activities during a class, provided the momentum needed 
for their sense confidence to spread. By the end of the program, many of the participants showed confidence even during activities they found challenging. One student said this this about a challenging project, "I kind of just go at it, and after I start something, I finish it even if it's really hard. I like doing challenging things because it helps you learn more."

Another instructional practice that built self-efficacy was that the instructors modeled appropriate responses to challenging learning situations. The challenges identified by the older sample group during the interviews align with the risk factors identified in the theoretical framework behind the intervention design (see table 2). The older participant group identified three main challenges during the intervention: academic projects (36\%), social interactions (36\%), and being outside (18\%). It was important to be aware of the challenges that each participant faced during the intervention. Each individual participant had different factors that created barriers to learning in the program. For example, Anya felt isolated by her learning disability, Viviane was fearful of Tryon Creek State Natural Area, and Hani was hungry and tired after school. Another participant described his challenges in this way, "I was born with ADHD, that's what makes me feel hyper. I don't like listening to the instructors while wanting to look along the trail and write things down." Challenges can also be defined as risk factors using the risk and resiliency theory (Anthony, Alter, \& Jenson, 2009). To help participants work through challenges, the other instructors and I were enthusiastic about projects, demonstrated how to carry out learning tasks, and we gave the students positive encouragement when they faced challenges. During the interview 
at the end of the intervention, a student recalled his experience on a challenging project. Because the instructors took time to help him through the challenge, he felt confident about his work when he was done. "The instructors helped me out with something if I was stuck on a project. [For example], the beak we made was challenging, I finished it by getting help on how to form the beak."

The data collected during the study provided many insights about the participants' experiences with self-efficacy during the intervention. It is important to provide students with opportunities to build self-efficacy during their education. "Enhanced self-efficacy positively affects life choices, motivation levels, quality of living, and resilience to harsh conditions (Bandura, 1997)." A confident sense of self can help the participants in my program overcome the risk factors they face in the future. Also, a sense of self-efficacy about topics in life sciences may inspire participants to pursue more formal and informal science education opportunities in the future.

Belonging. During the intervention, I was intentional about developing instructional practices that promoted the factors that helped participants feel a sense of belonging. The instructional practices that helped foster community during the intervention were: forming personal relationships with participants, beginning each class with a sharing circle, establishing consistent expectations, and treating all of the participants like they were scientists. Like the teachers in a study done by LadsonBillings (1995), I included instructional practices that fostered connectedness between participants by developed a sense of community, and encouraged students to learn 
collaboratively. In her study, Ladson-Billings (1995) pointed out that "culturally relevant teachers encouraged a community of learners rather than competitive, individual achievement."

During the beginning of each class, the group had a circle time. During this time, the instructors checked in with students, asked a question of the day, and allowed time for group discussion. This focus on the students as a group helped them build trust with the instructors and their peers. During circle time students exhibited many behaviors that demonstrated self-efficacy, belonging, and engagement that were recorded in my structured observations. In particular, circle time allowed students to share life stories and events (observed 11 times) and students volunteered to answer questions (observed 6 times). Both of these behaviors helped participants feel comfortable with others in the program, and helped them create a connection between their lives at home to their lives at Tryon Trekkers.

Many of the intervention's activities asked students to work collaboratively in small groups or partners. During an interview, one student felt like she belonged "because we learned together, and we worked as a group during most of our class." Collaborative groups helped participants build positive relationships with one another. Described in her participant profile, Anya showed that many students build self-efficacy when they feel a sense of belonging in their learning community by having the ability to work collaboratively with others. During her interview, she described that she felt like she could overcome challenges when she "[had] friends beside me to help me out, and 
talk with me about how things work. If I thought something different than them, I would try something different and see how it worked.”

As an instructor, I worked hard to build positive student-teacher relationships. During our group dinner time, the instructors and I greeted each child, asked them about their day, and often talked about topics that interested them. As a result of taking time for group and individual conversations, the instructors and I gained valuable insights about participants' personalities and interests. I used those insights to modify the curriculum to be more relevant and interesting to participants. Those students that didn't feel like they belonged noted cultural differences between their families and the afterschool group. During one interview a participants said, "I feel like I belong kind of, because this group is more different than my family. Because my family are Muslims and this group is not like them." This participant description indicated that there may be a cultural mismatch between the cultures created in the Tryon Trekkers program with the culture of the participant's home life.

It is important to consider the cultural context of those participating in an intervention. "All of the nuances of [risk factors] are specific to the cultural context in which these youth live, and are likely to be part of the explanation for the differential trajectories toward negative or positive development that are still unfolding for these young people (Forrest-Bank, et. al., 2014, p. 11). Research in cultural relevancy in education has supported the idea that culture should be integrated into educational practice and instruction in contexts relevant to the participants (Ladson-Billings, 1995). When building a supportive learning environment, it is important to consider the 
cultural background of the participants so that the community norms support each other. Anderman and Anderman (2014) suggest that in order to motivate culturally diverse students it is important to: learn about student cultures, talk to the students about their cultures, talk to parents, and acknowledge and accept differences in the learning community (p. 204).

In addition, it is important to consider the cultural perspectives of participants when designing activities that are relevant to the participants. During this intervention, I attempted to connect the natural environment at TCSNA with the participants' own community. To foster a sense of place, I showed the students that TCSNA was close to school, and that the participants could take their families to the park. For example, at the beginning of the intervention, I gave the participants a map that showed where the school was, and where TCSNA was. As we drove to the park, I challenged the participants to trace our progress on the map.

Another way that participants found belonging was by gaining knowledge about the park. During our hikes I taught participants how to identify plants and animals. During his interview, one student described what he learned at Tryon in this way, "about the banana slug, about the cool stuff I saw out the window, and cool plants and fruits like thimbleberries." Knowing and understanding things about the forest helped the participants feel a greater sense of comfort and belonging in the environment. Viviane's participant profile showed how a participant went from feeling uncomfortable and scared at Tryon to being excited and interested in the environment in the park. At the end of the interview, Viviane not only said that she wanted to spend more time 
outdoors, she commented that TCSNA was part of her own community. "My favorite activity was actually when we went to Tryon Creek. It's really close to my church so I can walk there."

During a study about how students connect with science done afterschool, Rahm, Moore, and Martel-Reny (2005) conclude that rich afterschool opportunities for at risk youth "build a science practice with youth that is based on respect, and a science they can relate to and that fits with their own worldview and culture (p. 290).” There were many ways to find a sense of belonging in Tryon Trekkers. The participants developed trust and connection with their peers and with the instructors. The participants were given formal opportunities to connect to others by learning cooperatively, participated in informal opportunities to connect by talking with instructors, and contributed thoughts and ideas during the circle time. During field trips to TCSNA participants connected with the forest by learning about the plants and animals. The feelings of connections the participants built in the forest allowed them to incorporate the park into their own community. Participants experienced how close the park was to the neighborhood near the school, and they felt knowledgeable enough to hike there.

Engagement. During the intervention there was a mixed level of engagement. My structured observations show that many students were engaged during activities by showing effort (observed 9 times) and by volunteering to describe phenomena (see table 6). At other times during the program participants were not engaged by being off-task 
(observed 2 times), asking to do something else (observed 5 times), and when participants had to be prompted to participate (observed 4 times). Hani's case is an example of a participant that struggled with being engaged during the program. During most of the classes she exhibited oppositional behavior. Her oppositional behavior may be explained as an avoidance behavior, or it may have been a symptom of physical fatigue and hunger. Hani's barriers for engagement form just one example of the things that prevent children from engaging with learning.

To measure engagement in the interviews the participants were asked about their favorite and least favorite activity. Many students identified that they favored the hands on projects ( $45 \%$ older participants, $55 \%$ younger participants), kinesthetic games $(27 \%, 36 \%)$, and the field trips $(36 \%, 18 \%)$. Participants showed a range of preferences for the types of activities featured in the intervention (see figure 1). Many participants identified favoring creative projects (5 participants), active games (6 participants), and field trips (5 participants). In addition, when asked about their least favorite activity, many of the participants could not identify something that disliked (12 participants).

The instructional practices that facilitated engagement were: having a place based curriculum, giving students choices about learning tasks, and having inquiry based learning opportunities. Engagement is the process of connecting with a learning task through interest, effort, focus, and attention. Many of the other instructional practices supported the participants so they could successfully engage with the science topics presented in the intervention. The place based curriculum incorporated using local animals when discussing structure and function. By taking field trips to TCSNA 
we explored nature in a location within the community. The participants in the program were excited to go on the field trips. In my ethnographic observations, I recorded that before going to the park, students had high energy, and asked many questions about the field trips.

During classes at the elementary school, I took time to get input from participants about how they wanted to learn during activities. Anderman \& Anderman (2014) connect giving students choices during lessons promotes intrinsic motivation. I think that allowing students to be responsible for their own learning invites them to invest more effort and attention toward their work. During an interview, one participant was asked how Tryon Trekkers differed from their experience in school. "You get to have a lot more activities that we get to choose, and involve exercise and animals. Usually in school you sit in the class and watch the teacher do something and then you do it." This example shows that the participant felt more in control of her own learning during Tryon Trekkers than during school.

The inquiry based activities asked the Tryon Trekker participants to become scientists. I utilized life science concepts from the Next Generation Science Standards to form essential questions that drove the inquiry learning during the program. The structure of the class first gave participants a short introduction about a topic, and then asked them to explore and discover their own ideas through multi-modal learning tasks. We often brought in specimens (living and non-living) from the Friends of Tryon Creek classroom. Most importantly these tasks required that the participants engage in learning through making observations, asking questions, finding evidence, and 
communicating their ideas. This style of learning demands engagement because participants are asked to use higher order thinking skills to connect with the scientific topics.

Connection to Nature. The results of this study has revealed an unexpected construct that contributed to the affective state of the participants. When the participants had experience at Tryon Creek State Natural Area (TCSNA), they reported positive motivation in relation to their experiences in the natural environment. The motivation that was fostered included features of the other motivational constructs (self-efficacy, belonging, and engagement), but they also featured an emphasis on the feelings that participants had about the forest. Some students were highly engaged by what they observed outside. "I really like being outside. It's just so interesting. Even if you know the place really well. I just look for movements and stuff. I like to look at the pollen in the wind. I feel happy when I am outside." This participant was not only engaged in the environment, felt a sense of belonging, but also attained a happy feeling from being outside. In his book "Last Child in the Woods," Richard Louv (2005) explains this phenomena with a quote by Robin Moore, the director of the National Learning Initiative. "Sensory experiences link the child's exterior world with their interior, hidden, affective world. Individual children test themselves by interacting with their environment, activating their potential and reconstructing human culture. A rich, open environment with continuously present alternative choices for creative engagement ( $\mathrm{p}$. 65)." During the interviews, over half of the participants reported that after 
participating in Tryon Trekkers, they would spend more time outside or in nature (see table 8).

Table 8. Connection to Nature Interview Data. Data from the interviews that show participant responses about spending time in outside or in nature. Sample group responses are combined for this question because participant responses were the same for both groups.

\begin{tabular}{|c|c|c|c|}
\hline Interview Question & $\begin{array}{c}\text { Participant } \\
\text { Response }\end{array}$ & $\begin{array}{c}\text { Number of } \\
\text { participants }\end{array}$ & $\begin{array}{c}\text { Percentage of } \\
\text { participants }\end{array}$ \\
\hline $\begin{array}{c}\text { Since participating in Tryon Trekkers, how } \\
\text { much time do you want to spend outside or in } \\
\text { nature at home or with your family? }\end{array}$ & More time & 12 & $54 \%$ \\
\cline { 2 - 4 } & $\begin{array}{c}\text { About the } \\
\text { same time }\end{array}$ & 8 & $36 \%$ \\
\cline { 2 - 4 } & Less time & 1 & $5 \%$ \\
\cline { 2 - 4 } & $\begin{array}{c}\text { Did not } \\
\text { answer }\end{array}$ & 1 & $5 \%$ \\
\hline
\end{tabular}

The structured observations show that the participants demonstrated positive behaviors towards a connection to nature when they showed concern for a living creature (observed four times). During the beginning of the program, many students were concerned about spending time outside (observed three times). Some participants were concerned about getting dirty. Others expressed concern about hiking. When asked about the hardest part of Tryon Trekkers, one participant said, "walking when we were doing the field trips because sometimes my legs were hurting and my side started to hurt."

During an interview another participant was asked about the most interesting thing she learned during the field trips at TCSNA. "It helps me realize how powerful 
nature is, and how much it matters in the world. It makes me really feel like nature is an amazing and awesome thing. If we didn't have it, we wouldn't be alive, and it's so important for humans and animals and life." This participant demonstrated connection with the environment personally and identified how all people are connected to nature. Through the experience during the field trips, the participants found meaning in nature and the environment.

\section{Application of Conceptual Knowledge}

During the Application of Conceptual Knowledge task the participants in the study were asked to demonstrate their understanding of the science concept they had been studying throughout the intervention. The task asked the students to recall the information they had learned during each of the class meetings and apply it to a new context. The task was administered at the end of the program during the last field trip at Tryon Creek State Natural Area. The scoring of the task using an Application of Conceptual Knowledge rubric that over half of the participants showed proficiency in the concept of structure and function. This task was not given to the participants before the intervention. This measurement is not able to show if the intervention changed the participants' conceptual understanding of the science topics only what level of understanding the participants had at the time of the task.

The results from the categorical scoring of the Create a Creature task show that students were most comfortable (84\% of participants) describing how their creature used structures to find food or water. For example, one student described how their creature found food in this way, "mine eats meats, berries, and leaves. It uses its legs to 
rip off skin of the meat." The participants described the creature's use of structures to facilitate moving through space or finding or building shelter (59\%) less frequently than food/water, and avoiding predators (64\%). One student described an elaborate defense that was part of his "Alarm Bird" creature. "It has a flap over its face and make a flashing hologram over its face making an alarming sound that scares off animals near it because the sound is so alarming."

During class time, we spent both week 4 and week 5 discussing how creatures used their body to find food. For example, during the third class we explored how birds had different beak structures to help them get different types of foods. We also played a kinesthetic game where the participants pretended to be animals and gathered poker chips that represented food and water. In addition, we discussed how woodpeckers find food during our first field trip on week 6 . We spent the second most time doing activities that addressed how animals avoided predators. We discussed predation during week seven of our class by playing a predator tag game and looking at the eye orientation on mammal skulls. The conceptual understanding of finding shelter is the most complex idea within the three functions. We spent the sixth class focused on this idea by examining how slugs moved. I think that the participants needed more examples of how animals find shelter and use space to be able to better understand this structure and function connection.

The results from the Application of Conceptual Knowledge task using the rubric (see figure 3 and 4) show that over half of each sample group show a rubric score of 
three or higher. During the task, the participants were first given the opportunity to demonstrate their conceptual understanding of structure and function by matching nine structures of local animals to three different functions. The demonstration of conceptual understanding task was scored independently of the rubric. All of the participant groups got one or less match wrong during this task. Then the participants were asked to show an understanding of how the physical structures of an organism helps it carry out an essential survival function by designing their own novel creature. During the task, all of the participants were prompted by a group leader with three essential survival functions, and asked to describe how their creature accomplished those functions using its physical structures. Fewer participants scored a four on the rubric ( $9 \%$ in the older group, and $17 \%$ in the younger group). These participants were able to explain both how their creature used physical structures to carry out functions, and why these structures were optimal for their specific creature's survival. One example of this type of descriptions is, "The create eats meats, berries, and leaves. It uses its legs to rip off skin of the meat. It flies, can walk, digs, can balance on one foot while it fights predators with other legs and arms. Bird can that can escape by digging a hole in the ground and hiding underground." About one third of each group showed a more rudimentary understanding of structure and function by only noting a structure or a function and not linking the two ideas together. This was designated on the rubric as a score of two. 
During the task, all of the participants were given verbal prompts about the functions an organism needs to have in order to survive. These three functions, finding food/water, finding shelter or moving through space, and avoiding predators, were covered throughout the intervention as topics of individual classes. Overall, many of the participants were successful in applying the concept of structure and function to a novel animal. The participants may have had a less complete understanding of finding shelter and moving through space and avoiding predators according to the categorical scoring of the Create a Creature Task. Those students that scored a two on the rubric showed that they hadn't yet fully understood the concept of structure and function. This lack of understanding may be explained by the infrequency of the class, as well as the short duration of each class period. It was difficult to link concepts week to week because a significant amount of time had passed since the last class. Each class was approximately an hour and ten minutes. We often did not have enough time during each class to include adequate reflection activities. Reflection time is an important part of the learning process. It is a time to review the topics covered during the class in order to reinforce the ideas for the learners. It is also a time to check for understanding. Although each class topic built upon the previous week's concepts, there was little time for review of concepts during class time.

Limitations of the Application of Conceptual Knowledge Rubric. My study was one of the first times that a research project used the Portland Metro STEM Partnership (PMSP) Application of Conceptual Knowledge (ACK) rubric. During the study, I 
adapted the general rubric format to fit the specific task in my study. The current PMSP instrument has not been formally validated by research. The individual dimensions used to design the rubric have been individually validated by previous research studies, but this specific instrument has not yet been tested or evaluated through a research study. Some of the rich data of the participant responses of the task was lost during the scoring of the rubric. The categorical scoring of the task revealed which function categories were better understood because they were included in more participant responses. The function categories with less responses may indicate that the participants did not understand those concepts. This information provided me with information about how to change the curriculum in the future to help students better understand all of the function categories. Using the instrument in this study has uncovered some problems with the current rubric design. First, the language presented in the general rubric must be modified to the design task it seeks to measure. The general rubric is not specific enough to be applied to tasks developed by the ACK framework. Second, the evaluation focus for the demonstration of conceptual knowledge in the rubric focuses on a participant's ability to use vocabulary. In my study, the program did not emphasize vocabulary, and therefor vocabulary was not an appropriate set of criteria to measure student conceptual understanding. Gaining an understanding of how the rubric worked for my study may be helpful as the PMSP seeks to modify or redesign the Application of Conceptual Knowledge instrument.

The first challenge using the ACK instrument was to modify the language of the rubric so that the scores applied directly to the Create a Creature task. Instead on 
leaving the general language proposed by the PMSP, I translated the concepts to fit this project. I chose to define the application of knowledge criteria as the degree to which the student linked and described structure and function within the context of their creature. This was an appropriate measure of ACK because the degree to which the participant could describe how and why a structure supports function, clearly provided evidence for how well the participant understood and applied the learning goal. For example, the wording of the criterion for a rubric score of four, was changed from the original PMSP definition "Students can consistently give a valid conclusion based on the correct application of relevant science concepts," to a Create a Creature task specific definition, "Students built a creature and he or she described how structures works by giving a detailed description of the creature's body parts. Then the student explained why the structure is best at performing its function." When PMSP partners use this rubric, they may also choose to modify the rubric categories.

The criteria used in the PMSP rubric for demonstrating conceptual understanding focuses on the use of vocabulary involved in the ACK task. The current criteria suggest that a participant's ability to demonstrate conceptual understanding is based on a complete use of vocabulary involved in the concept. In this research study, I designed the curriculum without an emphasis on concept vocabulary. Since the program was an informal learning environment, with participants of varying ages, the curriculum focused on big ideas and activities and experiences that demonstrated concepts without an emphasis in vocabulary. Because of this discrepancy, I chose to 
develop an alternative task and measurement for demonstration of conceptual understanding.

I recommend that this set of criteria within the rubric be reevaluated. It may be possible for a participant to demonstrate a complete understanding of a concept without using appropriate vocabulary. My intervention curriculum did not focus on vocabulary. The curriculum for the program was designed to explore science without a focus on specific vocabulary. In addition, inaccurate use of vocabulary may not be indicative of a lesser understanding of a concept. In the task that I designed for the Tryon Trekkers program, vocabulary was also not a central to measuring participants' conceptual understandings. For example, in my program there were a few participants that were English as a second language learners (ESOL). During the talk of demonstrating their conceptual understanding, these students were able to match appropriate structures and functions using pictures that represented animals with physical structures, and corresponding functions. The ESOL participants were able to appropriately match structure and function, but they were unable to describe the structure and function using "all appropriate vocabulary." Using the current PMSP, I would be unable to give them a score because they lack the English vocabulary to give a complete answer. If this rubric were used by PMSP partners that also wanted to measure ACK of a wide range of participants, they may also find defining conceptual understand by use of vocabulary to be equally as restraining.

Intervention Logistics Limitations. One of the most significant limiting factors in this study was time. The afterschool programming at Mitchell Elementary school was 
scheduled by terms, and defined by the SHINE program. The spring term of the afterschool program only lasted eight weeks. During these eight weeks, each sample group only met one time, for less than two hours. It was challenging to implement course content activities, as well as carry out instructional practices during these short classes. Many of the strategies to promote motivation require building trust and building community, which naturally takes time. For example, one participant did not begin to talk in complete sentences with me until the last class meeting. If we would have had more weeks of class, she may have volunteered to talk more to class, or provided more information during her interview.

During the intervention three of the meetings were field trips to Tryon Creek State Natural Area (TCSNA). Five of the meetings were at Mitchell Elementary School. Four out of these five class meetings contained activities that concentrated on introducing content. It was challenging to thoroughly cover the scientific content during these few meetings. This program only covered one scientific concept. If future programs would like to cover a wider variety of content, more time is needed. The duration of one class was around one hour and twenty minutes. It was challenging to include both course content and community building activities into this time frame.

Transporting the participants from school to TCSNA was also challenging. Travel time took a total of 30 minutes. Once participants arrived at the park, they had about forty minutes to engage in programming. The short time span limited the amount of both exploring content and community building done at the park. The time limitation limited our ability to utilize the park for both exploration and concept specific learning. 
If we had more time, we would have taken the participants further into the forest, played games, given time for silent journal reflection, and engaged in discussion.

Recommendations. In the future, if Friends of Tryon chooses to pursue teaching the Tryon Trekker program, I recommend that the class meets at least two times a week. This will help the group build community, and give the instructors more time to implement the instructional practices that support the protective factors in the program (self-efficacy, belonging, and engagement). The academic content of the program should be limited to one or two scientific concepts. If a wider range of science is included in the program, more class meetings are necessary.

Since TCSNA is the focal point of the program, I propose that future programs be held at the park. Transporting the participants to and from school limited our ability to utilize the environment for learning. If the program is held at a school, I recommend only taking one field trip to a natural location, and utilizing the rest of the time exploring natural phenomena on campus. This will maximize the time the students can spend engaged in learning rather than spending time being transported. Alternately, the hours of the program could be expanded to allow for more time at TCSNA during the field trips.

Curriculum Limitations. The curriculum design worked well for the program. The multi-modal activities provided a variety of experiences for the participants. The results collected from the observations and interviews indicated that the instructional practiced implemented in the program were helpful in developing participant motivation. The 
concepts covered in the curriculum were appropriate for both age groups. The grade band expectation for this age group included a deeper understanding of structure and function that includes understanding internal and external structures (NRC, 2012, p. 144).

This intervention included one science concept chosen by myself and Friends of Tryon Creek education staff. The science concept did not align with content being taught in school. It was not possible to align the afterschool content with in school science content because the intervention students from various age groups.

Recommendations. Because this program was aligned with concepts from the NGSS, students will encounter these concepts during their academic career regardless of whether or not they are learning the concepts in their classroom concurrently with the afterschool intervention. One change that might be made in the intervention by future instructors may be to have the learning objective for older students in the program align with the grade-band endpoint for fifth grade. For upper elementary students, they should understand structure and function using this endpoint. "Plants and animals have both internal and external structures that serve various functions in growth, survival, behavior, and reproduction (NRC, 2012, p. 144). An alternative suggestion would be to design an afterschool program that focuses on scientific practices defined in the Framework for k-12 Science Education (NRC, 2012). These practices are developed by all students over the course of their academic careers. These practices will be relevant to science learning for students regardless of their age or grade. 
Theoretical Framework Limitations. There were no explicit limitations to the theoretical framework based on the qualitative data collected in this study. The risk factors and the protective factors I chose to focus on were applicable to the intervention participants. The data collected from this study suggested that the instructional practices used in the intervention were supportive to the participant experience. There are many other affective constructs that could have been included in the study. The scope of this research experience did not permit me to consider more than three motivational constructs to evaluate the participants' experiences.

In the future it would be valuable to reexamine the affective components in the study using validated affective surveys as repeated measures to track participant affective states over time. In addition, I could run statistical analyses to determine if there was a correlation between the instructional practices used in the intervention to potential changes in motivation. By using a more experimental design, I could more specifically examine the connections between the risk factors, protective factors, and then instructional practices.

Qualitative Evaluation Limitation. The best experimental design for the questions addressed in this study was an evaluative case study because my research aimed to design a novel afterschool intervention that addressed the motivation and the conceptual understanding of its participants. This study featured a non-experimental design and featured qualitative data. Since the program development was a part of the research 
project, it was important to describe the experiences of the program participants. I also wanted to explore the relationship between a holistically supportive program design and the participants' perceptions of motivation. I was looking for general themes and qualities of the program, so interviews and ethnographic observations were the best method of data collection.

The non-experimental design limited my ability to draw conclusions about causality. I cannot say that my intervention caused the participants to be highly motivated in science, and have increased performance in STEM subjects. In order to explore direct relationships, a study must collect data before and after an experimental treatment, it must have a control, and it must have many replicates of samples. My study contained only two sample groups, with only eleven individuals in each group. These numbers were too small to analyze the data using statistics. There was no measure of motivation before the program began. I cannot draw conclusions about the direct effect of my intervention on participant motivation because I am unable to describe changes of motivational states before and after the intervention. In addition, there were no controls in my study. I have no way of knowing whether the participants felt a sense of motivation in their academic lives because of the intervention or because of some other factor in their lives.

Wendy Grolnick and her colleagues (2007) conducted a study similar to my study except that they used an experimental design to evaluate how a science based afterschool program effected motivation in youth participants. If I designed an 
experimental study, I would use a method similar to that of this study. Their experimental design used controls, repeated measures of motivation and academic performance before, during, and after the intervention, multiple sample groups, validated affective surveys, and analysis using statistics. The authors were able to draw direct conclusions about the effects of their afterschool program on academic motivation. This study was interested in seeing how the intervention changed participants' affective states as well as their academic performance. The results of their study showed that those participants that participated in the experimental intervention showed that their experienced caused "more autonomous motivation overall" and a buffering effect against the loss of interest in academic subjects (p. 341). The study also showed an increase of science grades after the study was complete. 
Conclusion. In conclusion, this study used a holistic based afterschool intervention design to give at risk youth the opportunity to learn STEM subjects and experience learning science outdoors. The intervention designed for the study addressed the social and emotional needs of at-risk youth during the intervention. Children that are at-risk have barriers that often prevent them from learning and being in successful in school. The goal of this study was to make learning available for at-risk students. I wanted to give the participants the opportunity to learn about science despite the risks they face in their lives. I used relevant theory in education to link my program's activities to protective factors that helped to build student motivation. Results from my interviews and observations showed that participants in the study felt successful during the program. They reported positive emotions during the intervention, and after the intervention they were interested in learning new things in STEM subjects and beyond.

The theoretical framework and curriculum design in this study could be applied and implemented in future SUN afterschool programs. Afterschool programs are often limited by time, resources, and quality of instruction (Lundh, et. al, 2013). Reflecting on my experience as an afterschool program instructor in various schools in the Portland metro area, I believe that the structure of this program could help improve the quality of afterschool instruction by providing a consistent and focused course goals for future instructors. As an instructor at many different sites, I experienced having little to no guidance about what or how to teach. Local SUN school programs could use my theoretical framework and curriculum to narrow the focus of science programs offered during afterschool. Each program could pick risk factors specific to their students, and then use corresponding instructional practices to provide support. Since I designed the 
course in the context of the time frame of a SUN program, the course could be easily applied at other SUN sites. My study demonstrated that afterschool programs have the ability to influence participant's affective views of learning. Other SUN sites may benefit by providing affective support to students that face risk-factors that interrupt learning. It would be valuable for other afterschool programs to adopt this holistic style of programming. I could develop other curriculums that focus on different STEM topics using the NGSS core concepts. Quality of instruction in afterschool programs can vary depending on the experience of the program instructor (Lundh, et. al, 2013). My curriculum and instructional practices could help to increase quality of afterschool learning by providing specific strategies for holistic science learning.

By making STEM learning available to all types of learners, this study contributes to the mission of STEM educators to developed well informed citizens and lifelong science learners (NGSS, 2012). A study by Rahm, Moore, and Martel-Reny (2005) also explored the roles of informal science education in the lives of at-risk youth. These authors concluded that studies that informal science programs have the ability to “develop a new relationship with science that made it something interesting and desirable, and not simply a distinct and abstract area of study unrelated to her life and her perceived future self (p. 286)." I believe that my study cultivated the program participants' new relationship with science. When Viviane saw the woodpecker at TCSNA, she no longer saw learning about woodpeckers as a boring topic in a book, it became something real to her. Her sense of belonging and engagement that was 
fostered with her experience seeing the woodpecker opened the door for her to find future inspiration in science and nature.

Bevan and Michalchick support the idea that "out of school time experiences that may not directly link to school science but that may open the door for ongoing future engagement with science, including in the school setting." When Anya felt confident and comfortable in the program, I observed her self-efficacy bloom. She developed a positive relationship with myself and the other instructors, she faced challenging learning tasks, and she developed her social and emotional skills with her peers. "Such positive experiences might engage children in noticing specific phenomena, developing skills on which they can later draw, or establishing peer or adult relationships that make science more appealing (Bevan \& Michalchik, 2013, p. 4)." My hope is that Anya and the other participants in the program bring their successes and excitement from the afterschool program to their lives as students in school.

When considering the quality of afterschool programs today, Krishnamurthi, and her colleagues (2013) called for new "tools and methods that can document outcomes without significantly interfering with the afterschool experience. Besides documenting outcomes, the field is also challenged to show how program activities contribute to those outcomes. The nature of children's experience in afterschool programs remains largely unexamined." My study used qualitative data to examine children's experience in a STEM based afterschool program. The Application of Conceptual Knowledge tool developed by the Portland Metro Stem Partnership can be an effective way to measure 
afterschool outcomes related to conceptual understanding. It can be integrated into the program and become an integral part of the learning experience for participants while allowing educators to assess what participants are learning. 


\section{References}

Anderman, E. M., \& Anderman, L. H. (2014). Classroom motivation. San Francisco, CA: Pearson Education Inc.

Anthony, E. K., Alter, C. F., \& Jensen J. M. (2009). Development of a risk and resiliency based out-of-school time program for children and youth. Social Work. 54(1).

Ansary, N.S., McMahon, T. J., \& Luthar, S. S. (2011). Socioeconomic context and emotional-behavioral achievement links: Concurrent and prospective associations among low and high income youth. Journal of Research on Adolescence, 22(1), 14-30.

Bandura, A. (1997). Self-efficacy: the exercise of control. New York NY: Freeman

Beven, B., \& Michalchik, V. (2013). Where it gets interesting competing models of stem learning after school. Afterschool Matters, 17, 1-8.

Berzin, S.C. (2010). Vulnerability in the transition to adulthood: Defining risk based on youth profiles. Children \& Youth Services Review, 32(4), 487-495.

Biederman J., Faraone, S.V., Monuteaux, M. C., \& Feighner, J. A. (2000). Patterns of alcohol and drug use in adolescents can be predicted by parental substance use disorders. Pediatrics, 106(4), 792-797.

Bruyere, B. L., Wesson, M., \& Teel, T. (2012). Incorporating environmental education into an urban after-school program in new york city. International Journal of Environmental \& Science Education, 7(2), 327-341.

Carson, R. (1956). The Sense of Wonder. New York, NY: Harper Collins Publishers, Inc.

Forrest-Bank, S., Nicotera, N., Anthony, E., Gonzales, B., \& Jenson, J. (2014). Risk, protection, and resilience among youth residing in public housing neighborhoods. Child \& Adolescent Social Work Journal, 31(4), 295-314.

Friedman, A. (Ed.). (2008). Framework for evaluating impacts of informal science education projects. Arlington, VA: National Science Foundation

Grolnick, W.S., Farkas, M.S. Sohmer, R., Michaels, S., \& Valsiner, J. (2007). Facilitating motivation in young adolescents: Effects of an after-school program. Journal of Applied Developmental Psychology. 28(4), 332-44. 
Hall, K. W., Williams, L. M., \& Daniel, L. G. (2010). An afterschool program for economically disadvantaged youth: Perceptions of parents, staff, and students. Research In The Schools. 17(1), 12-28.

Jenson, E. (2013). Engaging students with poverty in mind practical strategies for raising achievement. Alexandria, VA: ASCD.

Krishnamurthi, A., Bevan, B., Rinehart, J., \& Coulon V. R. (2013). What afterschool stem does best: How stakeholders describe youth learning outcomes. Afterschool Matters. 18, 42-49.

Ladson-Billings, G. (1995). Toward a theory of culturally relevant pedagogy. American Educational Research Journal. 32, 465-491

Littledyke, M. (2008). Science education for environmental awareness: Approaches to integrating cognitive and affective domains. Environmental Education Research. 14(1), 1-17.

Lundh, P., House, A., Means, B., Harris, C.J. (2013). Learning from science: Case studies of science offerings in afterschool programs. Afterschool Matters, p. 3141.

Masten, A. S., \& Obradovac, J. (2006). Competence and resilience in development. Annals of the New York Academy of Sciences, 1094, 13-27.

National Center for Children in Poverty. (2014). Child Poverty. Retrieved from http://www.nccp.org/topics/childpoverty.html

National Research Council. (2012). A framework for k-12 science education: Practices, crosscutting concepts, and core ideas. Washington D.C.: National Academies Press. Retrieved from http://www.nap.edu/catalog.php?record_id=13165

National Research Council. (2009). Learning science in informal environments: People, places, and pursuits. Washington, DC: National Academies Press.

NGSS Lead States. (2013a.) Next generation science standards appendix D—“all standards, all students": Making the next generation science standards accessible to all students. Washington DC: National Academies Press.

Papazian, A. E., Noam, G. G., Shah, A. M., \& Rufo-McCormick, C. (2013). The quest for quality in afterschool science. Afterschool Matters. 18, 17-24 
Rahm, J., Martel-Reny, M., \& Moore, J. C. (2005). The role of afterschool and Community science programs in the lives of urban youth. School Science \& Mathematics, 105(6), 283-291.

Skinner, E. A., \& Belmont, M. J. (1993). Motivation in the classroom: Reciprocal effects of teacher behavior and student engagement across the school year. Journal of Educational Psychology. 85(4), 571-581.

Simon, R. A., Aulls, M. W., Dedic, H., Hubbard, K., Hall, N. C. (2015). Exploring student persistence in STEM programs: A motivational model. Canadian Journal of Education. 38(1).

Sobel, D. (1996). Beyond ecophobia reclaiming the heart in nature education. Great Barrington, MA: The Orion Society and The Myrin Institute.

Stern, L., Ahlgren, A. (2002). Analysis of students' assessment in middle school curriculum materials: Aiming precisely at benchmarks and standards. Journal of Research in Science Teaching. 39(9).

Young, J., Haas, E., \& McGown, E. (2010). Coyote's Guide to connecting with nature. Santa Cruz, CA: OWLink Media 8 Shields. 


\section{Appendices}

Contents:
A. Create a Creature Task
B. Create a Creature Rubric
C. Structured Observation form
D. Interview Questions
E. Tryon Trekkers Program Lesson Plans
F. Categorized Ethnographic Observations
G. IRB Application

\section{A. Create a Creature TASK:}

Create a creature out of clay that has all of the body parts it needs to survive in the woods at Tryon Creek State Park. The creature can be made up, or similar to the creatures that we learned about during our class.

Make sure you:

- Describe your creatures by talking about the body parts

- Explain what each body part does

- Explain how the body part helps them get what they need to live at Tryon Creek State Park.

When you have finished building your creature, we will share what we made as a group.

\section{Prompts:}

Do you remember the three things that an animal needs to survive?

(Food/water, shelter, avoiding predators)

1. What does your creature eat? Where does it get its food?

2. Where does your creature live? Where is its home?

3. Does anything eat your creature? How does your creature stay safe? 


\section{B. Create a Creature Rubric}

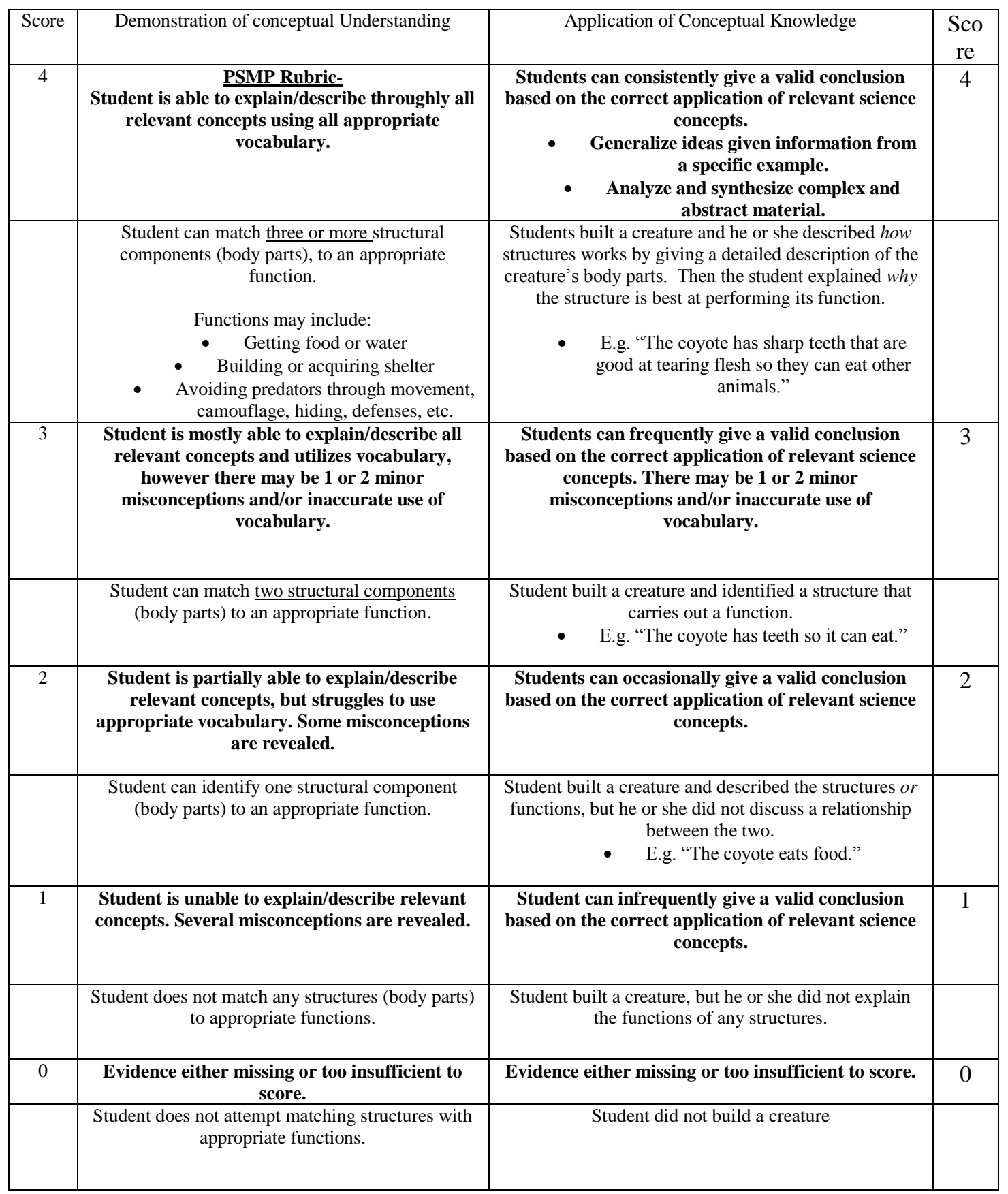




\section{Appendix C. Structured Affective Observation Form}

\begin{tabular}{|c|c|c|}
\hline Date: & & $\begin{array}{l}\text { Class } \\
\text { Topic: }\end{array}$ \\
\hline Treatment Group: & & Observer: \\
\hline Affective Construct & $\begin{array}{l}\text { Behavior } \\
\text { observed during } \\
\text { class }\end{array}$ & Comments \\
\hline $\begin{array}{l}\text { Competence/Self Efficacy-- } \\
\text { Students believe that they have the ability to succeed in STEM } \\
\text { classes and fields. }\end{array}$ & & \\
\hline $\begin{array}{l}\text { Student volunteers to show their project in class. }(+) \\
\text { (Shows that they find value in their project) }\end{array}$ & & \\
\hline $\begin{array}{l}\text { Student expresses worry that they are incapable of some aspect of } \\
\text { class. (-) }\end{array}$ & & \\
\hline $\begin{array}{l}\text { Student does not participate in an activity. (-) } \\
\text { Makes a deliberate choice to refrain from participation. }\end{array}$ & & \\
\hline $\begin{array}{l}\text { Relatedness/Belonging-- } \\
\text { Students feel that "people like them," are welcome, and would be } \\
\text { accepted in the study and professions of STEM. }\end{array}$ & & \\
\hline $\begin{array}{l}\text { Student share life events and stories in class }(+) \\
\text { Student makes a connection between their lives and content. }\end{array}$ & & \\
\hline Student takes time to talk with instructors one on one. $(+)$ & & \\
\hline Student doesn't talk to others during class (-) & & \\
\hline $\begin{array}{l}\text { Engagement- } \\
\text { High quality participation in academic work, including effort (hard } \\
\text { work, exertion, follow-through) and enthusiasm (interest, curiosity) }\end{array}$ & & \\
\hline $\begin{array}{l}\text { Student shows effort during activities. (+) } \\
\text {-Concentrated } \\
\text {-Animated } \\
\text {-Creative }\end{array}$ & & \\
\hline $\begin{array}{l}\text { Student is off-task during the activity-talking, not following } \\
\text { directions, doing something different. (-) }\end{array}$ & & \\
\hline
\end{tabular}




\begin{tabular}{|l|l|l|}
\hline Student asks to do something else. (-) & & \\
\hline Connection To Nature (Nisbet, et al) & & \\
\hline Student tells a story about an experience they had in nature (+) & & \\
\hline Student says they don't like being outside or in nature (-) & & \\
\hline Student notices wildlife outside and shows excitement. (+) & & \\
\hline $\begin{array}{l}\text { Student asks questions about wildlife or plants that they don't } \\
\text { know. (+) }\end{array}$ & & \\
\hline
\end{tabular}




\section{Appendix D. Interview Questions}

Self Efficacy-students believe that they have the ability to succeed in Tryon Trekkers.

1. What would you tell other kids they would learn if they participated in Tryon Trekkers?

2. A. Did you do anything new in Tryon Trekkers that you have never done before? How did you feel about it?

B. If you were to do it now, how would you feel?

3. What was the hardest part of Tryon Trekkers? How did you overcome this challenge?

Belonging/Relatedness- student feels that they are welcome and accepted in Tryon Trekkers. They feel that the program connects to their community or their everyday life.

4. What did you think about having a Nature Name?

5. Did you get along with the other kids in the class? How did you feel about working in groups with other students?

6. Did you feel like a part of Tryon Trekkers? If so, what did the instructors do to make you feel welcome? If not, why?

7. Do you think that what you learned will relate to your life? Can you give an example?

\section{Engagement}

8. What activity was your favorite? Why?

- Outdoor games, circle time, art projects, group activities, "create a creatures"

9. What was your least favorite activity? Why?

\section{Connection to Nature}

10. Do you spend time outside, or in nature at home or with your family?

11. Had you been hiking before our class?

12. What is the most interesting part of nature that you learned about in Tryon Trekkers? 


\section{Appendix E. Tryon Trekkers Spring Term Lesson Plans}

\section{Course Format}

Check in- 10 minutes

Topic Demo- 15 minutes

Outdoor games- 25 minutes

Project- 20 minutes

Total time: 1 hour 10 minutes (3:20pm -4:35pm)

\section{Class 1: Introduction}

\section{Learning Objective: Organisms look different and they do different things.}

a. Make observations of animal bodies. There are many different shapes and sizes of bodies.

b. Recognize similarities and differences of body parts.

c. Ask questions about the uses of animal body parts.

\section{$\underline{\text { Instructional Practices- }}$}

- All students are scientists-We will set the tone of the class by establishing that we are all scientists, and we will be studying the local animals through making observations and going on field trips.

- Establish Expectations-Be very clear about the rules of the course through the circle discussion and class agreement. Establish a class culture by doing nature names and journals.

(10 minutes)

Check In: Name Game

What is your name, and your favorite animal, plus an animal movements

(15 minutes)

Topic Introduction: Structural Riddle Stations

Set up three stations (one instructor per station)

-One hint per station with a group of animal specimens to guess from -Each structural riddle should feature hints for each animal using structural details -Each group should work together to solve the riddle, and then write the answer in their journal 
(25 minutes) Outdoor Games:

Scavenger Hunt about plant structures. Collect nature materials that fill these categories.

-Plants (categories of structures)

-defenses, taller, leaf size, flowers, etc.

(10 minutes) Project: Choose Nature Names \& Decorate Journals

- Photos that students can pick from a group of laminated photos with labels

- Write nature name on Journal and Name tag

Older group- Find nature name in identification books and write down a few facts about your animal.

The importance of Journals:

"Journaling is the routine that stretches and etches all the details a little further into the brain. The sketcher enters a lively image-questioning sequence with the thing observed. Because it fires up the brain's visual imagination, drawing imprints images in the mind's eye library. Journaling whether written or dictated, connects the language parts of the brain to sensory experiences from nature, and both bring each other alive." -Coyote's Guide, Jon Young, pg. 64

Using a Nature Journal:

"Its important to keep a journal regularly. At the top of every page write the date, the season, the time of day, a marker point north, and a note on the weather." -Coyote's Guide, Jon Young, pg. 64

(10-15 min) Rules, Assent, and Expectations

"Have students write the rules. Ask students to contribute ideas for class rules or consequences through classroom discussion. This requires a power-sharing mentality in which you ask yourself, 'how can I expect to keep kids invested in the process if I don't give them a piece of the action?'"

-Engaging Students with Poverty in Mind, Eric Jensen, pg. 76

Reflection: Compare and Contrast Nature Name animals.

For returning students- "Encourage students to become mentors. Mentoring others can provide students with a sense of control over their lives, build dependable relationships, and help both mentors and mentees with academics."

-Engaging Students with Poverty in Mind, Eric Jensen, pg. 77 


\section{Class 2: Local Habitats}

Learning Objective: What do organisms need to survive?

Instructional Practices: sharing circle, reinforce expectations

-Establish sharing circle at the beginning of this class

-Remind students of expectations

Circle time Question: What is something that you have that you couldn't live without? (15 minutes)

Topic Introduction: Survival needs poster

"We are going to talk about what animals need to survive. In order to think about these things, we will break into three groups and think about what different creatures need to survive."

Break the students up into three groups. Each group will be responsible for listing the needs of humans, pets, and wildlife

Older kids: Each group write/draw needs on a poster and present to the rest of the groups.

Younger kids: How are animals the same? They have similar needs- - food, water, shelter/space

(Activity Beauty Basics—Project Wild page 58)

(25 minutes)

Outdoor Game:

Poker Chip Game-Collect what your creature needs to survive.

-Cards with different animals (same as nature name animals)

-Poker chips

(20 minutes)

Project: Build a Clay Creature

(Design an animal that has body parts that help them get food, find shelter, and get water)

(10 minutes)

Reflection: Sharing clay creature. 


\section{Class 3: Field Trip To TRYON CREEK Observation Skills}

Learning Objective: What habitats do we have? What organisms could they support?

Instructional Practices: Form personal relationships with students, all students are scientists, model appropriate responses to challenges

Hiking Question: "Today you are wildlife scientists. We will be hiking and looking for evidence of animals."

Looking for evidence of animals finding food, water, or space/shelter

- Stops and draw/write in the journal

- Finding animals running/camouflaging

With your journals, write down one piece of evidence that you found. Everyone must find one thing each.

Reflection Question:

Have you ever been hiking before?

How did being in the forest make you feel?

\section{Class 4: How to animals eat?}

Learning Objective: Identify structural body parts that help animals eat food.

Instructional practices: consistent expectations, flexible activity schedule, inquiry based

(10 minutes)

Check in:

3-5- What tools do humans use to help them eat?

(spoon, knife, fork, straw, chopsticks, hands, ice cream cone, popsicle stick, bread, etc.)

1-2 -What is your favorite food? Demonstrate how you would eat it.

**Show a bird skull with a unique beak, or multiple.

(15 minutes)

Introduction Stations:

Bird beaks - Fill the bill, or bird skulls with example foods. 
Add worksheet.

(25 minutes)

Outdoor Games:

-Animal Food Scavenger hunt

(20 minutes)

Project:

Engineering design project-Build a bird beak.

Now that you have learned about the different body parts animals use to collect and eat food, we are going to create our own bird beak to test this process. You will become Beak Engineers, and make your own beak design. We will take these beaks to Tryon next week for our field trips, and you will be able to test collecting natural materials along our hike.

\section{3-5:}

1. Begin with a piece of paper. Fold the paper in a way that can fit your hand to open and close a mouth.

2. Use these supplies to attach to your paper beak to help your bird eat food

3. Before you start building your bird beak, sketch it out on a piece of paper, and predict what kind of food your beak is best at collecting. When you are finished, show the design to a teacher, and you will get permission to collect your supplies.

1-2: Modifications

Build the bird beak puppet templates for this age group.

Engineering Design expectations for grades 1-2

Engineering design in the earliest grades introduces students to "problems" as situations that people want to change. They can use tools and materials to solve simple problems, use different representations to convey solutions, and compare different solutions to a problem and determine which is best. Students in all grade levels are not expected to come up with original solutions, although original solutions are always welcome. Emphasis is on thinking through the needs or goals that need to be met, and which solutions best meet those needs and goals.

\section{Class 5: Field Trip \#2}

Learning Objective: Observe wildlife in the native habitat. Observe structures and relate them to functions.

Instructional Practices: Model appropriate behavior to challenges, develop one-on-one relationships with students, place based 
Structure and Function Highlight:

-Focus on woodpecker beaks and how the beak and tongue help it find food in the environment.

Introduction: You are going to practice your wildlife biology skills today by exploring the park to find evidence of woodpeckers. Last week we learned about how bird beaks help certain species of birds get food.

We have three types of woodpeckers that live in Tryon, there are a couple of different ways to see evidence that they are here. Could someone tell me what type of evidence we may be able to find on our hike?

One way that we could observe these creatures is by seeing or hearing the birds.

I want to remind you that we have to be very quiet, and paying attention to what is around us to actually see or hear a woodpecker. We often hear them a lot, but it is going to take some concentration by you guys to really be quiet enough to hear them.

This means no chatting, no loud noises, yelling, or sound effects. Fox walking and deer ears.

Here is an example of three different calls we will be listening for. (Play pilliated, downy, and sap sucker)

Our mission is to find evidence about how woodpeckers use their beak adaptations to find food.

On the trail-use the woodpecker skull, the PVC pipe tool and the pictures to show the mechanism for how wood pecker beaks work. You can do this when the students find a woodpecker snag in the woods.

Reflection question: (connection to nature question)

Now that you have been to Tryon twice, is this a place where you feel comfortable.

Why or why not?

Journal time: Draw yourself here at Tryon. What would you be doing?

\section{Class 6: How do organisms move?}

Learning Objective: Discover what body parts slugs use to help them move. Instructional practice: Inquiry based learning, flexible schedule, correct behavior oneon-one

(10 minutes)

Question of the Day: How do slugs move? 
Composite slug drawing - ask two groups to draw a slug by only contributing one shape to the drawing. Challenge student to draw every detail they know about slugs.

(40 minutes)

Slug observations

1. Bring students outside

2. Give students journal, pencil, plexi-glass, and a slug

3. Allow students to get into pairs.

4. Ask student to draw a slug's body in their journal, write a description of the slug and its behavior.

5. Pause. Instructor should show the different body parts to the participants, and show the body part words on a hand-out. Challenge the students to add labels to their slug diagram.

6. Reflection-Use what you know about how a slug's body moves to predict why slugs have slime

\section{Class 7- Survival}

Learning Objective: How do animals stay alive? Explore defenses, camouflage, and predator avoidance behavior.

Instructional Practice: All students are scientists, flexible schedule, inquiry based

(10 minutes)

Circle time

Question of the Day: How do animals stay safe?

"You are a squirrel engineer. Your job is to design a squirrel that can glide the farthest." Outdoor game and project: Build a flying squirrel

1. Warm kids up with a tag game

2. Sit in a circle and give instructions for the project.

3. Distribute materials

4. Allow participants to build their squirrels

5. Let participants experiment with flight.

6. Q: What makes the squirrels fly the best? How can you change your squirrel's design to fly better?

7. Reflection discussion — why does flying help a squirrel stay safe?

\section{Class 8: Tryon Celebration}

Learning Objective: Structure and Function Assessment 
Instructional Practices: place based, flexible activities, model appropriate responses

Students will break up into groups. They will complete the ACK task, and inform an instructor about their creature.

-Each creature will be photographed.

-Each response will be recorded on a results table by the group leader

Large group reflections:

What was your favorite part of the program?

How do you feel about your nature name?

\section{References}

Young, J., Haas, E., \& McGown, E. (2010). Coyote's Guide to connecting with nature. Santa Cruz,

CA: OWLink Media 8 Shields.

Cornell, J. 1998. Sharing nature with children. DAWN Publications. Nevada City, Nevada. 


\section{Appendix F. Categorized Ethnographic Observations}

These observations were taken from my journal entries during the intervention. The observations in this chart were taken from students from both sample groups. They are collections of observations from those students who I commented the most about.

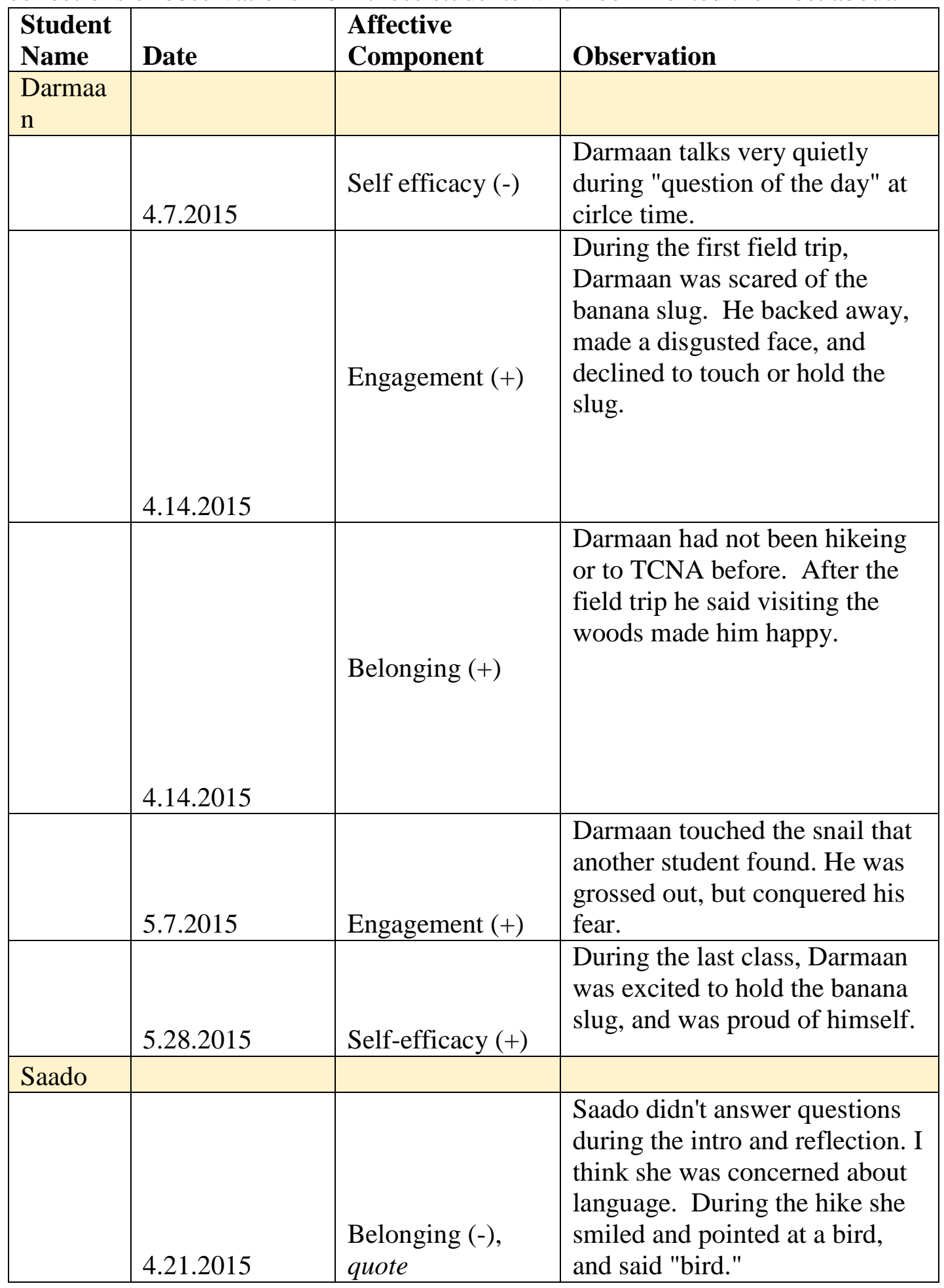




\begin{tabular}{|c|c|c|c|}
\hline & & Engagement (+) & $\begin{array}{l}\text { Even though Saado didn't } \\
\text { contribute verbally to the group, } \\
\text { she followed directions and } \\
\text { listened to me when I talked. }\end{array}$ \\
\hline & $4.28,2015$ & Belonging (+) & $\begin{array}{l}\text { Saado raised her hand to give } \\
\text { an answer during the "Question } \\
\text { of the day" in our circle time } \\
\text { discussion. }\end{array}$ \\
\hline & 5.5.2015 & Belonging (+) & $\begin{array}{l}\text { Saado started talking to me one } \\
\text { on one. She said sentences with } \\
3-4 \text { words each where } \\
\text { previously she had only said } 1-2 \\
\text { words at a time. }\end{array}$ \\
\hline & & Engagement $(+)$ & $\begin{array}{l}\text { Saado saw a woodpecker, } \\
\text { stopped and observed for over } 5 \\
\text { minutes. }\end{array}$ \\
\hline \multicolumn{4}{|l|}{ Hayden } \\
\hline & 4.7.2015 & Engagement (-) & $\begin{array}{l}\text { Hayden threw a worm at } \\
\text { another participant. }\end{array}$ \\
\hline & 4.14 .2015 & Self-efficacy (-) & $\begin{array}{l}\text { Hayden does not participate in } \\
\text { an activity. He wandered away } \\
\text { from the group. When } \\
\text { redirected back to join his group } \\
\text { he appeared agitated and was } \\
\text { resistant to interact with his } \\
\text { peers. }\end{array}$ \\
\hline & 4.28.2015 & Engagement (+) & $\begin{array}{l}\text { Hayden was fascinated with the } \\
\text { skull molds we brought to class. }\end{array}$ \\
\hline & 4.28 .2015 & Engagement (-) & $\begin{array}{l}\text { Hayden showed distress when } \\
\text { he didn't get the group he } \\
\text { wanted. }\end{array}$ \\
\hline & 5.5.2015 & $\begin{array}{l}\text { Belonging (-), } \\
\text { Engagement (-) }\end{array}$ & $\begin{array}{l}\text { Hayden had trouble focusing } \\
\text { with the group and had to be } \\
\text { asked multiple times by the } \\
\text { instructor to stay on the trail } \\
\text { and interact with natural } \\
\text { material safely. }\end{array}$ \\
\hline \multicolumn{4}{|l|}{ Anya } \\
\hline & 4.14.2015 & Self-efficacy (-) & $\begin{array}{l}\text { Anya was concerned when I } \\
\text { was taking notes in class. She } \\
\text { asked Lori what I was doing. }\end{array}$ \\
\hline & 4.21.2015 & Self-efficacy (-) & $\begin{array}{l}\text { On the bus, Anya told me that } \\
\text { she had dyslexia. }\end{array}$ \\
\hline
\end{tabular}




\begin{tabular}{|c|c|c|c|}
\hline & 4.30 .2015 & Belonging (+) & $\begin{array}{l}\text { Anya took time each class to } \\
\text { talk to me one on one. During } \\
\text { the bus ride she talked about } \\
\text { school and how she got in } \\
\text { trouble with her teacher. She } \\
\text { told me she got "demerits" from } \\
\text { her teacher for laughing during } \\
\text { a group activity. She often tells } \\
\text { me her teacher is mean. }\end{array}$ \\
\hline & 4.3.2015 & $\begin{array}{l}\text { Belonging (+), } \\
\text { Self-efficacy (-) }\end{array}$ & $\begin{array}{l}\text { She liked that there were no } \\
\text { teachers present during the field } \\
\text { trip }\end{array}$ \\
\hline & 5.5.2015 & Self-efficacy (-) & $\begin{array}{l}\text { Anya and I talked on the bus. } \\
\text { She said she was in the "dumb } \\
\text { group" for math and she said it } \\
\text { made her feel bad about herself, } \\
\text { but that being in the group } \\
\text { sometimes helped her } \\
\text { understand math better. She } \\
\text { talked more about her dislexia } \\
\text { and explained that she didn't do } \\
\text { well in school because of her } \\
\text { disability. She said she } \\
\text { especially didn't like reading } \\
\text { and language arts because she } \\
\text { got letters mixed up. }\end{array}$ \\
\hline & 5.5.2015 & Belonging (+) & $\begin{array}{l}\text { Anya was adopted from an } \\
\text { Eastern European country } \\
\text { (Bulgaria) when she was five } \\
\text { years old. }\end{array}$ \\
\hline & 5.26 .2015 & Belonging (+) & $\begin{array}{l}\text { Anya gave us (all the } \\
\text { instructors) hugs and said she } \\
\text { would miss us. }\end{array}$ \\
\hline \multicolumn{4}{|l|}{ Ella } \\
\hline & 4.14.2015 & Self-efficacy $(+)$ & $\begin{array}{l}\text { When I was sitting nearby } \\
\text { making observations, Ella didn't } \\
\text { volunteer to share. Usually Ella } \\
\text { is eager to share }\end{array}$ \\
\hline & 4.21 .2015 & Engagement (+) & $\begin{array}{l}\text { Took time to make observations } \\
\text { along the trail }\end{array}$ \\
\hline & 4.21 .2015 & Relatedness (+) & $\begin{array}{l}\text { Ella told stories about her } \\
\text { family taking hikes in the } \\
\text { woods during the field trip }\end{array}$ \\
\hline
\end{tabular}




\begin{tabular}{|c|c|c|c|}
\hline & & Engagement (+) & $\begin{array}{l}\text { At the end of the field trip Ella } \\
\text { told me that she didn't want to } \\
\text { leave, and she wished we had } \\
\text { more time to spend at Tryon. }\end{array}$ \\
\hline & & quote & $\begin{array}{l}\text { "I felt excited and happy at } \\
\text { Tryon" }\end{array}$ \\
\hline & 4.28 .2015 & Relatedness (+) & $\begin{array}{l}\text { Ella told a story about her own } \\
\text { life related to the topic of } \\
\text { animals during circle time. } \\
\text { "The great horned owl is my } \\
\text { favorite bird." }\end{array}$ \\
\hline & 5.5.2015 & $\begin{array}{l}\text { Connection to } \\
\text { nature }(+)\end{array}$ & $\begin{array}{l}\text { The group saw a dead mole } \\
\text { along the trail. She expressed } \\
\text { concern for the animal by } \\
\text { asking what had happened to it, } \\
\text { and giving an "aweee". }\end{array}$ \\
\hline \multicolumn{4}{|l|}{ Hazzar } \\
\hline & 4.7 .2015 & Belonging (+) & $\begin{array}{l}\text { Hazzar was eager to give } \\
\text { answers to questions during } \\
\text { circle time. He had to be } \\
\text { instructed to let others } \\
\text { volunteer. }\end{array}$ \\
\hline & 4.16 .2015 & Engagement (-) & $\begin{array}{l}\text { Attention span is } 4: 00 \mathrm{pm}(45 \\
\text { minutes) }\end{array}$ \\
\hline & 4.30 .2015 & Engagement (-) & $\begin{array}{l}\text { Hazzar was distracted by other } \\
\text { students. }\end{array}$ \\
\hline & 4.30 .2015 & Engagement (-) & $\begin{array}{l}\text { Hazzar had trouble following } \\
\text { directions and had a short } \\
\text { attention span. He got three } \\
\text { strikes from the teacher and } \\
\text { intentionally disregarded } \\
\text { instructions. }\end{array}$ \\
\hline & 5.14.2015 & Engagement (-) & $\begin{array}{l}\text { Hazzar had trouble completing } \\
\text { the interview. His body was } \\
\text { moving a lot, and he often } \\
\text { didn't listen to the question, or } \\
\text { didn't understand the question. } \\
\text { He was eager to talk. }\end{array}$ \\
\hline & 5.28 .2015 & Belonging (+) & $\begin{array}{l}\text { Hazzar was talking on the bus } \\
\text { in arabic with other students, } \\
\text { and taught me some words. }\end{array}$ \\
\hline Arm & & & \\
\hline
\end{tabular}




\begin{tabular}{|c|c|c|c|}
\hline & 4.16.2015 & Belonging (+) & $\begin{array}{l}\text { During circle time, Arman } \\
\text { described another context wher } \\
\text { he learned about animals. "I } \\
\text { was in a play and I was a } \\
\text { raven." }\end{array}$ \\
\hline & 4.16.2015 & Belonging (+) & $\begin{array}{l}\text { During dinner time, Arman told } \\
\text { me about his family. He was } \\
\text { excited because it was his } \\
\text { birthday and his sister was } \\
\text { going to take him and buy him } \\
\text { some red shoes. }\end{array}$ \\
\hline & 4.30.2015 & & $\begin{array}{l}\text { Arman family is from northern } \\
\text { Iraq, and he said he was } \\
\text { Kurdish. }\end{array}$ \\
\hline \multicolumn{4}{|l|}{ Hani } \\
\hline & 4.16 .2015 & Engagement (-) & "What time is it?" \\
\hline & 4.30.2015 & Self-efficacy (-) & $\begin{array}{l}\text { Hani initially said "no" to each } \\
\text { activity that was presented: } \\
\text { circle time, food, game, journal, } \\
\text { and project. Her saying no } \\
\text { encouraged other kids to } \\
\text { protest, but the others } \\
\text { volunteered to participate after } \\
\text { demonstrations and prompting. }\end{array}$ \\
\hline & 4.30.2015 & Engagement (-) & $\begin{array}{l}\text { Hani didn't like to play the } \\
\text { game. She went to both } \\
\text { teachers to complain about not } \\
\text { feeling well. Each teacher } \\
\text { prompted her to try again. On } \\
\text { the third attempt to join the } \\
\text { game she laid down on the } \\
\text { ground. Each time her } \\
\text { comments got more intense and } \\
\text { voice increased in volume. "I } \\
\text { am bored, I don't want to do } \\
\text { this." }\end{array}$ \\
\hline & 5.7 .2015 & Self-efficacy (-) & $\begin{array}{l}\text { Hani complaining showed lack } \\
\text { of coping skills when she had to } \\
\text { do something she didn't want. } \\
\text { During this field trip she was } \\
\text { verbal about not wanting to be } \\
\text { there multiple times. When I } \\
\text { asked her what she needed, she } \\
\text { said she just wanted to go }\end{array}$ \\
\hline
\end{tabular}




\begin{tabular}{|c|c|c|c|}
\hline & & & $\begin{array}{l}\text { home. I suspected that she was } \\
\text { hungry and tired. }\end{array}$ \\
\hline & 5.7.2015 & Engagement $(+)$ & $\begin{array}{l}\text { Hani was verbal about refusing } \\
\text { to participate during the hike, } \\
\text { but she was intermittently } \\
\text { engaged by the environment. } \\
\text { She found a snail and showed } \\
\text { the rest of the students what she } \\
\text { had found. }\end{array}$ \\
\hline & 5.7 .2015 & Belonging (-) & $\begin{array}{l}\text { Hani asked multiple times to be } \\
\text { in the other group. }\end{array}$ \\
\hline & 5.7.2015 & Engagement (-) & $\begin{array}{l}\text { When Hani refused to } \\
\text { participate in activities, and she } \\
\text { was given consequences she } \\
\text { said "yay" and seemed happy to } \\
\text { be separated from the group. } \\
\text { She continued to be disruptive } \\
\text { once she was removed from the } \\
\text { group. }\end{array}$ \\
\hline \multicolumn{4}{|l|}{ Avery } \\
\hline & 4.21.2015 FT & Engagement (-) & $\begin{array}{l}\text { Avery gave negative verbal } \\
\text { feedback during the field trip. } \\
\text { She said she was bored because } \\
\text { she had been to Tryon before. }\end{array}$ \\
\hline & 4.21 .2015 & quote & $\begin{array}{l}\text { "I felt calm, not really excited, } \\
\text { annoyed because everyone is } \\
\text { making a big fuss about Tryon." }\end{array}$ \\
\hline & 4.7.2015 & Engagement $(+)$ & $\begin{array}{l}\text { Avery spent a lot of time } \\
\text { talking with me, Instructor } 2 \text {, } \\
\text { and volunteer, telling us about } \\
\text { her life. }\end{array}$ \\
\hline & 4.30 .2015 & Relatedness (-) & $\begin{array}{l}\text { Avery came into class } \\
\text { concerned that another student } \\
\text { was spreading gossip about her. } \\
\text { She approached both Lori and I } \\
\text { separately about the issue. }\end{array}$ \\
\hline
\end{tabular}




\begin{tabular}{|c|c|c|c|}
\hline & 4.30 .2015 & Relatedness (-) & $\begin{array}{l}\text { During class Avery took tools } \\
\text { out of other children's' hands } \\
\text { while they were using them. }\end{array}$ \\
\hline & 4.30 .2015 & Relatedness (-) & $\begin{array}{l}\text { She gave negative feedback } \\
\text { when she did not get her way } \\
\text { during class. }\end{array}$ \\
\hline & 5.5.2015 & Engagement (-) & $\begin{array}{l}\text { Avery talked about how Tryon } \\
\text { wasn't as good as Alaska. She } \\
\text { talked about visiting her } \\
\text { grandparents on a float plane in } \\
\text { Alaska, and about how the } \\
\text { forest is more beautiful there. }\end{array}$ \\
\hline & 5.26 .2015 & Belonging (-) & $\begin{array}{l}\text { Avery sat by herself on the bus } \\
\text { and did not talk to anyone. }\end{array}$ \\
\hline \multicolumn{4}{|l|}{ Viviane } \\
\hline & 4.21 .2015 & Engagement (-) & $\begin{array}{l}\text { Viviane seemed low energy at } \\
\text { the beginning of the hike, she } \\
\text { did not contribute to intro } \\
\text { discussion. She showed more } \\
\text { enthusiasm during the walk and } \\
\text { during the reflection }\end{array}$ \\
\hline & 4.21 .2015 & quote & $\begin{array}{l}\text { "I have never been camping } \\
\text { before, or in the woods for a } \\
\text { long time, except last time } \\
\text { during Tryon Trekkers. I felt } \\
\text { calm walking, but I felt grossed } \\
\text { out when I looked at the bird } \\
\text { poop." }\end{array}$ \\
\hline & 5.5.2015 & $\begin{array}{l}\text { Belonging }(+), \\
\text { Engagement }(+)\end{array}$ & $\begin{array}{l}\text { The girls were running ahead } \\
\text { along the trail during the second } \\
\text { field trip. They were skipping, } \\
\text { jumping, and smiling. This } \\
\text { indicates that they felt happy } \\
\text { and more comfortable in the } \\
\text { forest than the previous field } \\
\text { trip. }\end{array}$ \\
\hline & 5.5.2015 & woodpecker quote & $\begin{array}{l}\text { "Is this real right now? Am I in } \\
\text { a dream?" }\end{array}$ \\
\hline
\end{tabular}




\begin{tabular}{|l|l|l|} 
& $\begin{array}{l}\text { The students were mesmerized } \\
\text { by the woodpecker. They } \\
\text { stood, speechless with attention } \\
\text { and curiosity as they watched. } \\
\text { They quietly crept closer, } \\
\text { within } 8 \text { feet of the bird, as it } \\
\text { continued to hammer away at } \\
\text { its hole on the tree. }\end{array}$ \\
\hline $\begin{array}{l}\text { Woodpecker } \\
\text { experience }\end{array}$ &
\end{tabular}




\section{Appendix G. IRB Application}

\section{IRB APPLICATION for EXPEDITED / FULL REVIEW}

IMPORTANT: PSU faculty and students must submit any research plan involving Human Subjects to the IRB for review. Use this application to request Expedited or Full review human subjects' research approval. If you believe the activities are Exempt, you may use the IRB Exempt Application. If you believe the activities do not meet the definition of "human subjects research" complete the Review Not Required Form and submit to hsrrc@pdx.edu. See Instructions page of this application for more details.

Hard-copy submissions will not be accepted. Please submit electronically.

*All questions must be answered. Please enter N/A for questions that do not apply.*

\section{Section I: Investigator's Assurance}

$\bigotimes$ This is a new protocol submission

$\square$ This is a revised initial review protocol submission with requested modifications

$\square$ This is an amendment submission

Indicate which Sections are revised: (Check each applicable section and include all protocol revisions in red text or use track changes - see Instructions on Pg. 3)

$\square$ Section I $\square$ Section II (indicate which parts: A-T): $\square$ Section III (indicate changed attachments/addendums):

Principal Investigator (or faculty advisor for students): Chessa Eckels Anderson EMail: chessa@pdx.edu

Co-Principal Investigator: $\quad$ E-Mail:

Other Personnel (GA, Project Mgr., etc.): Melissa Potter E-Mail: mepotter@pdx.edu Department: Center for Science Education Campus Mail Code: CSE Preferred Phone \#: 503-329-9686

Title of Protocol: How does an outdoor and STEM based afterschool program impact at-risk students' motivational resilience and ability to apply conceptual knowledge of environmental science topics. Mailing Address:

Proposed Duration of Project (months/years): March 2016 Anticipated Start Date: March 2015

Is this project funded?

$\square$ Yes $\square$ Not yet (Application has been submitted) $\bigotimes$ No

Type of Funding: $\square$ Federal $\square$ Federal pass-through $\square$ State $\square$

Foundation $\bigotimes$

Funding Agency: $\quad$ PIAF \#: 
STUDENTS ONLY:

\ Master's Thesis $\square$ PhD/EdD Dissertation (Approval Date: ） $\square$ Other:

Under advisement from the above faculty member, I verify that I will conduct this research in accordance with PSU's Human Subjects Research Review Policy.

Student Name: Chessa Eckels Anderson(type in your name and email electronic copy to your PSU mentor)

PSU Student ID \#: 944206155 Email: chessa @pdx.edu Date: 1/26/2015

Investigator's Responsibilities and Assurances:

(Mark each box with an ख when understood/agreed/certified)

I understand PSU's policies concerning research involving human subjects and:

1. $\bigotimes$ I understand that I have ultimate responsibility for the protections of the rights and welfare of human participants, the conduct of this study, and the ethical performance of this research.

2. $\bigotimes$ I will maintain IRB related documents (including signed consent forms, as applicable) for a minimum of three years after the completion of the study.

3. $\bigotimes$ I understand that it is my responsibility to ensure that all study personnel receive the mandatory human subjects' research protection education (either CITI or NIH) and to maintain a training documentation file.

\section{I agree to:}

4. $\bigotimes$ Comply with all PSU/IRB policies, decisions, conditions and requirements.

5. $\bigotimes$ Obtain prior approval from the IRB before amending or altering the research protocol or changing the approved consent/assent form.

6. $\bigotimes$ Notify the Office of Research Integrity of the development of any financial interest not already disclosed.

7. $\bigotimes$ Notify the Office of Research Integrity for all adverse events and unanticipated problems as soon as possible. In case of DHHS supported activities, I will also report these problems to the Department of Health and Human Services (through the respective granting office).

\section{I certify that:}

8. $\bigotimes$ The time and resources are available to complete this project.

9. $\triangle$ The equipment, facilities, and procedures to be used in this research meet recognized standards for safety.

10. $\bigotimes$ New information that may affect the risk-benefit assessment for this research will be reported to the Office of Research Integrity.

11. $\bigotimes$ I agree to ensure adequate supervision of all research study personnel and to meet with the investigator(s), if different then myself, on a regular basis to monitor progress.

12. $\bigotimes$ The information provided in this application and all attachments is complete and correct. 
Signature of Principal Investigator or Faculty Advisor: Chessa Eckels Anderson Date: $1 / 26 / 201$

(Type in name and submit by email to hsrrc@pdx.edu ) 
Section II: Project Narrative (complete sections below)

\section{A. Research Description:}

1. Explain why, what, how, who and when.

i. Why: (i.e., describe specific study aims, research questions to be studied, study goals and a brief description of the scientific background.)

This study aims to explore the relationship between the affective components of learning and the ability to understand and apply concepts during a science based afterschool intervention. The goal of the study is to develop a framework for outdoor education afterschool programming for at-risk youth. The researcher will also produce a curriculum that can be used by other after school programs in the future.

The research question I will be asking is: how does an outdoor and STEM based afterschool program impact at-risk students' motivational resilience and ability to apply conceptual knowledge of environmental science topics.

ii. The scientific background behind this study can be supported by the Portland STEM Partnership's common measurement systems as outlined by Sexton et. al. (2013). In addition, Risk and Resiliency theory (Forrest-Bank, S., et al. 2014) will be the foundation for supporting at risk students.

iii. What \& How: (i.e., describe what the researchers and the participants will be doing and how these activities will be accomplished.) The researchers will be developing and facilitating the afterschool curriculum based on STEM education and Risk and Resiliency Theory developed by the researcher. These activities will include active games, exploratory hands on activities, and art projects. Activities will be taught both indoors and outdoors at Mitchell elementary school. The program will visit Tryon Creek State Park two times. There will be two sections of the program, one on Tuesday, and one on Thursday.

iv. The participants will participate in the activities outlined by the curriculum developed by the researcher. The activities involved in the intervention will be: hands-on life science activities, outdoor games, and nature themed art projects. Many of these activites will ask students to observe and describe the natural environment through kinetic experience, storytelling, and dramatic play. They will attend the program one day a week for seven weeks between 3:15 pm and 4:40 pm.

V.

vi. Who: (i.e., describe who the participants are and how they will be identified.) The participants are students ages 6-11 (grades 1-5) at 
Mitchell Elementary School in Portland, Oregon. Each participant voluntarily chooses classes to enroll in the afterschool program. Those families that qualify for free and reduced lunch receive free admission to the program by Neighborhood House as part of the SUN afterschool program. Students are assigned afterschool classes by the SUN program coordinator based on interest, and class availability. Participants in this study will be those that enroll in the Animal Adventures class, and that provide consent and assent to participate in the study. The researcher will not know which participant have or have not given consent, and all participants will participate in the same intervention.

vii. When: (i.e., describe the order of research activities in a timeline.) The afterschool program will begin April $6^{\text {th }}$ and last seven weeks. Each group will attend afterschool program one day a week. The research portion of the program (observation, and data collections) will not begin until the IRB application has been approved. Assent (from students), and consent (from parents) will be distributed (sent home with students) and collected by instructors not involved in research as soon as the IRB application has been approved. This is estimated to occur during the third week of April. Once assent and consent has been collected the reseracher will begin to collect observations, as well as assess student projects using the Application of Conceptual Knowledge Rubric.

\section{B. Study Design \& Setting}

1. Describe the study design: The study design is a program evaluative case study.

2. Identify the sites or locations where the research/data analysis will be conducted: Tryon Creek State Park, Mitchell Elementary School

3. Describe the Principal Investigator's experience conducting research at study site(s) (or similar sites) and familiarity with populations and communities: The researcher conducted a pilot program at Mitchell Elementary school for ten weeks previous to the intervention program. Through this pilot program, the researcher became familiarized with Mitchell students and their parents, the SUN Afterschool coordinator, and the school grounds. In addition, the research was employed by two SUN afterschool programs at different schools.

4. Is the research conducted outside the United States? $\square$ Yes $\square$ No

a. If yes, describe site-specific regulations or customs affecting the research, local scientific and ethical review structure:

5. Are there any permissions that have been, or will be, obtained from cooperating institutions, community leaders, or individuals, including approval of an IRB or research ethics committee? $\square$ Yes $\square$ No 
a. If yes, provide a list of the permissions (also include copies with the application, if available):

6. Does the research require approval from other PSU compliance committees?

(e.g., Radiation Safety Committee (RSC), Institutional Animal Care and Use Committee (IACUC), and Institutional Biosafety Committee (IBC), etc.) Yes $\bigotimes$ No

If yes, the PI is responsible for seeking approval from the other committees required for this research. Work cannot start until final approval is received from all appropriate committees. List each compliance committee review required:

7. Provide an approximate number of subjects to be enrolled and justify the sample size: 30 students. There will be two classes that will participate in the afterschool program. This sample size accomodates requirements for class size set forth by Mitchell Elementary SUN program, and the Friends of Tryon Creek education coordinator. Classes may be no larger than 15 students in order to accommodate transportation of the participants to and from Tryon Creek State Natural Area.

(Provide information for each subject group, as defined in the sections 8A and 8B below. For example, minors' \#, crime victims' \#s, etc.):

8. Approximate total number of subjects to be recruited: 30 students

a. Please identify subjects that will be recruited by checking all that apply in $8 \mathrm{~A}$ and $8 \mathrm{~B}$. Submit additional materials as required.

A. Children or Adult: Check all that apply

\begin{tabular}{|l|l|}
\hline \multicolumn{1}{|c|}{ Age } & Consent/Permission /Assent Required \\
\hline$\square$ Birth to 3 years & Parental Permission Form \\
\hline$\square 4-7$ years & $\begin{array}{l}\text { Parental Permission Form and Verbal } \\
\text { Child's Assent }\end{array}$ \\
\hline$\square 8-17$ years & $\begin{array}{l}\text { Parental Permission Form and Child's } \\
\text { Written Assent }\end{array}$ \\
\hline$\square 18$ \& over & Written Consent \\
\hline
\end{tabular}

B. Potentially Vulnerable Populations: If potentially vulnerable populations will be recruited, identify these groups by checking below.

Neonates/Fetuses

$\bigotimes$ Children (Complete Addendum 4 and include in application.)

$\square$ Prisoners (Complete Addendum 5 and include in application. If using prisoner data sets collected for other than research purposes complete Addendum 5a and include in application.)

$\square$ Pregnant women

Decisionally impaired (for groups not already identified on this list)

HIV/AIDS patients 


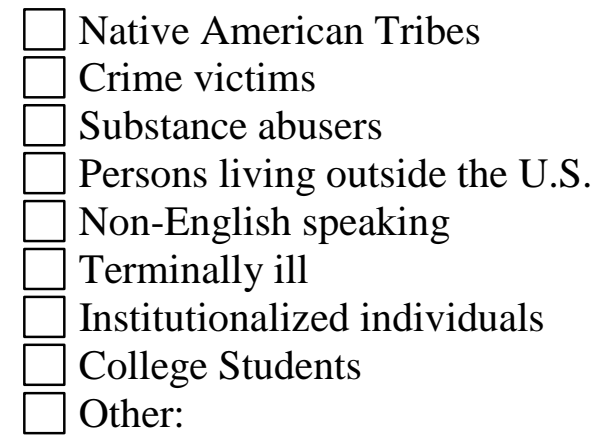

9. Are there groups of people purposefully being excluded? $\square$ Yes $\square$ No

A. If yes, identify the groups that are being excluded [Check all that apply in 9A and explain the reasons for exclusion in 9B below]:

$\begin{array}{ll}\square \text { Ethnic/racial groups } & \square \text { Non-English speaking } \\ \square \text { Adults 65 or older } & \square \text { Sexual orientation } \\ \square \text { Children (under 18) } & \square \text { Marital status } \\ \square \text { Pregnant women } & \square \text { Religion } \\ \square \text { Males } & \square \text { Other: } \\ \square \text { Females } & \end{array}$

B. Explain the reasons for the exclusion criteria identified in \#9A:

10. Describe safeguards to protect the rights and welfare of vulnerable populations: All data collected within this study will be done under the normal educational experience provided to all students. All data will be coded to a master list in a manner that prevents the reseracher, the teacher, from knowing which participant provides consent and/or assent to the study. The students' experience in the program will be the same regardless of their consent and/or assent to the study.

Participants' legal gardians will be sent a consent form in the mail at least two weeks before the participant begins the program. Consent forms will be sent in three languages (Somali, Spanish, and English).Participant assent will be collected on the first day of programming by a program teacher that is not the researcher. The teacher will collect verbal assent from participants under the age of 7 , and written assent, in language understandable by participants ages 7-11.

(See Additional Requirements for Research with Vulnerable Populations for guidance regarding children, prisoners and participants who become incarcerated after enrolling. Contact ORI for guidance regarding human fetuses and neonates.)

\section{Data Collection Methods}


Check all method(s) to be used (Include copies of all the data collection methods checked in Survey/Questionnaire or Interview sections below, including translations, if applicable.):

1. $\bigotimes$ Survey/Questionnaire - Identify modality(ies)

$\bigotimes$ In person $\square$ Web-based $\square$ E-mail $\square$ Postal mail

Telephone

$\square$ Other:

2. $\bigotimes$ Interview - Identify modality(ies)

$\bigotimes$ One-on-one $\square$ Focus group $\square$ Oral history $\square$ Other:

3. $\bigotimes$ Observation of Public Behavior - Identify modality(ies)

$\triangle$ Classroom $\square$ Public meetings $\square$ Other:

4. $\square$ Examination of Archived Data/Secondary or Records

Briefly describe the records to be examined:

5. $\square$ Taste Evaluation

$\square$ Wine/alcohol $\quad \square$ *Non-wholesome food $\quad \square$ Genetically altered food

*Wholesome food may meet Category 6 exemption. Fill out Exempt form.

6. $\square$ Examination of Human Pathological or Diagnostic Tissue Specimens (e.g., blood, bodily fluids)

7. $\square$ Unproven or Untested Procedures

$\square$ Biomedical $\square$ Psychological $\square$ Other:

If any checked, describe:

8. $\square$ Recordings - Identify type(s)

$\square$ Voice $\square$ Video $\square$ Photograph/Image

$\begin{array}{lll}\text { Check Method of recording: } & \square \text { Analog } & \square \text { Digital } \\ \text { Check the purpose of the recordings: } & \square \text { For transcription } \\ \square \text { Other }\end{array}$

If checked 'Other' explain: (For example, recorded for speech pattern analysis, archiving purposes, presentation at the meetings, etc.)

9. $\square$ Internet:

10. $\square$ Social Media:

11. $\square$ Other:

\section{Recruitment Methods}

Does the study involve the recruitment of participants? $\square$ Yes $\square$ No 
If no, skip to Section $E$.

1. Describe recruitment/advertising methods:

Check all that apply and attach all recruitment materials that will be used:

$\begin{array}{ll}\square \text { Person to person } & \square \text { Media (TV, newspaper, radio, Web site) } \\ \square \text { Phone } & \square \text { Social Media } \\ \square \text { Postal mail } & \square \text { Other: } \\ \square \text { E-mail } & \end{array}$

2. How will potential subjects be identified and how will potential subjects be approached to participate? (Answer for each subject group)

Explain in detail: Potential subjects will choose to attend the course based on a short description of the program that is featured within the Mitchell Elementary SUN School Spring Term Activity Guide. This activity guide is sent home with all students with the application form for the afterschool program.

3. Who will obtain consent/assent and when will that be done? (Answer for each subject group)

Explain in detail: Consent will be obtained after IRB has given approval for research. The researcher will distribute the consent forms to the participants' parents/gaurdians by giving forms to participants to take home. The consent form is attached in Appendix A. The wording of the consent form may change slightly before the final mailing to participants. The consent forms will be collected from participants by the SUN program coordinator, or by a program teacher not involved in the research (These third parties will mearly collect consent and assent forms. They will not be involved in data collection, coding, or data analysis) and submitted to research faculty advisors to be coded to de-identify program participants for the researcher. Assent will be collected from students during programming after receiving IRB approval by a program teacher not involved in research. Assent will be collected verbally from participants under the age of 7, and it will be collected in written form from participants ages 7-11 in language appropriate for understanding.

4. What screening procedures or tools will be used? (Answer for each subject group)

Explain in detail: In this study, the researcher will use the Student 
Affective Obser vation Checklist, Interview Questions, developed by the researcher and the Application of Conceptual Knowledge task developed by the Portland Metro STEM Partnership common measurement initiative. These instruments (and rationale behind these instruments) are included in Appendix D. In addition to the Application of Conceptual Knowledge task, the framework for developing Application of Conceptual Knowledge tasks and rubrics is also provided in Appendix D. The observational checklist instrument may be modified by adding applicable questions, changing the wording of questions to be appropriate for participant understanding, or subtracting irrelevent questions. These changes will be submitted to the IRB via an amendment to the current IRB application.

\section{E. Consent Process}

Choose all that apply and attach appropriate forms to this application. (See Informed Consent or Waiver of Consent Checklists for guidance.)

1. $\square$ Adult(s) $\quad$ Children $\quad$ Parent(s) $\quad$ Guardian(s)/legally authorized representatives

\begin{tabular}{|c|c|}
\hline$\bigotimes$ Written & $\begin{array}{l}\text { A consent, assent, or permission form that contains all of the } \\
\text { required elements of informed consent. }\end{array}$ \\
\hline $\begin{array}{l}\square \text { Alteration of } \\
\text { Informed } \\
\text { Consent/Assent } \\
\text { process }\end{array}$ & $\begin{array}{l}\text { Requesting IRB approval for waiver of some or all of the } \\
\text { elements of informed consent, assent, or permission (i.e. medical } \\
\text { record review, deception research, or collection of biological } \\
\text { specimens). } \\
\text { If checked, complete Addendum } 1 \text { and submit with the } \\
\text { application. }\end{array}$ \\
\hline $\begin{array}{l}\square \text { Waiver of } \\
\text { Documentation of } \\
\text { Informed } \\
\text { Consent/Assent }\end{array}$ & $\begin{array}{l}\text { Requesting IRB approval for waiver of the requirement for } \\
\text { documentation of informed consent, assent, or permission (i.e. } \\
\text { telephone survey or mailed survey, internet research, or certain } \\
\text { international research). } \\
\text { If checked, complete Addendum } 2 \text { and submit with the } \\
\text { application. }\end{array}$ \\
\hline $\begin{array}{l}\square \text { Waiver of Informed } \\
\text { Consent/Assent } \\
\text { Process }\end{array}$ & $\begin{array}{l}\text { Requesting IRB approval for waiver of the requirement for the } \\
\text { informed consent, assent, or permission process (i.e. medical } \\
\text { record review, deception research, or collection of biological } \\
\text { specimens). } \\
\text { If checked, complete Addendum } \mathbf{3} \text { and submit with the } \\
\text { application. }\end{array}$ \\
\hline
\end{tabular}

2. What steps have been taken to prevent potential coercion or undue influence in recruiting subjects and obtaining consent or assent? (For example, if the project involves students of the PI or a product developer who will be testing the product, a neutral third party must be engaged in these processes.) Explain in detail: A 
neutral third party will collect consent and assent for the program. All students enrolled in the program will participate in the pogramming regardless of completion of assent or consent. The researcher and facilitator or programming will not know which students have given consent and assent for research.

\section{F. Study Procedures}

1. Describe any study procedures that have not been described elsewhere: The curriculum will be developed by the researcher using a number of theoretical philosophies: Risk and Resiliency Theory, Environmental Education philosophy, and teaching strategies that are effective for students low socioeconomic status outlined by Eric Jensen. These sources will be used to develop a curriculum that supports a new intervention strategies. The curriculum incorporate topics in native animals as well as structure and function of animal adaptations.

2. Does the study involve the collection of data/specimens (including the use of existing data/specimens)? xYES No

a. If yes, indicate how, when, where and from whom specimens or data will be obtained and what data or specimens will be collected:

3. Is there a data and safety monitoring plan (required for greater than minimal risk studies)? $\square$ Yes $\square$ No

a. If yes, describe the plan:

4. Are there any anticipated circumstances under which participants will be withdrawn from the research without their consent? $\square$ Yes $\square$ No

a. If yes, describe the circumstances, as well as any associated procedures to ensure orderly termination: If the student does not follow rules of Mitchell Elementary school or the Mitchell SUN Program rules, the students may be removed from the program by the SUN Program coordinator and thus be removed from the study.

\section{G. Risks/Benefits}

1. Potential risks to participants (check all that apply):

$\square$ Invasion of privacy to the subject or family

$\bigotimes$ Breach of confidentiality

Physical harm or discomfort

$\square$ Psychological/emotional discomfort or distress

$\square$ Psychological effect that is more than discomfort or distress

$\square$ Social stigmatization

$\square$ Economic (e.g., employment, insurability)

Legal

Any study related activity which subjects might consider sensitive, 
offensive, threatening, or degrading?

$\square$ Withholding standard care and procedures

$\square$ Significant time or inconvenience

$\square$ Other:

2. Does the study pose risk to individuals other than the participants?

Explain in detail: There is no risk to individuals other than the participants.

3. Indicate the risk category that most accurately describes the risk level for the risks identified in Section G, questions $1 \& 2$ above:

$\bigotimes$ Not greater than minimal risk ${ }^{1}$

$\square$ Greater than minimal risk, but presenting the prospect of direct benefit to individual subjects

$\square$ Greater than minimal risk, no prospect of direct benefit to individual subjects, but likely to yield generalizable knowledge about the subject's disorder or condition

$\square$ Research not otherwise approvable which presents an opportunity to understand, prevent, or alleviate a serious problem affecting the health or welfare of subjects

4. How will these potential risks be minimized in order to protect subjects' rights and welfare? (See Additional Requirements for Research with Vulnerable Populations for guidance regarding children, prisoners and participants who become incarcerated after enrolling. Contact ORI for guidance regarding human fetuses and neonates.)

Explain in detail: The risks will be mimimized by following departmental proceedures for the prevention of breach of confidentiality. These practices may include keeping data on password protected computers, having a neutral third party collect assent and consent, participants will be de-identified by the researcher's faculty advisor, and data will be presented with de-identified data.

5. In the event that any of these potential risks occur, how will it be handled (e.g. compensation, counseling, etc.)?

Explain in detail: If a breach in confidentiality occurs, participants will be informed of the information that has been unintendedly released. The researcher will be available to discuss the type of information collected. Since the researcher is not collecting sensitiver personal data,

\footnotetext{
${ }^{1}$ Minimal risk" means that the probability and magnitude of harm or discomfort anticipated in the research are not greater in and of themselves from those ordinarily encountered in daily life or during the performance of routine physical or psychological examination or tests. 45 CFR 46.102 (i)
} 
no follow up with professionals are not necessary. The PSU Office of Research Integrity and IRB will be notified if there is a breach of confidentiality.

6. Is it probable that a subject's previously unknown physical or psychological condition will be discovered (e.g. disease, depression, genetic predisposition, illegal activity etc.) as a result of the study activities? $\square$ Yes $\square$ No

a. If yes, what would types of conditions could be discovered and how will these situations be handled?

\section{Explain in detail:}

7. Describe the expected benefits of this project (NOTE: compensation is not considered a benefit):

a. To the individual subjects:

Explain in detail: There are no benefits to participating in the research portion of this program.

b. To society:

Explain in detail:

8. Explain how, in your assessment, benefits of this study outweigh the risks. (e.g. risk/benefit ratio):

\section{H. Available Resources}

1. Are there research staff members, in addition to the Principal Investigator/Student Investigator?

\section{$\bigotimes$ No (If no, skip to 3)}

$\square$ Yes

a. If yes, outline training plans to ensure that research staff members are adequately informed about the protocol and study-related duties:

2. If necessary to the research, describe the minimum qualifications for each research role (e.g., RN, social worker), their experience in conducting research, and their knowledge of study sites and culture(s):

3. Briefly describe how the research facilities and equipment at the research site(s) support the protocol's aims (e.g., private rooms available for interview, etc.): Marhkam elementary school will provide a classroom to be used for the afterschool program. In addition, the school grounds will be accessible to utilize for group games and nature observations. The Mitchell SUN office coordinator's office is available for interviews.

4. Are there provisions for medical and/or psychological support resources (e.g., in the event of incidental findings, research-related stress)? $\square$ Yes $\square$ No $\bigotimes$ N/A (not needed)

a. If yes, describe the provisions and their availability:

\section{Reportable Events}


Outline plans for communicating reportable events (e.g. adverse events or

unanticipated problems involving risks to participants or others, breach of confidentiality, child abuse, and suicidal ideation): Reportable events will be communicated to the faculty advisor promptly after the event has occurred. These unanticipated problems will then be reported to cooresponding support agencies, or the IRB at Portland State University if they apply to the research methods in the study.

\section{J. Research Related Injuries}

1. Does this research involve greater than minimal risk to participants? $\square$ Yes $\bigotimes$ No

\section{If no, skip to section $K$.}

2. If yes, are there provisions for medical care and compensation for researchrelated injuries?

$\square$ Yes $\square$ No

a. If yes, outline these provisions (Medical treatment should be available including first aid, emergency treatment and follow-up care as needed. If the research plan deviates from this policy, provide appropriate justification. Compensation for physical injuries that result from study participation is not generally required):

\section{K. Participant Privacy}

Describe provisions to protect participants' privacy (their desire to control access of others to themselves, e.g., the use of a private interview room) and to minimize any sense of intrusiveness that may be caused by study questions or procedures. In order to mimize bias by the researcher, who is also the participant's teacher, all feasible steps will be taken to limit the researcher's knowledge of each participant's consent status. To do this a third party (faculty advisor), will collect consent forms, and code the data in a manner that prevents the researcher to know consent and dissent.

\section{Data Confidentiality}

1. Will the information obtained be recorded in such a manner that participants can be identified, either directly or through identifiers linked to the participants?

2. Yes X No If no, skip to Section $M$.

3. Will data be made public? YES X $\square$ No

a. If no, describe provisions to maintain confidentiality at each phase of the data in the research. If engaging in internet or social media research, provide copies of the sites privacy policy and include an explanation of how approval is obtained for performing research activities that include these sites or explain why approval is not required:

b. If yes, verify by checking "yes" that participants will be informed of what data will be public and this information is included in the consent/assent 
form/processes.

NO

\section{Confidentiality of Data Collection Instruments}

Instructions: List all data collection instruments covered in this IRB application. For each instrument, enter the letter designating the level of confidentiality for this instrument at each data stage. Use the following Confidentiality codes:

$\mathbf{A}=$ Anonymous (No identifiers that link the data to a specific subject) $\boldsymbol{U}=$ Unlinked-Confidential (Collected with identifier or code, but all identifiers $\&$ codes are removed)

$\boldsymbol{C}=$ Coded -Confidential (Linked to a specific subject by a code, not by a direct identifier)

I=Intentionally Identified (Personal identifiers and research data are stored together in one file)

\begin{tabular}{|c|c|c|c|c|c|}
\hline \multirow{2}{*}{\multicolumn{2}{|c|}{ Instrument }} & \multicolumn{4}{|c|}{ Data Stage } \\
\hline & & Collection & Analysis & Storage & Dissemination \\
\hline & Example: Teacher Survey & A & A & A & A \\
\hline & Example: Teacher Interview & I & $\mathrm{C}$ & $\mathrm{C}$ & A \\
\hline & $\begin{array}{l}\text { Academic Identity Survey } \\
\text { has been removed. }\end{array}$ & C & $\mathbf{A}$ & $\mathbf{A}$ & $\mathbf{A}$ \\
\hline 1. & $\begin{array}{l}\text { Application of Conceptual } \\
\text { Knowledge taks }\end{array}$ & I & C & C & C \\
\hline 2. & Sudent interviews & I & C & C & C \\
\hline 3. & $\begin{array}{l}\text { Student Affective } \\
\text { Observation Checklist }\end{array}$ & I & C & C & C \\
\hline
\end{tabular}

5. Method(s) of protection and location of data storage: (Check all that apply)

$\bigotimes$ Locked office

$\triangle$ Locked cabinet

$\bigotimes$ Coded to a master list

$\square$ Other:

When coded to a master list, check the appropriate description of how the master list will be kept separate from the data:
$\triangle$ Restricted Computer
$\triangle$ Password Protected
Data
$\square$ Locked Private
Office
$\bigotimes$ Fire Wall
System
$\square$ Other:

6. Location of data:

Building and room number: Center for Science Education, FAB 175 
Electronic storage location: Password protected computers, and restricted shared files on a fire wall protected server.

7. How long will research materials be stored, and when will they be destroyed, including voice/video/digital/images? (PSU guidelines require all research materials (consent forms, surveys etc.) to be kept for a minimum of three years after completion of the study.) Three years. Once three years has expired, paper copies will be shredded, and electronic copies will be deleted.

8. Will the data be transmitted? $\square$ Yes $\square$ No

a. If yes: i. How long will data be transmitted and stored? Transmitted within one year and stored for three years.

ii. What are the plans for the data at the end of the storage period (how will it be destroyed, or will it be returned to data provider)?

Data in paper form will be shredded, and electronic data will be deleted.

9. How will research team members and/or other collaborators have access to information about study participants? They will only have access to coded materials through restricted shared files.

\section{Costs and Payments}

1. Identify any costs that participants may incur during the study, including transportation, costs, childcare, or other out-of-pocket expenses: None.

2. Will subjects be compensated for these costs? $\square$ Yes $\square$ No

a. If yes, what is the compensation, how much will the subject be offered, and how will they receive it? (i.e., money or gift certificate, extra credit, etc.)

3. Are there any OTHER payments, compensations or reimbursements that participants may receive during the study that are not related to participant incurred costs?

$\square$ Yes $\bigotimes$ No

If yes, specify the amount, method and timing of disbursements:

4. Will compensation be extra credit?

$\square$ Yes $\square$ No

a. If yes, students must be able to complete an alternative assignment for extra credit, should they choose not to participate in the research. This assignment must be comparable, with respect to time and effort, as the participation in research. Describe the alternative assignment:

5. When will the participants be compensated?

$\square$ Before the study $\square$ Installments during the study
$\square$ Withdraw/complete the study

\section{N. Multi-site Study Management}

1. Does the study involve multiple sites? $\square$ Yes $\quad$ No 
a. If yes, describe plans for communication among sites regarding adverse events, interim results, protocol modifications, monitoring of data, etc.:

\section{O. Investigational Drug, Biologic or Device}

1. Does the study does involve an investigational Drug, Biologic or Device? Yes $\bigotimes$ No

If no, skip to Section $P$.

2. Identify and describe the drug/biologic/device (e.g., marketing status):

3. Is there an IND/IDE, classification of a device as significant vs. non-significant risk?

$\square$ Yes $\square$ No

4. Describe its administration or use:

5. Compare the research drug/biologic/device to the local standard of care:

6. Describe plans for receiving, storage, dispensing and return (to ensure that they will be used only for participants and only by authorized investigators):

7. If proven beneficial, describe anticipated availability and cost to participants post-study, and plans (if applicable) to make available:

\section{P. HIPAA Privacy Protections}

1. Are HIPAA privacy protections required? $\square$ Yes $\square$ No

(Protected Health Information obtained from a Covered Entity [e.g. a hospital or community health center] requires these protections. PSU is not a Covered Entity.)

If no, skip to Section $Q$.

If yes, fill out the HIPAA Application Supplemental form.

If unsure, refer to the HIPAA Application Supplemental form for guidance, or call ORI for assistance.

\section{Q. Human Data and Human Specimen Banking}

(These are repositories established by PSU investigators for the purpose of storing data and/or specimens for future research purposes. Data banking includes electronic data files and databases.)

1. Does the study include Specimen Banking? $\square$ Yes $\square$ No

2. Does the study include Data Banking? $\square$ Yes $\bigotimes$ No

If no to questions 1 and 2, skip to Section R. If yes to questions 1 or 2, complete questions 3-6.

3. Identify what will be collected and stored, and what information will be associated with the specimens:

4. Describe where and how long the data/specimens will be stored and whether participants' permission will be obtained to use the data/specimens in other future research projects:

5. Identify how and who may access data/specimens:

6. Will specimens and/or data be sent to $\mathbf{O R}$ from research collaborators outside of PSU? 
$\square$ Yes $\bigotimes$ No

a. If yes, describe the plan:

\section{R. Sharing Study Results}

1. Is there a plan to share study results with individual participants? $\square$ Yes $\square$ No

a. If yes, describe the plan:

2. Is there a plan to disseminate aggregate results to the community where the research is conducted? $\square$ Yes $\square$ No

a. If yes, describe the plan:

\section{S. Disclosure of Financial Interests}

Does the PI, Co-PI, or any other person responsible for the design, conduct, or reporting of this research have an economic interest in, or act as an officer or director of, any outside entity whose financial interest would reasonably appear to be affected by the results of the study? $\square$ Yes $\bigotimes$ No

If yes, complete below:

a. Name of the person with a potential financial conflict of interest (COI):

b. Explain the potential financial conflict of interest:

c. Explain how the potential financial conflict of interest will be managed: (If the financial interest is a "significant financial interest" as defined in PSU's Financial Conflict of Interest Policy, submit the management plan established with the Financial Conflict of Interest Committee.)

\section{T. Regulatory Compliance}

This section is for documenting compliance with other regulatory requirements.

1. Are student records being used? $\square$ Yes $\square$ No

a. If yes, describe how compliance will be maintained with the Family Educational Rights and Privacy Act (ERPA):

2. Does this project have funding from any of the following federal agencies? (Check all that apply)

\footnotetext{
$\square$ Department of Defense (DOD)

Department of Education Department of Energy Department of Justice
}

$\square$ Department of Navy
$\square$ Environmental Protection Agency
(EPA)
$\square$ National Institute of Health
$\square$ National Science Foundation (NSF




\section{Section III: Appendices}

\section{a. Informed Consent/Assent/Permission forms}

(See Informed Consent or Waiver of Consent Checklists for guidance.)

\section{b. Training and Experience}

All staff engaged in human subjects' interaction and intervention, identifiable human data or private information about live human subjects activities are required to complete training as described below. The submission packet must include proof of training for student investigators and PI's. It is the PI's responsibility to ensure that all other staff have completed this training and keep documentation of this training. The IRB may request documentation of this training at any time as part of a post approval monitoring activities.

Beginning January 1, 2014, IRB applications received without training documentation are considered incomplete until the required training is completed. The effective application receipt date will be when the complete application (including training) is received by ORI.

Training is available via the interactive online Collaborative Institutional Training Initiative (CITI) Course: The Protection of Human Research Subjects at https://www.citiprogram.org/. Upon completion of the course, please submit a copy of the certificate electronically to the IRB office, or notify the IRB to verify completion of CITI training. Alternatively, we accept evidence of completion of the National Institute of Health's Protecting Human Research Participants course, however we are not able to verify NIH training electronically, so if you have completed the NIH course, please scan and email documentation of completion to the IRB at hsrrc@pdx.edu.

In addition to the CITI or NIH training, please describe any specialized training, education, or experience that would help to minimize the risks, particularly if working with vulnerable populations and/or sensitive topics. If the researcher will be advised by an expert or on-site mentor, note this information in the application.

c. $\quad$ Recruitment Materials (Posters, Flyers, Scripts)

d. Data Collection Instruments (Interviews, Surveys, Focus Group Questions)

e. $\quad$ Expedited Checklist (optional)

The IRB makes the final determination of whether a non-exempt project is eligible for review under expedited or full board review. If you believe that the research is non-exempt and eligible for expedited review, you may fill out the expedited checklist and attach to this application.

\section{f. Addendums as appropriate}

